\title{
Changes in psychosocial work environment and health: a mutual relationship
}

Citation for published version (APA):

De Raeve, L. (2008). Changes in psychosocial work environment and health: a mutual relationship.

[Doctoral Thesis, Maastricht University]. Universiteit Maastricht. https://doi.org/10.26481/dis.20080919ld

Document status and date:

Published: 01/01/2008

DOI:

10.26481/dis.20080919ld

Document Version:

Publisher's PDF, also known as Version of record

\section{Please check the document version of this publication:}

- A submitted manuscript is the version of the article upon submission and before peer-review. There can be important differences between the submitted version and the official published version of record.

People interested in the research are advised to contact the author for the final version of the publication, or visit the DOI to the publisher's website.

- The final author version and the galley proof are versions of the publication after peer review.

- The final published version features the final layout of the paper including the volume, issue and page numbers.

Link to publication

\footnotetext{
General rights rights.

- You may freely distribute the URL identifying the publication in the public portal. please follow below link for the End User Agreement:

www.umlib.nl/taverne-license

Take down policy

If you believe that this document breaches copyright please contact us at:

repository@maastrichtuniversity.nl

providing details and we will investigate your claim.
}

Copyright and moral rights for the publications made accessible in the public portal are retained by the authors and/or other copyright owners and it is a condition of accessing publications that users recognise and abide by the legal requirements associated with these

- Users may download and print one copy of any publication from the public portal for the purpose of private study or research.

- You may not further distribute the material or use it for any profit-making activity or commercial gain

If the publication is distributed under the terms of Article $25 \mathrm{fa}$ of the Dutch Copyright Act, indicated by the "Taverne" license above, 
CHANGES IN PSYCHOSOCIAL

WORK ENVIRONMENT AND HEALTH:

A MUTUAL RELATIONSHIP 
ISBN: $978-90-9023320-8$

Lay-out: Lore De Raeve, Epidemiologie, Universiteit Maastricht

Cover: Wim Coninx

Printed by: Wilco, Amersfoort

2008, L. De Raeve

All rights reserved. No part of this thesis may be reproduced or transmitted in any form or by any means, electronic or mechanical, including photocopying, recording or any information storage or retrieval system, without permission in writing from the author, or, when appropriate, from the publishers of the publications. 


\title{
CHANGES IN PSYCHOSOCIAL WORK ENVIRONMENT AND HEALTH: A MUTUAL RELATIONSHIP
}

\author{
PROEFSCHRIFT
}

ter verkrijging van de graad van doctor aan de Universiteit Maastricht, op gezag van de Rector Magnificus, Prof. mr. G.P.M.F. Mols,

volgens het besluit van het College van Decanen, in het openbaar te verdedigen

op vrijdag 19 september 2008 om 12.00 uur

door

Lore De Raeve 


\section{Promotor}

Prof. dr. ir. P.A. van den Brandt

\section{Copromotores \\ Dr. ing. IJ. Kant \\ Dr. R.M. Vasse}

\section{Beoordelingscommissie}

Prof. dr. F.J.N. Nijhuis (voorzitter)

Prof. dr. A.J. van der Beek (Emgo Instituut, VUmc Amsterdam)

Prof. dr. F.J.H. van Dijk (Coronel Instituut voor Arbeid en Gezondheid, AMC Amsterdam)

Prof. dr. J.A. Knottnerus

Dr. F.C.J. Stevens

The Maastricht Cohort Study is part of the Netherlands concerted research action on "Fatigue at Work", granted by the Netherlands Organization for Scientific Research (NWO).

The studies presented in this dissertation were conducted under the auspices of the school for Public Health and Primary Care: CAPHRI at Maastricht University, The Netherlands. The school for Public Health and Primary Care: CAPHRI is part of the Netherlands School of Primary Care Research ( $\mathrm{CaRe}$ ), which has been acknowledged since 1995 by The Royal Netherlands Academy of Art en Sciences (KNAW). 


\section{CONTENTS}

1 Introduction 7

2 Health effects of transitions in work schedule, working hours and overtime in a prospective cohort study

3 Mental health effects of changes in psychosocial work characteristics: a prospective cohort study

$4 \quad$ Risk factors for interpersonal conflicts at work

5 interpersonal conflicts at work as a predictor of self-reported health outcomes and occupational mobility

6 Changes in mental health as a predictor of changes in working time arrangements and occupational mobility: results from a prospective cohort study

$7 \quad$ General discussion

Summary

Samenvatting

Dankwoord

About the author 
1

Introduction 


\section{WORK ENVIRONMENT AND HEALTH}

Work plays an important role in the lives of many people. Work structures the day, ensures social contacts, provides an income and financial security, offers possibilities for professional development and provides status and identity ${ }^{1,2}$. From this perspective, work is often thought to have a positive effect on health ${ }^{3,4}$, while the absence of work is often associated with negative health effects ${ }^{5-8}$. However, certain work characteristics such as hazardous chemical, biological and ergonomic factors in the workplace have negative health effects and may lead to sickness absence ${ }^{9,10}$. On the other hand, health status often influences the likelihood of finding or keeping a job and good health is often a prerequisite for active labor force participation $4,11,12$. Work and health are thus largely intertwined.

During the last decades, the work environment underwent some remarkable changes. Due to labor legislation and ameliorated techniques, many unhealthy physical, chemical, ergonomic, and biological exposures at work, and their accompanying diseases, have been substantially reduced or eliminated. However, other changes also emerged within the work environment that might affect employee health and well-being. Some developments are the changing structure of the work force, the rapid growth of the service sector, the 24-hour economy, and the increased computerization ${ }^{13}$. In general, the work content has changed from physically demanding work to mentally and emotionally charging tasks, along with a steady increase in work load ${ }^{14}$. Working under rising pressure and at an increasing pace, are important causes of decreased well-being and health problems. Furthermore, more is asked of the employees in terms of employability, flexibility, efficiency, performance, and involvement, whereas less and less is offered by the organizations. Fixed contracts are less frequent, career opportunities are small and the professional autonomy is restrained by all kinds of regulations and protocols ${ }^{15}$. Moreover, the work situation extended in terms of long working hours, overtime work, and non-standard shifts ${ }^{16,17}$ and the boundaries between work and leisure time slowly fade away. Along with these changes, mental health problems, such as mental distress, fatigue, and burnout became more common among workers. These changes that have taken place in the work environment and their associated health problems have led to an increasing awareness of the importance of the psychosocial work environment for employee health and well-being.

\section{PSYCHOSOCIAL WORK ENVIRONMENT AND HEALTH}

The psychosocial work environment refers to the content of work, the psychological demands of work, the organization of work, and the social relations at the workplace ${ }^{18}$. 
The impact of the psychosocial work environment on health and well-being is welldocumented. Several aspects of the psychosocial work environment, such as supportive work relations, learning opportunities, opportunities for skill use, physical security, financial security, opportunities for interpersonal contact, job control, autonomy, good employment prospects, job variety, and participation in decision making have previously been associated with favorable health and well-being outcomes ${ }^{2,3,19-23}$. Other factors in the psychosocial work environment have previously been associated with adverse health and well-being outcomes. High job demands and low decision latitude have previously been associated with cardiovascular health problems ${ }^{24-26}$, musculoskeletal disorders ${ }^{27-}$ ${ }^{29}$, mental disorders ${ }^{30-33}$, fatigue ${ }^{34-36}$, poor self-reported health ${ }^{37-39}$, and sickness absence ${ }^{40,41}$. Job insecurity has also been associated with negative consequences for employee health and well-being in previous research 21, 42-44. Working time arrangements, such as shift work, working long hours, or overtime have previously been associated with sleep loss, prolonged fatigue, mental health problems, poor subjective health, cardiovascular disease, gastrointestinal disorders, injuries, and increased morbidity and mortality ${ }^{45-52}$. Interpersonal relationships at work have also been associated with a range of different health and well-being outcomes. Poor relationships with superiors, colleagues, or subordinates have previously been associated with physical symptoms ${ }^{53}$, depressive symptoms ${ }^{30}$, mental disorders ${ }^{33}$, poor self-reported health ${ }^{54}$, and sickness absence ${ }^{9}$. Interpersonal conflicts at work have previously been associated with poor sleep quality ${ }^{55,56}$, psychiatric morbidity ${ }^{57}$, burnout ${ }^{58,59}$, anxiety, frustration, depression ${ }^{60-62}$, and work disability ${ }^{63}$.

Apart from the fact that several characteristics of the work environment may influence employee health, health itself may also influence different domains of the work situation, such as work status, labor participation, or reintegration into the labor market. Health may influence the likelihood of finding or keeping a job ${ }^{4,64}$, but it may also be a reason to leave the labor force through, for example, unemployment ${ }^{8,64,65}$, (early) retirement ${ }^{66,}$ ${ }^{67}$, or work disability ${ }^{66,67}$. Employees may also remain in the labor force and find ways to change the work situation itself in an attempt to adapt to their health status, for example by changing job function or by decreasing their weekly working hours. Existing research has mainly focused on individuals leaving the labor force because of ill health ${ }^{11,66,68,69}$. Far less research has been conducted on changes in the work situation itself as a result of deteriorated health. A previous study of Van Amelsvoort et al. ${ }^{70}$ found that poor mental health was associated with an increased risk of leaving a shift work job.

Along with recent changes that have taken place in the work environment and the shift from physically to mentally demanding work, the consequences for the health of workers have also moved from physical to mental complaints and mental health problems have become more common in workers in recent years. About $20 \%$ of the European working population experiences some type of mental health problem ${ }^{71}$. Comparable percentages 
were found in the Dutch population ${ }^{72,73}$. Mental health problems are a leading cause of illness and disability worldwide and have negative consequences for the individual, the organization, as well as society. This has led to a renewed attention for the relationship between the psychosocial work environment and mental health from both occupational health research and society. Especially on a societal level, including employers, occupational health care professionals and policy makers, there is an urgent need for prevention and intervention strategies in the workplace aimed at reducing both the negative effects of the work environment on mental health and the negative effects of mental health on characteristics of the work environment. However, to be able to design effective prevention and intervention strategies in the workplace, insight into a causal relationship between the psychosocial work environment and mental heaith is indispensable. Although some attention has yet been devoted to the causal relationship between the work environment and mental health, there is still a lack of clarity concerning the issue of causality in previous research.

The majority of studies examining the relationship between the psychosocial work environment and mental health is based on a cross-sectional design ${ }^{74}$. Although these studies provide insight in the strength of the associations between the work environment and health, they do not allow any conclusions regarding the direction of the relationship as both work characteristics and mental health are measured at the same point in time. Therefore, causal inference is not possible. To establish causal relations, a longitudinal design is preferred ${ }^{75}$. Although several longitudinal studies have already been conducted $^{34,36,76}$, many of them often fail to disentangle a cause and effect relationship between characteristics of the work environment and mental health outcomes. Several methodological shortcomings, such as small study populations, the inability to control for the initial value of the outcome variable, or the inability to measure exposure before outcome, often prevent researchers from providing some kind of evidence for a causal relationship between characteristics of the work situation and mental health outcomes ${ }^{77}$. Moreover, previous research has often examined the influence of work characteristics measured at baseline on the occurrence of a health outcome during a specified period of follow-up. For example, job demands are measured at baseline, while fatigue is measured at one-year follow-up. When comparing workers with high demands with those with low demands at baseline and examining the effect on fatigue one year afterwards, a serious misclassification might occur as a rather extensive part of the study population might have already experienced a change in their demands within this one-year followup period. The changes that take place in the work environment may thus invalidate baseline data as a predictor of future health ${ }^{78}$. Therefore, when examining a possible causal relationship between the psychosocial work environment and mental health, the dynamic nature of the work environment should be taken into account. 


\section{DYNAMICS IN THE PSYCHOSOCIAL WORK ENVIRONMENT}

In previous research, the perception of the work environment is often assumed to be stable. The psychosocial work environment seems, however, subject to change ${ }^{78}$. Previous studies ${ }^{78,79}$ reported a relatively high number of workers who experienced changes in job demands, job control, or social support over time. For example, Hoogendoorn et al. ${ }^{78}$ found that $36.8 \%$ of the study population experienced a change in job demands. Moreover, they also reported that $38.6 \%$ of the workers experienced a change in supervisor social support and that $29.4 \%$ experienced a change in co-worker social support. A study of Shields et al. ${ }^{80}$ reported relatively high percentages of employees both changing from a standard working week of $35-40 \mathrm{hrs} / \mathrm{wk}$ to long ( $>40$ hrs/wk) working hours ( $21 \%$ men, $8 \%$ women) as well as from standard to fewer hours ( $15 \%$ men, $23 \%$ women). When studying the relationship between the psychosocial work environment and mental health, the dynamic nature of the work environment should be taken into account.

From a methodological point of view, the dynamics in the work environment can be used as a means of gaining insight into the possible causal relationship between characteristics of the work environment and mental health. Based on guidelines for causal inference ${ }^{81,82}$, one can assume that a change in exposure (i.e., a change in the psychosocial work environment) results in an altered outcome (i.e., a change in mental health). Therefore, studying the relationship between changes in the psychosocial work environment and changes in mental health may be the key to gaining information on a possible causal relationship, as the change creates a new situation upon which a change in health can be studied.

\section{AIM OF THIS STUDY}

The general aim of this thesis is to gain more insight into a possible causal relationship between the psychosocial work environment and mental health and well-being by studying changes in psychosocial work characteristics and changes in mental health and well-being over time. As the domains of both the psychosocial work environment as well as mental health are very extensive, it is necessary to make some choices in this regard. Based on their prevalence, their assumed impact on health and well-being, and their susceptibility for change, this thesis focuses on the effects of working time arrangements, job demands and job control, and interpersonal conflicts at work on mental health and occupational mobility. Furthermore, this thesis also examines the reverse relationship between mental health, and working time arrangements and occupational mobility. This resulted in the following specific research questions: 
1. What is the impact of changes in working time arrangements on changes in mental health outcomes?

2. What is the effect of changes in job demands and job control on changes in mental health outcomes?

3. Does the onset of an interpersonal conflict result in changes in mental health outcomes and occupational mobility?

4. What is the effect of changes in mental health on changes in working time arrangements and occupational mobility?

\section{METHODOLOGICAL CONSIDERATIONS}

Although it is difficult to prove an actual causal relationship in observational research, a causal relationship between the psychosocial work environment and mental health can be made plausible. Therefore, several methodological issues should be considered.

First, a prerequisite for examining causality is that the change in exposure must take place before a change in the outcome ${ }^{81,82}$. In the light of the temporal sequence of cause and effect, the time lag for measuring changes in exposure and changes in the outcomes is important. The appropriateness of the time lag depends both on the type of exposure and on the type of outcome. For example, it is possible that certain work characteristics (e.g. job demands) need to accumulate over time before they start to have an effect on health, whereas others (e.g. working hours) may have a more immediate effect. Moreover, some outcomes might react faster than others following a change in exposure. For example, changes in the work environment might have a rather immediate effect on perceived general health, whereas it takes longer for an effect to occur in terms of occupational mobility, as the latter may be perceived as a more radical change. The same is true for the effects of changes in health. People may tend to change their working hours rather quickly in response to deteriorated health, whereas it might take longer to decide and actually realize a job change. Depending on the relationship studied, the appropriate time frame should be considered. In this respect, it must be noticed that time lags being too short or too long both result in an underestimation of the actual effect ${ }^{83}$.

When studying changes in work characteristics, it is important to notice that changes in several aspects of the work situation are often interrelated. For example, an increase in job demands may be associated with an increase in working long hours, or a change in work schedule may be linked with a change in job function. Therefore, when studying the effects of changes in some aspects of the work environment, it is important to account for other factors in the work environment by, for example, controlling for other workrelated factors or by selecting a particular group of employees in which certain factors 
are kept constant. When examining the relationship between changes in the work environment and subsequent changes in health, it is also important to control for initial health to account for possible selection effects.

To be able to fulfill the above methodological requirements, a longitudinal design is required, with repeated measurements on both work characteristics and health. Furthermore, a large study population is needed, with a considerable amount of dynamics in exposure over time. Moreover, to gain insight in the time course of cause and effect, short time intervals between the measurements are needed. As the time course of cause and effect might be different depending on the exposure and the outcome measured, several exposure and outcome variables could be measured that might react differently over the course of time. Additionally, several socio-demographic characteristics need to be measured, because this could outline the differences in effect between different subgroups, such as men and women. These variables also need to be included because of their ability to correct for possible confounding in the relationship between work and health.

In this thesis, data from the Maastricht Cohort Study, a prospective cohort study on 'fatigue at work' were used to examine the research questions in this thesis.

\section{MAASTRICHT COHORT STUDY}

The Maastricht Cohort Study was set up in 1998 as part of the Netherlands concerted research action on 'Fatigue at Work' ${ }^{72}$. The initial aim of the Maastricht Cohort Study was to gain insight into the prevalence and incidence of fatigue in the working population, to identify risk factors in the onset and natural course of fatigue, and to study the effectiveness of different treatments of fatigue that can be used in occupational health settings ${ }^{72,73}$.

\section{Design}

The Maastricht Cohort Study is a prospective cohort study in which employees from 45 different companies (both blue-collar and white-collar jobs) were followed by means of ten self-administered questionnaires. Once a year, in May, employees received an extensive questionnaire with items on work-related factors (e.g. work content, work relations, working conditions, terms of employment), domestic and social factors (e.g. private situation, leisure time activities, life events), personality factors (e.g. coping, negative affectivity), demographics (e.g. age, gender, education), and health factors (e.g. fatigue, need for recovery, psychological distress, burnout, general self-reported health, long-term illnesses). The extensive questionnaire was followed by two short four-monthly 
questionnaires (in September and in January), capturing mainly outcome measures. Between May 1998 and January 2001, participants were asked to complete nine questionnaires. A tenth questionnaire was sent in May 2002, four years after the first questionnaire was sent out.

\section{Study population}

In May 1998, the baseline questionnaire was sent out to 26,978 employees. Altogether, 12,161 employees completed and returned the baseline questionnaire (response rate of $45 \%$ ). Twenty-one questionnaires were excluded from analysis because of technical reasons. The baseline (TO) cohort thus consisted of 12,140 people. All employees who returned the baseline questionnaire $(\mathrm{TO})$ received the two short questionnaires $\mathrm{T}_{1}$ in September 1998 (response rate 87.2\%, n=10592) and T2 in January 1999 (response rate $84.6 \%, n=10270$ ) Employees who completed the baseline questionnaire and at least one of the following two short questionnaires ( $\mathrm{T} 1$ and/or $\mathrm{T} 2$ ) received the extensive oneyear follow up questionnaire (T3) in May 1999 (response rate 79.5\%, $n=9655$ ). Employees who returned the questionnaire at $\mathrm{T} 3$ also received the short questionnaires T4 in September 1999 (response rate $73.8 \%, n=8956$ ) and T5 in January 2000 (response rate $71.6 \%, n=8692$ ). Employees who returned the questionnaire at $\mathrm{T} 3$ and at least one of the consecutive short questionnaires (T4 and/or T5) also received the extensive questionnaire (T6) in May 2000 (response rate 66.5\%, $\mathrm{n}=8070$ ). Employees returning the T6 questionnaire also received the short questionnaire T7 in September (response rate $63.1 \%, n=7662$ ) and the T8 questionnaire in January 2001 (response rate $61.6 \%, n=7482$ ). In the T8 questionnaire, employees were asked if they were willing to fill out another questionnaire. Those who responded positively to that question received the final T9 questionnaire in May 2002, four years after the first questionnaire was sent out (response rate $45.6 \%, n=5539$ ).

\section{Dynamics in the Maastricht Cohort Study}

Within the Maastricht Cohort Study, there seems to be a considerable amount of dynamics in exposure over time (see Table 1). Changes in job demands and decision latitude occur rather frequently. Moreover, interpersonal conflicts with co-workers and supervisors are also rather prevalent. Additionally, while changes in working hours or overtime are rather frequent, changes in work schedules do not occur very often within the Maastricht Cohort Study. Apart from the dynamics in exposure over time, changes in mental health can also be observed. A rather extensive part of the employees in the Maastricht Cohort Study experience changes in self-reported health outcomes. Changes in self-reported general health and psychological distress seem to occur most often, (about $38 \%$ ), followed by changes in need for recovery (about $28 \%$ ) and prolonged fatigue (about 18\%). 
Table 1 Changes in the psychosocial work environment and changes in health in employees responding to the baseline and one-year follow-up questionnaire of the Maastricht Cohort Study $(n=9655)$

\begin{tabular}{|c|c|c|c|c|}
\hline Work characteristic & TO & $T 3$ & 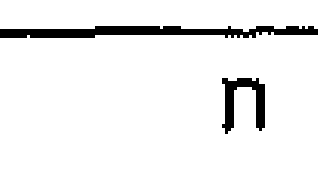 & $\%$ \\
\hline \multirow[t]{3}{*}{ Working hours/ week } & $36-40$ & $36-40$ & 4044 & 80.1 \\
\hline & $36-40$ & $>40$ & 707 & 14.0 \\
\hline & $36-40$ & $<35$ & 295 & 5.8 \\
\hline \multirow[t]{4}{*}{ Overtime } & No & No & 4260 & 45.1 \\
\hline & No & Yes & 849 & 9.0 \\
\hline & Yes & No & 3204 & 33.9 \\
\hline & Yes & Yes & 1130 & 12.0 \\
\hline \multirow[t]{4}{*}{ Work schedule } & Day & Day & 6370 & 78.7 \\
\hline & Shift & Day & 90 & 1.1 \\
\hline & Shift & Shift & 1616 & 20.0 \\
\hline & Day & Shift & 19 & 0.2 \\
\hline \multirow{4}{*}{ Co-worker conflict } & No & No & 8409 & 89.2 \\
\hline & Yes & No & 457 & 4.9 \\
\hline & No & Yes & 339 & 3.6 \\
\hline & Yes & Yes & 217 & 2.3 \\
\hline \multirow[t]{4}{*}{ Supervisor conflict } & No & No & 7999 & 85.6 \\
\hline & Yes & No & 593 & 6.3 \\
\hline & No & Yes & 439 & 4.7 \\
\hline & Yes & Yes & 310 & 3.3 \\
\hline \multirow[t]{3}{*}{ Psychological job demands ${ }^{\dagger}$} & \multicolumn{2}{|c|}{ Stable between TO and T3 } & 6762 & 74.9 \\
\hline & \multicolumn{2}{|c|}{ Increase between T0 and T3 } & 927 & 10.3 \\
\hline & \multicolumn{2}{|c|}{ Decrease between TO and T3 } & 1336 & 14.8 \\
\hline \multirow{3}{*}{ Decision latitude } & \multicolumn{2}{|c|}{ Stable between T0 and T3 } & 7722 & 82.7 \\
\hline & \multicolumn{2}{|c|}{ Increase between TO and T3 } & 769 & 8.2 \\
\hline & \multicolumn{2}{|c|}{ Decrease between T0 and T3 } & 847 & 9.1 \\
\hline \multirow[t]{3}{*}{ Self-reported general health ${ }^{\top}$} & \multicolumn{2}{|c|}{ Stable between T0 and T3 } & 5920 & 62.3 \\
\hline & \multicolumn{2}{|c|}{ Increase between TO and T3 } & 2068 & 21.8 \\
\hline & \multicolumn{2}{|c|}{ Decrease between T0 and T3 } & 1513 & 15.9 \\
\hline \multirow[t]{3}{*}{ Need for recovery ${ }^{\dagger}$} & \multicolumn{2}{|c|}{ Stable between T0 and T3 } & 6851 & 72.3 \\
\hline & \multicolumn{2}{|c|}{ Increase between TO and T3 } & 1525 & 16.1 \\
\hline & \multicolumn{2}{|c|}{ Decrease between TO and T3 } & 1098 & 11.6 \\
\hline \multirow[t]{3}{*}{ Prolonged fatigue $^{\dagger}$} & \multicolumn{2}{|c|}{ Stable between TO and T3 } & 7633 & $\overline{81.8}$ \\
\hline & \multicolumn{2}{|c|}{ Increase between TO and T3 } & 858 & 9.2 \\
\hline & \multicolumn{2}{|c|}{ Decrease between $\mathrm{TO}$ and $\mathrm{T} 3$} & 836 & 9.0 \\
\hline \multirow[t]{3}{*}{ Psychological distress $^{\top}$} & \multicolumn{2}{|c|}{ Stable between TO and T3 } & 5991 & 63.2 \\
\hline & \multicolumn{2}{|c|}{ Increase between $\mathrm{TO}$ and $\mathrm{T} 3$} & 1788 & 18.8 \\
\hline & Decre & en T0 and T3 & 1707 & 18.0 \\
\hline
\end{tabular}

Thable $=$ maximum 1 standard deviation change in the total scale score; increase $=$ more than 1 standard deviation increase in the total scale score; decrease $=$ more than 1 standard deviation decrease in the total scale score 
The dynamic nature of both the psychosocial work environment and mental health in the Maastricht Cohort Study enables us to study the relationship between changes in the work environment and changes in mental health. Moreover, in a cohort study (1) the sequence of observations corresponds with the natural course of events, (2) exposures occur before health problems develop, and (3) both exposures and outcomes are measured at the individual level ${ }^{72,82,84}$, which allows studying the effects of intraindividual changes in the psychosocial work environment on subsequent changes in health and well-being outcomes. Moreover, the prospective design of the Maastricht Cohort Study also provides opportunities to examine the reversed relationship, i.e., the effect of changes in mental health on subsequent changes in the work environment. Therefore, the Maastricht Cohort Study, with repeated measurements on a broad range of measures on work and health during a four-year follow-up period, and a study population with a considerable amount of dynamics in both the psychosocial work environment and in mental health, constitutes an appropriate sample frame to gain insight into a possible causal relationship between the psychosocial work environment and health and well-being and to answer the research questions in this thesis.

\section{OUTLINE OF THE THESIS}

In chapter 2, the relationship between transitions in working time arrangements (work schedule, working hours, and overtime) and self-reported health outcomes (self-reported general health, need for recovery, prolonged fatigue, and psychological distress) was studied. Chapter 3 presents the results of a study examining the effects of changes in psychosocial work characteristics (psychological job demands and decision latitude) on changes in need for recovery and prolonged fatigue. In chapter 4 , an additional study was performed examining the influence of work-related factors as risk factors in the onset of interpersonal conflicts at work. Chapter 5 presents a study on the effects of interpersonal conflicts at work in terms of self-reported health outcomes (self-reported general health, need for recovery, and prolonged fatigue) and occupational mobility (internal mobility, i.e., changing jobs within the company, and external mobility, i.e., changing jobs from one employer to another). Chapter 6 reverses the possible causal sequence examined in the previous chapters and presents the results of a study that examines whether changes in mental health predict changes in working time arrangements and occupational mobility. Chapter 7 , the general discussion, presents a more general overview of the results and conclusions of the studies described in the present thesis, their strengths and weaknesses, the impiications for future research, and the practical implications. 


\section{REFERENCES}

1. Jahoda M. Employment and unemployment: a social-psychological analysis. Cambridge (UK): Cambridge University Press; 1982.

2. Jahoda M. Work, employment and unemployment: Values, theories, and approaches in social research. Am Psych. 1981;36(184-191).

3. Creed PA, Macintyre SR. The relative effects of deprivation of the latent and manifest benefits of employment on the well-being of unemployed people. J Occup Health Psychol. 2001;6(4):324-31.

4. Ross CE, Mirowsky J. Does employment affect health? J Health Soc Behav. 1995;36(3):23043.

5. Claussen B. Health and re-employment in a five-year follow-up of long-term unemployed. Scand J Public Health. 1999;27(2):94-100.

6. Hammarström A. Health consequences of youth unemployment--review from a gender perspective. Soc Sci Med. 1994;38(5):699-709.

7. Wadsworth ME, Montgomery SM, Bartley MJ. The persisting effect of unemployment on health and social well-being in men early in working life. Soc Sci Med. 1999;48(10):1491-9.

8. Dooley D, Fielding J, Levi L. Health and unemployment. Annu Rev Public Health. 1996;17:449-65.

9. Melchior M, Niedhammer I, Berkman LF, Goldberg M. Do psychosocial work factors and social relations exert independent effects on sickness absence? A six year prospective study of the GAZEL cohort. J Epidemiol Community Health. 2003;57(4):285-93.

10. Michie $S$, Williams $S$. Reducing work related psychological ill health and sickness absence: a systematic literature review. Occup Environ Med. 2003;60(1):3-9.

11. Mutchler JE, Burr JA, Massagli MP, Pienta A. Work transitions and health in later life. J Gerontol B Psychol Sci Soc Sci. 1999;54(5):S252-61.

12. Schuring $M$, Burdorf $L$, Kunst $A$, Mackenbach $J$. The effects of ill health on entering and maintaining paid employment: evidence in European countries. J Epidemiol Community Health. 2007;61(7):597-604.

13. de Jonge J. A critical examination of the demand-control-support model from a work psychological perspective. Int J Stress Manag. 1997;4(4):235-58.

14. Bond JT, Galinsky E, Swanberg JE. the 1997 national study of the changing workforce. New York: Families and Work Institute; 1997.

15. Schaufeli WB, Bakker A, Jonge Jd. De Psychologie van arbeid en gezondheid. Houten: Bohn Stafleu Van Loghum; 2003.

16. Hamermesh D. Workdays, workhours, and work schedules: Evidence for the United States and Germany. Kalamazoo, Michigan: Upjohn Institute; 1996.

17. Rones PL, lig RE, Gardner JM. Trends in hours of work since the mid-1970s. Mon Labor Rev. 1997;120(4):3-14.

18. Eriksson N. The psychosocial work environment and worker health (Umeå studies in Sociology $n^{\circ} 110$ ). Umeå, Sweden: Umeå University, department of sociology; 1996.

19. Hackman JR, Oldham GR. Work redesign. Menlo Park, CA: Addison Wesley; 1980.

20. Warr P. Work, unemployment and mental health. New York: Oxford University Press; 1987. 
21. Virtanen P, Koivisto AM. Wellbeing of professionals at entry into the labor market: a follow up survey of medicine and architecture students. J Epidemiol Community Health. $2001 ; 55(11): 831-5$.

22. Pikhart H, Bobak M, Siegrist J, Pajak A, Rywik S, Kyshegyi J, et al. Psychosocial work characteristics and self rated health in four post-communist countries. $J$ Epidemiol Community Health. 2001;55(9):624-30.

23. Karasek RA. Job demands, job decision latitude, and mental strain: implications for job redesign. Adm Sci Q. 1979;24:285-308.

24. Peter $R$, Siegrist J. Psychosocial work environment and the risk of coronary heart disease. Int Arch Occup Environ Health. 2000;73 Suppl:S41-5.

25. Schnall $P L$, Landsbergis PA, Baker D. Job Strain and Cardiovascular-Disease. Annu Rev Publ Health. 1994;15:381-411.

26. Guimont $C$, Brisson $C$, Dagenais GR, Milot A, Vezina M, Masse $B$, et al. Effects of job strain on blood pressure: a prospective study of male and female white-collar workers. Am J Public Health. 2006;96(8):1436-43.

27. Buckle P. Upper limb disorders and work: the importance of physical and psychosocial factors. J Psychosom Res. 1997;43(1):17-25.

28. Davis KG, Heaney $C A$. The relationship between psychosocial work characteristics and low back pain: underlying methodological issues. Clin Biomech. 2000;15(6):389-406.

29. Clays E, De Bacquer D, Leynen F, Kornitzer M, Kittel F, De Backer G. The impact of psychosocial factors on low back pain: longitudinal results from the Belstress study. Spine. 2007;32(2):262-8.

30. Niedhammer I, Goldberg M, Leclerc A, Bugel I, David S. Psychosocial factors at work and subsequent depressive symptoms in the Gazel cohort. Scand J Work Environ Health. 1998;24(3):197-205.

31. Stansfeld SA, Fuhrer $R$, Shipley MJ, Marmot MG. Work characteristics predict psychiatric disorder: prospective results from the Whitehall II Study. Occup Environ Med. 1999;56(5):302-7

32. Sanne B, Mykletun A, Dahl AA, Moen BE, Tell GS. Testing the Job Demand-Control-Support model with anxiety and depression as outcomes: the Hordaland Health Study. Occup Med. $2005 ; 55(6): 463-73$.

33. Stansfeld S, Candy B. Psychosocial work environment and mental health - a meta-analytic review. Scand J Work Environ Health. 2006;32(6):443-62.

34. Bültmann U, Kant I, Van den Brandt PA, KasI SV. Psychosocial work characteristics as risk factors for the onset of fatigue and psychological distress: Prospective results from the Maastricht Cohort Study. Psychol Med. 2002;32(2):333-45.

35. Bültmann U, Kant IJ, Schroer CAP, Kasl SV. The relationship between psychosocial work characteristics and fatigue and psychological distress. Int Arch Occup Environ Health. 2002;75(4):259-66.

36. Janssen $N$, Nijhuis FJ. Associations between positive changes in perceived work characteristics and changes in fatigue. J Occup Environ Med. 2004;46(8):866-75.

37. Borg V, Kristensen TS, Burr $H$. Work environment and changes in self-rated health: $A$ five year follow-up study. Stress Medicine. 2000;16(1):37-47.

38. Niedhammer I, Chea M. Psychosocial factors at work and self reported health: comparative results of cross sectional and prospective analyses of the French GAZEL. cohort. Occup Environ Med. 2003;60(7):509-15. 
39. Rahkonen O, Laaksonen M, Martikainen P, Roos E, Lahelma E. Job control, job demands, or social class? The impact of working conditions on the relation between social class and health. J Epidemiol Community Health. 2006;60(1):50-4.

40. Niedhammer I, Bugel I, Goldberg M, Leclerc A, Gueguen A. Psychosocial factors at work and sickness absence in the Gazel cohort: a prospective study. Occup Environ Med. 1998;55(11):735-41.

41. North FM, Syme SL, Feeney A, Shipley M, Marmot M. Psychosocial work environment and sickness absence among British civil servants: The Whitehall II Study. Am J Public Health. 1996;86(3):332-40.

42. Ferrie JE, Shipley MJ, Stansfeld SA, Marmot MG. Effects of chronic job insecurity and change in job security on self reported health, minor psychiatric morbidity, physiological measures, and health related behaviours in British civil servants: the Whitehall II study. J Epidemiol Community Health. 2002;56(6):450-4.

43. Virtanen P, Vahtera J, Kivimaki M, Pentti J, Ferrie J. Employment security and health. J Epidemiol Community Health. 2002;56(8):569-74.

44. Sverke $M$, Hellgren J, Naswall $K$. No security: a meta-analysis and review of job insecurity and its consequences. J Occup Health Psychol. 2002;7(3):242-64.

45. Harrington JM. Shift work and health-a critical review of the literature on working hours. Ann Acad Med Singapore. 1994;23(5):699-705.

46. Sparks K, Cooper C, Fried $Y$, Shirom A. The effects of hours of work on health: A metaanalytic review. J Occup Organ Psych. 1997;70:391-408.

47. Spurgeon A, Harrington JM, Cooper CL. Health and safety problems associated with long working hours: a review of the current position. Occup Environ Med. 1997;54(6):367-75.

48. van der Hulst M. Long workhours and health. Scand J Work Environ Health. 2003;29(3):17188.

49. van Amelsvoort LG, Schouten EG, Kok FJ. Impact of one year of shift work on cardiovascular disease risk factors. J Occup Environ Med. 2004;46(7):699-706.

50. Harrington JM. Health effects of shift work and extended hours of work. Occup Environ Med. 2001;58:68-72.

51. Jansen $N W H$, van Amelsvoort LGPM, Kristensen TS, van den Brandt PA, Kant 1. Work schedules and fatigue: a prospective cohort study. Occup Environ Med. 2003;60 Suppl 1:i4753.

52. Härmä M. Workhours in relation to work stress, recovery and health. Scand J Work Environ Health. 2006;32(6):502-14.

53. Oxenstierna $G$, Ferrie J, Hyde $M$, Westerlund $H$, Theorell T. Dual source support and control at work in relation to poor health. Scand J Public Health. 2005;33(6):455-63.

54. Stansfeld SA, Bosma $H$, Hemingway $H$, Marmot MG. Psychosocial work characteristics and social support as predictors of SF-36 health functioning: The Whitehall II study. Psychosom Med. 1998;60(3):247-55.

55. Fortunato VJ, Harsh J. Stress and sleep quality: The moderating role of negative affectivity. Pers Indiv Differ. 2006;41(5):825-36.

56. Nakata A, Haratani $T$, Takahashi $M$, Kawakami $N$, Arito $H$, Kobayashi $F$, et al. Job stress, social support, and prevalence of insomnia in a population of Japanese daytime workers. Soc Sci Med. 2004;59(8):1719-30. 
57. Romanov $\mathrm{K}$, Appelberg $\mathrm{K}$, Honkasalo ML, Koskenvuo M. Recent interpersonal conflict at work and psychiatric morbidity: A prospective study of 15,530 employees aged 24-64. J Psychosom Res. 1996;40(2):169-76.

58. Fujiwara K, Tsukishima E, Tsutsumi A, Kawakami N, Kishi R. Interpersonal conflict, social support, and burnout among home care workers in Japan. J Occup Health. 2003;45(5):31320.

59. Harvey $S$, Blouin $C$, Stout D. Proactive personality as a moderator of outcomes for young workers experiencing conflict at work. Pers Indiv Differ. 2006;40(5):1063-74.

60. Spector PE, Jex SM. Development of four self-report measures of job stressors and strain: Interpersonal Conflict at Work Scale, Organizational Constraints Scale, Quantitative Workload Inventory, and Physical Symptoms Inventory, J Occup Health Psychol. 1998;3(4):356-67.

61. Spector PE, Dwyer DJ, Jex SM. Relation of job stressors to affective, health, and performance outcomes - a comparison of multiple data sources. J Appl Psychol. 1988;73(1):11-9.

62. Hagerty BM, Williams RA. The effects of sense of belonging, social support, conflict, and loneliness on depression. Nurs Res. 1999;48(4):215-9.

63. Appelberg K, Romanov K, Heikkilä K, Honkasalo ML, Koskenvuo M. Interpersonal conflict as a predictor of work disability: a follow-up study of 15,348 Finnish employees. J Psychosom Res. 1996;40(2):157-67.

64. Mastekaasa A. Unemployment and health: Selection effects. I Community Appl Soc. 1996;6(3):189-205.

65. Arrow JO. Estimating the influence of health as a risk factor on unemployment: a survival analysis of employment durations for workers surveyed in the German Socio-Economic Panel (1984-1990). Soc Sci Med. 1996;42(12):1651-9.

66. Bound JM, Schoenbaum M, Steinbrickner TR, Waidmann T. The dynamic effects of health on the labor force transitions of older workers. Labor Economics, 1999;6(2):179-202.

67. McDonough P, Amick BC, 3rd. The social context of health selection: a longitudinal study of health and employment. Soc Sci Med. 2001;53(1):135-45.

68. Riphahn RT. Income and employment effects of health shocks - A test case for the German welfare state. J Popul Econ. 1999;12(3):363-89.

69. Mheen H, van de, Stronks K, Schrijvers CT, Mackenbach JP. The influence of adult ill health on occupational class mobility and mobility out of and into employment in The Netherlands. Soc Sci Med. 1999;49(4):509-18.

70. van Amelsvoort LG, Jansen NW, Swaen GM, van den Brandt PA, Kant I. Direction of shift rotation among three-shift workers in relation to psychological health and work-family conflict. Scand J Work Environ Health. 2004;30(2):149-56.

71. Harnois G, Gabriel P. Mental health and work: Impact, issues and good practices. Joint document of the World Health Organisation and the International Labor Organisation. Geneva: WHO; 2000. Report No.: WHO/MSD/MPS/00.2.

72. Mohren D, Jansen NW, Van Amelsvoort LG, Kant I. An Epidemiological Approach of Fatigue and Work. Experiences from the Maastricht Cohort Study. Maastricht, NL: Programma Epidemiologie van Arbeid en Gezondheid; 2007.

73. Kant I, Bültmann U, Schroer KAP, Beurskens AJHM, Van Amelsvoort LGPM, Swaen GMH. An epidemiological approach to study fatigue in the working population: the Maastricht Cohort Study. Occup Environ Med. 2003;60 Suppl 1:i32-9. 
74. Van der Doef M, Maes S. The Job Demand-Control(-Support) model and psychological wellbeing: a review of 20 years of empirical research. Work Stress. 1999;13(2):87-114.

75. Cook TD, Campbell DT. Quasi-Experimentation. Design and Analysis for Field Settings. Boston: Houghton Mifflin; 1979.

76. Rugulies R, Bültmann U, Aust B, Burr H. Psychosocial work environment and incidence of severe depressive symptoms: prospective findings from a 5-year follow-up of the Danish work environment cohort study. Am J Epidemiol. 2006;163(10):877-87.

77. Zapf D, Dormann C, Frese M. Longitudinal studies in organizational stress research: a review of the literature with reference to methodological issues. $J$ Occup Health Psychol. 1996;1(2):145-69.

78. Hoogendoorn WE, Bongers PM, de Vet HC, Twisk JW, van Mechelen W, Bouter LM. Comparison of two different approaches for the analysis of data from a prospective cohort study: an application to work related risk factors for low back pain. Occup Environ Med. 2002;59(7):459-65.

79. de Lange AH, Taris TW, Kompier MA, Houtman IL, Bongers PM. Effects of stable and changing demand-control histories on worker health. Scand $J$ Work Environ Health. 2002;28(2):94-108.

80. Shields M. Long working hours and health. Health Rep. 1999;11(2):33-48.

81. Gordis L. From association to causation: deriving inferences from epidemiologic studies. In: Gordis L, editor. Epidemiology. Philadelphia, PA: W.B. Saunders Company; 1996.

82. Rothman KJ, Greenland S. Causation and causal inference in epidemiology. Am J Public Health. 2005;95 Suppl 1:S144-50.

83. Frese M, Zapf D. Methodological issues in the study of work stress: Objective vs subjective measurement of work stress and the question of longitudinal studies. In: Cooper CL, Payne $\mathrm{R}$, editors. Causes, Coping and Consequences of Stress at Work. Chichester, UK: Wiley; 1988. p. 375-411.

84. Bouter LM, Dongen MCJM, van, Zielhuis GA. Epidemiologisch onderzoek: Opzet en interpretatie. Houten: Bohn, Stafleu van Loghum; 2005. 


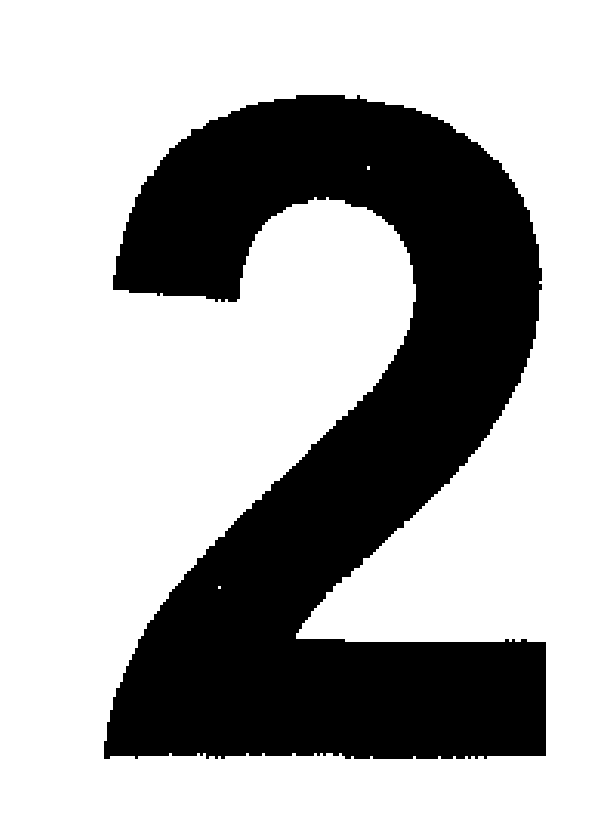

\section{Health effects of transitions in work schedule, working hours and overtime in a prospective cohort study}

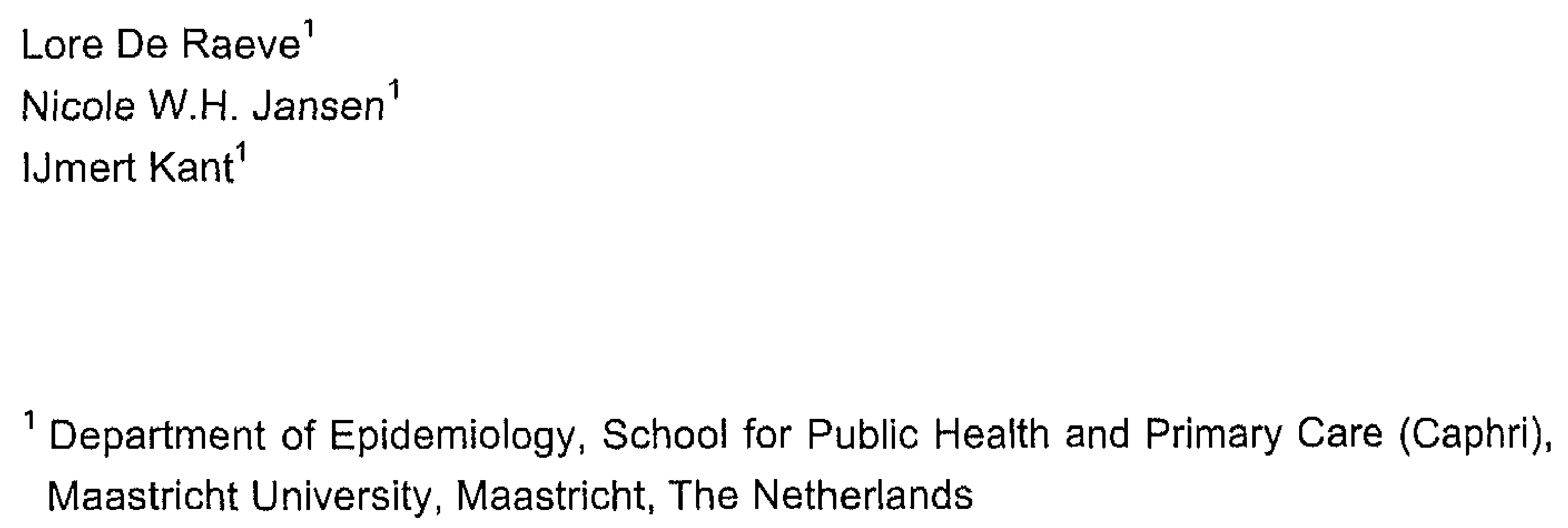




\section{ABSTRACT}

Objectives: The aim of this study was to examine the longitudinal relationship between transitions in work schedules, working hours and overtime and changes in several selfreported health outcomes (general health, fatigue, need for recovery and psychological distress).

Methods: Three-year follow-up data from the Maastricht Cohort Study on fatigue at work were used. Gender stratified logistic regression analyses using generalized estimating equations were conducted for each of the dichotomized health outcomes, with control for a range of possible confounding factors.

Results: This study showed that transitions in work time arrangements were prospectively related to changes in several self-reported health outcomes. Substantial and significant associations were found for transitions in work schedule and the incidence of prolonged fatigue and need for recovery among men. Moreover, transitions in working hours affected the need for recovery among men, while they influenced general health and psychological distress among women. Finally, transitions in overtime were significantly associated with the incidence of need for recovery in both men and women.

Conclusions: Transitions in work time arrangements are related to changes in health, and studying transitions may be an important means of gaining insight into a possible causal relationship between employment and health. Given the considerable impact of work time arrangements on the individual worker, employers, and society and the high frequency in which transitions within work time arrangements can occur, these findings underline the need for interventions addressing work time arrangements in order to reduce or prevent their impact on employee health. 


\section{INTRODUCTION}

The relationship between employment and health is frequently studied within the field of work and health. A large amount of research investigating the relationship between employment and health has focused on the impact of work time arrangements, capturing different work schedules (day work versus various types of shift work), working hours and overtime. Shift work, for example, has been shown to be associated with sleep loss, prolonged fatigue, mental health problems, cardiovascular disease and gastrointestinal disorders ${ }^{1-3}$. Working long hours or overtime has shown to be associated with poor subjective health, more injuries, unhealthy behavior, and increased morbidity and mortality ${ }^{1,4-7}$.

The observed associations between work time arrangements and health may primarily be explained by two mechanisms: the selection hypothesis and the causation hypothesis. The causation hypothesis assumes that employment is causally related to health, while the selection hypothesis assumes that health determines the likelihood of finding or keeping a job ${ }^{8-13}$. With respect to work time arrangements, these hypotheses imply that work time arrangements can have an effect on health or that health predicts the choice of a certain work time arrangement. The general impression emerging from longitudinal research on this issue is that both hypotheses seem to be valid and reinforce each other sequentially ${ }^{12,14}$. Clear evidence of either hypothesis is, however, almost non-existent as most of the studies in this field are cross-sectional in nature. However, even longitudinal studies are often unable to sort out selection and causation effects, among other things because of a lack of dynamics in exposure over time. On the basis of guidelines for causal inference ${ }^{15,16}$ we can assume that a change in exposure (i.e., a change in work time arrangements) results in an altered outcome (i.e., health). Therefore, studying the relationship between transitions in work time arrangements and changes in health may be the key to gaining information on the causation effect, as the transition creates a new situation and consequently enables the study of a direct change in health.

Overall, literature on transitions in work time arrangements is very scarce. A study by Jansen et al. ${ }^{3}$ found that shift workers changing to day work reported significantly higher levels of fatigue prior to their change when compared with those remaining in shift work. Shields ${ }^{17}$ examined the relationship between changes in working hours and changes in health behavior. She concluded that a transition from standard to long working hours was associated with increased smoking among men and women, increased drinking in women and unhealthy weight gain among men. 
If the net health effect of transitions in work time arrangements is to be studied, the influence of possible confounding factors must be taken into account. Several studies have shown that the association between work time arrangements and health may depend on demographic variables, work and home characteristics, and personality factors ${ }^{4-6}$. With respect to work schedules, differences between day and shift workers have been reported ${ }^{18,}{ }^{19}$. Moreover, Jansen et al. ${ }^{3}$ stated that perceived work characteristics may play an important role in the relationship between work schedules and fatigue. In addition, the relationship between work time arrangements and health may differ between men and women because of differences in role patterns and labor force participation between the genders and their different expectations and choices regarding the division of time spent at work or with family.

On the basis of the literature indicating that shift work, long working hours, and overtime are associated with considerable adverse health effects, we hypothesized that: (1) a transition from shift work to day work is beneficial for health, (2) reducing the number of working hours per week is favorable for health and (3) quitting overtime is beneficial for health. We expected that the effects of the transitions would depend both on the health outcomes studied as well as on the time span within which the outcome is measured. It is possible that some health outcomes respond differently or more quickly over time than others to a certain transition.

The aim of this study was to examine the relationship between transitions in work schedules (shift work versus day work), working hours, and overtime and changes in several health outcomes (self-reported general health, fatigue, need for recovery, and psychological distress), separately for men and women, while controlling for a range of possible confounding factors. Data from the Maastricht Cohort Study on fatigue at work were used to address this aim in a longitudinal design. Both transitions in work time arrangements and changes in health were studied within one year of follow-up.

\section{METHODS}

\section{Study population}

This study was based on data from the Maastricht Cohort Study, a prospective study on fatigue at work ${ }^{20}$, in which employees from 45 different companies were followed by means of self-administered questionnaires, which they received at four-month intervals. Once a year, in May, the employees received an extensive questionnaire with items on work and non-work-related factors, demographics, and health factors. Twice a year (in September and January), the employees received a short questionnaire, capturing mainly outcome measures. In May 1998, the baseline questionnaire was sent out to 
26,978 employees. Altogether, 12,161 employees completed and returned the baseline questionnaire (response rate of $45 \%$ ). Twenty-one questionnaires were excluded from analysis due to technical problems. The baseline (TO) cohort for this study thus consisted of 12,140 people and captured both blue-collar and white-collar workers. Detailed information on sectors and trades represented in the Maastricht Cohort Study and on non-response has been reported elsewhere ${ }^{3,20}$. Employees who had completed the baseline questionnaire and at least one of the following two short questionnaires ( $\mathrm{T} 1$ and T2) received the one year follow up questionnaire (T3) in May 1999 (response rate $79.5 \%, n=9655$ ). The employees who returned the questionnaire at $\mathrm{T} 3$ and at least one of the consecutive short questionnaires (T4 and T5) also received the extensive questionnaire (T6) in May 2000 (response rate 66.5\%, $n=8070$ ). For the purpose of this study, data from TO, T3 and T6 were used.

The data were pooled in order to maximize the number of transitions and hence also the power and statistical significance of the study. Consequently, information from two transition periods was combined. For the transition period between TO and T3, TO was identified as the baseline measurement, while T3 was called the follow-up measurement. With regard to the transition period between T3 and T6, T3 was identified as the baseline measurement, while T6 was called the follow-up measurement. The pooling thus resulted in two measurement points: time $T$ and time $T+1$. In the remainder of this paper these measurement points have been referred to as the baseline measurement and the follow-up measurement respectively. Changes from the baseline measurement to the follow-up measurement were used to determine the existence of a transition in work time arrangements. Changes in selfreported health outcomes were determined by assessing incident cases of the health outcomes at follow-up. Therefore, all prevalent cases at baseline were excluded. From this pooled cohort, employees with multiple jobs were excluded, since information about work time arrangements and job content of other jobs was lacking. In addition, only employees working 36 to 40 hours per week at baseline were selected, as a fultime workweek in the Netherlands generally consists of 36 to 40 hours. Moreover, this selection was made to increase comparability with respect to working hours. The resulting study population was called study population A, consisting of 10,888 employees. Transitions in work schedule (day work versus shift work) were studied within this population. To study the effects of transitions in working hours and overtime, an additional selection of this cohort was made. Only employees involved in day work at the time of both the baseline and follow-up measurements were selected. This additional selection resulted in study population $B$, consisting of 6271 employees. The baseline characteristics of study populations $A$ and $B$ are presented in table 1. 
Table 1 Baseline characteristics of study populations $A$ and $B$

\begin{tabular}{lll}
\hline Variable & $\begin{array}{l}\text { Study population A } \\
(n=10888)\end{array}$ & $\begin{array}{l}\text { Study population B } \\
(n=6271)\end{array}$ \\
\hline Gender, male (\%) & 84.1 & 82.5 \\
Age, mean (SD) & $41.73(8.96)$ & $43.07(8.56)$ \\
Education (\%) & & \\
Low & 23.1 & 12.8 \\
Medium & 46.1 & 45.5 \\
High & 30.8 & 41.7 \\
Psychological job demands [12-48] ${ }^{\dagger}$, mean (SD) & $32.85(5.64)$ & $32.57(5.48)$ \\
Decision latitude [24-96] ${ }^{\dagger}$, mean (SD) & $71.37(11.17)$ & $73.49(9.91)$ \\
Co-worker social support [4-16] ${ }^{\dagger}$, mean (SD) & $11.81(1.60)$ & $11.83(1.48)$ \\
Supervisor social support [4-16] ${ }^{\dagger}$, mean (SD) & $10.33(2.36)$ & $10.49(2.22)$ \\
Shift work (\%) & 27.9 & 0 \\
Frequent overtime (\%) & 38.7 & 39.4 \\
Self-reported general health poor (\%) & 15.8 & 14.4 \\
Need for recovery case (\%) & 30.3 & 26.0 \\
Fatigue case (\%) & 22.6 & 20.2 \\
Psychological distress case (\%) & 22.4 & 20.8 \\
\hline
\end{tabular}

${ }^{\dagger}$ Scale range

\section{Measures}

Work time arrangements

The employees provided information on several aspects of their work time arrangements, like work schedule, working hours, and overtime work. Work schedule captured day work versus shift work. In this study, day work comprised normal working hours between 7 am and $7 \mathrm{pm}$. Shift work captured two-shift, three-shift, four-shift, fiveshift and irregular shift work. No further distinction was made between shift work with and without frequent night work. Regarding working hours, the employees were asked for their working hours per week. As has already been described, all employees who were selected worked 36 to 40 hours per week at baseline. The number of working hours per week at follow-up was recoded into $<36$ hours, 36 to 40 hours and $>40$ hours per week. This information was used to track transitions in working hours per week between baseline and follow-up. Finally, overtime was assessed by asking employees whether they frequently worked overtime (yes/no).

\section{Health outcomes}

Self-rated general health was measured using one item from the SF-36 ${ }^{21}$, giving an overall rating of health on a five-point scale ( $1=$ excellent, $2=v e r y$ good, $3=$ good, $4=$ moderate, $5=$ bad). In line with several other studies ${ }^{22-25}$, this measure was dichotomized by grouping response scores 1-3 into the category of good general health 
and scores 4-5 into the category of poor general health. The need for recovery from work was assessed using an 11-item scale from the Dutch Questionnaire on the Experience and Evaluation of Work [Dutch abbreviation, VBBA] ${ }^{26,27}$. The items represent short-term effects of a day of work. The total score ranged from 0 to 100 (Cronbach's $\alpha=0.78$ ). As no cut-off point existed for classifying persons with a high score on the total scale, we used the upper tertile to define employees with a considerable need for recovery from work, the so-called need for recovery cases. Prolonged fatigue was measured with the Checklist Individual Strength (CIS), a 20-item questionnaire developed to measure several aspects of prolonged fatigue ${ }^{28}$. Whereas the scale for need for recovery measured the recuperation period after one day of work and thus represented short-term effects, the CIS asked employees how they felt during the past two weeks. The CIS is a self-report instrument consisting of the following four subscales: subjective experience of fatigue (eight items), concentration (five items), motivation (four items), and physical activity level (three items). The items of the CIS are scored on seven-point Likert scales. Higher scores indicate a higher degree of fatigue, lower levels of concentration, reduced motivation, or less activity. A composite CIS-total score, ranging from 20 to 140 , was constructed by adding the individual's scores on the four factors. The Cronbach's a of the total CIS scale in our study was 0.93 . Persons scoring $>76$ were designated as probable cases of prolonged fatigue ${ }^{29}$. Psychological distress was measured using the 12-item version of the General Health Questionnaire $(\mathrm{GHQ})^{30,31}$. Employees scoring four or more on the $12 \mathrm{GHQ}$ - items were considered to be probable cases of psychological distress.

\section{Confounding factors}

Information on age, gender and educational level was obtained through self-report in the baseline (TO) questionnaire. Moreover, psychological job demands, decision latitude and social support at work were measured at baseline by a Dutch version of the Job Content Questionnaire ${ }^{32,33}$. Psychological job demands were assessed by the sum of five items (Cronbach's $\alpha=0.69$ ). Decision latitude (Cronbach's $\alpha=0.81$ ) was measured by the sum of the following two subscales: skill discretion and decision authority. Response options varied from strongly agree to strongly disagree on a four-point scale. Social support was assessed by the following two scales, each consisting of four items: supervisory support (Cronbach's $\alpha=0.85$ ) and co-worker support (Cronbach's $\alpha=0.75$ ). Physical demands were measured with a one-item question "Would you consider your work to be physically demanding?" 34 . Furthermore, occupational mobility was defined as a change in job function between TO and T3 and included as a confounder in the model. As such, it was possible to study the health effects of changes in work time arrangements independent of changes in job function. 


\section{Statistical analysis}

We used logistic regression analyses for repeated measurements (generalized estimating equations, GEE) to assess the relationship between transitions in work time arrangements from time $T$ to time $T+1$ and changes in several self-reported health outcomes from time $T$ to time $T+1$. GEE can be used as a method for dealing with correlated data arising from repeated measurements ${ }^{35,36}$. First, all prevalent cases from the involved dependent variable at baseline were excluded. As such, only incident cases for each health outcome were studied. Separate logistic regression models were fitted for each of the dichotomized health measures: self-reported general health, prolonged fatigue, need for recovery, and psychological distress. Odds ratios (OR) and $95 \%$ confidence intervals $(95 \% \mathrm{Cl}$ ) were calculated. In the analyses, we corrected for age (continuous), education, occupational mobility, psychological job demands, decision latitude, social support of co-workers and supervisors, and physical demands of the job. We also examined the influence of smoking behavior and changes in other work time arrangements as possible confounders, but as they did not imply a relevant change in the regression coefficient, they were omitted from the analyses. All analyses were stratified for gender and were performed using SAS 9.1 statistical packages ${ }^{35}$.

\section{RESULTS}

\section{Transitions in work schedules}

The associations between transitions in work schedules and changes in self-reported health were calculated for employees working 36 to 40 hours per week, either in day work or in shift work at baseline (study population A). Because of the small number of women in each transition category, the analyses were performed for men only (see table 2). The results of the GEE analysis showed that men working in shifts at both the baseline and the follow-up measurement had significantly higher odds of developing a higher need for recovery, more prolonged fatigue, or poorer general health than men in day work at the time of both the baseline and the follow-up measurement. After correction for confounders, all the odds ratios lacked significance. In addition, men changing from shift work to day work had significantly higher odds of becoming a need for recovery case or a psychological distress case than men in day work. In the fully corrected model, the odds ratio for psychological distress lacked significance. Finally, men changing from day work to shift work had considerably higher and significant odds of becoming a prolonged fatigue case, even in the fully corrected model. 
Health effects of transitions in work time arrangements

Table 2 Health effects of transitions in work schedules in men (study population A)

\begin{tabular}{|c|c|c|c|c|}
\hline \multirow{2}{*}{\multicolumn{2}{|c|}{$\begin{array}{l}\text { Work schedule } \\
\text { Baseline } \rightarrow \text { follow-up }\end{array}$}} & \multicolumn{3}{|c|}{ Fatigue case } \\
\hline & & \multirow{2}{*}{$\frac{n}{3583}$} & \multirow{2}{*}{$\frac{O R^{a}[95 \% \mathrm{Cl}]}{1.00 \text { (ref) }}$} & \multirow{2}{*}{$\frac{\mathrm{OR}^{\mathrm{b}}[95 \% \mathrm{Cl}]}{1.00 \text { (ref) }}$} \\
\hline Day & $\rightarrow$ day & & & \\
\hline Shift & $\rightarrow$ day & 95 & $1.39[0.82-2.38]$ & $1.03[0.55-1.90]$ \\
\hline Shift & $\rightarrow$ shift & 1045 & $1.40[1.16-1.70]$ & $1.25[0.98-1.59]$ \\
\hline \multirow[t]{3}{*}{ Day } & $\rightarrow$ shift & 43 & $2.33[1.22-4.44]$ & $2.43[1.18-5.01]$ \\
\hline & & \multicolumn{3}{|c|}{ Poor general health } \\
\hline & & $n$ & $\mathrm{OR}^{a}[95 \% \mathrm{Cl}]$ & $O R^{\mathrm{b}}[95 \% \mathrm{Cl}]$ \\
\hline Day & $\rightarrow$ day & 3892 & 1.00 (ref) & 1.00 (ref) \\
\hline Shift & $\rightarrow$ day & 117 & $0.89[0.46-1.71]$ & $0.65[0.31-1.33]$ \\
\hline Shift & $\rightarrow$ shift & 1197 & $1.41[1.15-1.71]$ & $1.22[0.95-1.58]$ \\
\hline \multirow[t]{3}{*}{ Day } & $\rightarrow$ shift & 45 & $1.54[0.70-3.39]$ & $1.46[0.59-3.63]$ \\
\hline & & \multicolumn{3}{|c|}{ Need for recovery case } \\
\hline & & $\pi$ & $\mathrm{OR}^{\mathrm{a}}[95 \% \mathrm{Cl}]$ & $\mathrm{OR}^{\mathrm{b}}[95 \% \mathrm{Cl}]$ \\
\hline Day & $\rightarrow$ day & 2986 & 1.00 (ref) & 1.00 (ref) \\
\hline Shift & $\rightarrow$ day & 64 & $2.50[1.47-4.26]$ & $2.12[1.19-3.75]$ \\
\hline Shift & $\rightarrow$ shift & 809 & $1.41[1.15-1.73]$ & $1.10[0.85-1.43]$ \\
\hline \multirow[t]{3}{*}{ Day } & $\rightarrow$ shift & 29 & $1.40[0.59-3.29]$ & $1.31[0.52-3.32]$ \\
\hline & & \multicolumn{3}{|c|}{ Psychological distress case } \\
\hline & & $\mathrm{n}$ & $\mathrm{OR}^{\mathrm{a}}[95 \% \mathrm{Cl}]$ & $\mathrm{OR}^{\mathrm{b}}[95 \% \mathrm{Cl}]$ \\
\hline Day & $\rightarrow$ day & 3623 & 1.00 (ref) & 1.00 (ref) \\
\hline Shift & $\rightarrow$ day & 101 & $1.79[1.14-2.80]$ & $1.62[0.99-2.67]$ \\
\hline Shift & $\rightarrow$ shift & 1095 & $0.92[0.76-1.11]$ & $0.89[0.70-1.13]$ \\
\hline Day & $\rightarrow$ shift & 42 & $0.51[0.19-1.41]$ & $0.67[0.23-1.89]$ \\
\hline
\end{tabular}

\section{Transitions in working hours}

The health effects of transitions in working hours were calculated for both male and female employees working 36 to 40 hours per week in day work at baseline (study population $B$ ). As shown in tables 3 and 4 , a rather high number of both men and women underwent a transition in their working hours from the baseline to the follow-up measurement (note: the different numbers of included observations resulted from missing observations in the outcome variables or in the confounders). Table 3 shows that male employees changing from 36 to 40 hours per week to $>40$ hours per week had significantly higher odds of experiencing an elevated need for recovery from the baseline to the follow-up measurement (OR $1.48 ; 95 \% \mathrm{Cl} 1.09-2.01$ ) than men who did not change the number of hours they worked per week. The odds for the other health outcomes were not significant. 
Table 3 Health effects of transitions in working hours in men (study population B)

\begin{tabular}{|c|c|c|c|c|}
\hline \multirow{2}{*}{\multicolumn{2}{|c|}{$\begin{array}{l}\text { Working hours/ week } \\
\text { Baseline } \rightarrow \text { follow-up }\end{array}$}} & \multicolumn{3}{|c|}{ Fatigue case } \\
\hline & & $n$ & $\mathrm{OR}^{\mathrm{a}}[95 \% \mathrm{Cl}]$ & $\mathrm{OR}^{\mathrm{b}}[95 \% \mathrm{Cl}]$ \\
\hline $36-40$ & $\rightarrow 36-40$ & 2916 & 1.00 (ref) & 1.00 (ref) \\
\hline $36-40$ & $\rightarrow>40$ & 589 & $0.96[0.73-1.26]$ & $0.95[0.70-1.29]$ \\
\hline \multirow[t]{3}{*}{$36-40$} & $\rightarrow<36$ & 74 & $1.27[0.69-2.35]$ & $1.37[0.69-2.72]$ \\
\hline & & \multicolumn{3}{|c|}{ Poor general health } \\
\hline & & $n$ & $\mathrm{OR}^{\mathrm{a}}[95 \% \mathrm{Cl}]$ & $\mathrm{OR}^{\mathrm{b}}[95 \% \mathrm{Cl}]$ \\
\hline $36-40$ & $\rightarrow 36-40$ & 3180 & 1.00 (ref) & 1.00 (ref) \\
\hline $36-40$ & $\rightarrow>40$ & 628 & $0.97[0.73-1.31]$ & $0.96[0.69-1.35]$ \\
\hline \multirow[t]{3}{*}{$36-40$} & $\rightarrow<36$ & 79 & $1.01[0.49-2.09]$ & $0.78[0.31-1.95]$ \\
\hline & & \multicolumn{3}{|c|}{ Need for recovery case } \\
\hline & & $n$ & $\mathrm{OR}^{\mathrm{a}}[95 \% \mathrm{Cl}]$ & $\mathrm{OR}^{\mathrm{b}}[95 \% \mathrm{Cl}]$ \\
\hline $36-40$ & $\rightarrow 36-40$ & 2474 & 1.00 (ref) & 1.00 (ref) \\
\hline $36-40$ & $\rightarrow>40$ & 446 & $1.47[1.13-1.91]$ & $1.48[1.09-2.01]$ \\
\hline \multirow[t]{3}{*}{$36-40$} & $\rightarrow<36$ & 63 & $1.04[0.52-2.10]$ & $1.37[0.64-2.92]$ \\
\hline & & \multicolumn{3}{|c|}{ Psychological distress case } \\
\hline & & $n$ & $\mathrm{OR}^{\mathrm{a}}[95 \% \mathrm{Cl}]$ & $\mathrm{OR}^{\mathrm{b}}[95 \% \mathrm{Cl}]$ \\
\hline \multicolumn{2}{|c|}{$36-40 \rightarrow 36-40$} & 2955 & 1.00 (ref) & 1.00 (ref) \\
\hline \multicolumn{2}{|c|}{$36-40 \rightarrow>40$} & 588 & $0.88[0.68-1.12]$ & $0.79[0.60-1.05]$ \\
\hline \multicolumn{2}{|c|}{$36-40 \rightarrow<36$} & 76 & $1.01[0.56-1.83]$ & $1.07[0.56-2.04]$ \\
\hline
\end{tabular}

The associations between transitions in working hours and changes in self-reported health outcomes for women are presented in Table 4. The transition from 36 to 40 hours per week at the time of the baseline measurement to $<36$ hours per week at the time of the follow-up measurement was significantly associated with a deterioration in selfreported general health $(\mathrm{OR} 2.59 ; 95 \% \mathrm{Cl} 1.33-5.03)$ and more psychological distress (OR $1.99 ; 95 \% \mathrm{Cl} 1.18-3.35$ ) than working 36 to 40 hours per week at the time of both the baseline and the follow-up measurement. The association between a change in working hours from 36 to 40 hours per week at baseline to $>40$ hours per week at follow-up and a deterioration in self-reported health was only borderline significant (OR $1.97 ; 95 \% \mathrm{Cl}$ 0.99-3.91). 
Table 4 Health effects of transitions in working hours in women (study population B)

\begin{tabular}{|c|c|c|c|c|}
\hline \multirow{2}{*}{\multicolumn{2}{|c|}{$\begin{array}{l}\text { Working hours/ week } \\
\text { Baseline } \rightarrow \text { follow-up }\end{array}$}} & \multicolumn{3}{|c|}{ Fatigue case } \\
\hline & & $n$ & $\mathrm{OR}^{\mathrm{a}}[95 \% \mathrm{Cl}]$ & $\mathrm{OR}^{\mathrm{b}}[95 \% \mathrm{Cl}]$ \\
\hline $36-40$ & $\rightarrow 36-40$ & 570 & 1.00 (ref) & 1.00 (ref) \\
\hline $36-40$ & $\rightarrow>40$ & 68 & $1.32[0.72-2.41]$ & $1.71[0.90-3.24]$ \\
\hline \multirow[t]{3}{*}{$36-40$} & $\rightarrow<36$ & 75 & $1.06[0.58-1.95]$ & $1.20[0.62-2.31]$ \\
\hline & & \multicolumn{3}{|c|}{ Poor general health } \\
\hline & & $n$ & $\mathrm{OR}^{\mathrm{a}}[95 \% \mathrm{Cl}]$ & $\mathrm{OR}^{\mathrm{b}}[95 \% \mathrm{Cl}]$ \\
\hline $36-40$ & $\rightarrow 36-40$ & 620 & 1.00 (ref) & 1.00 (ref) \\
\hline $36-40$ & $\rightarrow>40$ & 76 & $1.88[0.99-3.57]$ & $1.97[0.99-3.91]$ \\
\hline \multirow[t]{3}{*}{$36-40$} & $\rightarrow<36$ & 91 & $2.05[1.15-3.64]$ & $2.59[1.33-5.03]$ \\
\hline & & \multicolumn{3}{|c|}{ Need for recovery case } \\
\hline & & $n$ & $\mathrm{OR}^{\mathrm{a}}[95 \% \mathrm{Cl}]$ & $\mathrm{OR}^{\mathrm{b}}[95 \% \mathrm{Cl}]$ \\
\hline $36-40$ & $\rightarrow 36-40$ & 490 & 1.00 (ref) & 1.00 (ref) \\
\hline $36-40$ & $\rightarrow>40$ & 55 & $1.64[0.86-3.15]$ & $1.62[0.80-3.28]$ \\
\hline \multirow[t]{3}{*}{$36-40$} & $\rightarrow<36$ & 60 & $0.62[0.26-1.45]$ & $0.60[0.23-1.56]$ \\
\hline & & \multicolumn{3}{|c|}{ Psychological distress case } \\
\hline & & $\mathrm{n}$ & $\mathrm{OR}^{\mathrm{a}}[95 \% \mathrm{Cl}]$ & $\mathrm{OR}^{\mathrm{b}}[95 \% \mathrm{Cl}]$ \\
\hline $36-40$ & $\rightarrow 36-40$ & 549 & 1.00 (ref) & 1.00 (ref) \\
\hline $36-40$ & $\rightarrow>40$ & 67 & $1.27[0.72-2.24]$ & $1.31[0.72-2.41]$ \\
\hline $36-40$ & $\rightarrow<36$ & 84 & $1.85[1.14-2.98]$ & $1.99[1.18-3.35]$ \\
\hline
\end{tabular}

Uncorrected

${ }^{b}$ Corrected for age (continuous), education, occupational mobility, psychological job demands, decision latitude, supervisory support, co-worker support and physical demands

\section{Transitions in overtime}

As was the case for transitions in working hours, transitions in overtime were also calculated for male and female employees working 36 to 40 hours per week in day work at the time of the baseline measurement (study population B). As shown in table 5, a fairly large number of both men and women experienced a transition in overtime work. These transitions were related to changes in need for recovery and psychological distress. Working overtime at the time of both the baseline and the follow-up measurement was significantly associated with a decreased need for recovery (OR 0.58 ; $95 \% \mathrm{Cl} 0.36-0.93$ ) and less psychological distress (OR $0.69 ; 95 \% \mathrm{Cl} 0.49-0.98$ ) among men. Having quit overtime work by the time of the follow-up measurement was associated with significantly higher odds of becoming a need-for-recovery case among both men (OR $1.63 ; 95 \% \mathrm{Cl} 1.23-2.15$ ) and women (OR $1.96 ; 95 \% \mathrm{Cl} 1.04-3.96$ ) than not working overtime at both measurement points. 
Table 5 Health effects of transitions in overtime in men and women (study population B)

\begin{tabular}{|c|c|c|c|c|}
\hline \multirow[b]{2}{*}{ Overtime } & \multirow[b]{3}{*}{$\rightarrow$ follow-up } & \multicolumn{3}{|l|}{ Men } \\
\hline & & \multicolumn{3}{|c|}{ Need for recovery case } \\
\hline Baseline & & $n$ & $\mathrm{OR}^{\mathrm{A}}[95 \% \mathrm{Cl}]$ & $\mathrm{OR}^{\mathrm{b}}[95 \% \mathrm{Cl}]$ \\
\hline No overtime & $\rightarrow$ no overtime & 1619 & 1.00 (ref) & 1.00 (ref) \\
\hline No overtime & $\rightarrow$ overtime & 252 & $1.19[0.82-1.72]$ & $1.31[0.87-1.98]$ \\
\hline Overtime & $\rightarrow$ no overtime & 774 & $1.50[1.18-1.89]$ & $1.63[1.23-2.15]$ \\
\hline \multirow[t]{3}{*}{ Overtime } & $\rightarrow$ overtime & 320 & $0.52[0.33-0.82]$ & $0.58[0.36-0.93]$ \\
\hline & & \multicolumn{3}{|c|}{ Psychological distress case } \\
\hline & & $\mathrm{n}$ & $\mathrm{OR}^{\mathrm{a}}[95 \% \mathrm{Cl}]$ & $\mathrm{OR}^{\mathrm{b}}[95 \% \mathrm{Cl}]$ \\
\hline No overtime & $\rightarrow$ no overtime & 1860 & 1.00 (ref) & 1.00 (ref) \\
\hline No overtime & $\rightarrow$ overtime & 305 & $1.28[0.94-1.73]$ & $1.16[0.83-1.64]$ \\
\hline Overtime & $\rightarrow$ no overtime & 1044 & $0.99[0.80-1.22]$ & $0.82[0.64-1.05]$ \\
\hline \multirow[t]{2}{*}{ Overtime } & $\rightarrow$ overtime & 391 & $0.79[0.57-1.08]$ & $0.69[0.49-0.98]$ \\
\hline & & \multicolumn{3}{|c|}{ Women } \\
\hline Overtime & & \multicolumn{3}{|c|}{ Need for recovery case } \\
\hline Baseline & $\rightarrow$ follow-up & $n$ & $\mathrm{OR}^{\mathrm{a}}[95 \% \mathrm{Cl}]$ & $\mathrm{OR}^{\mathrm{b}}[95 \% \mathrm{Cl}]$ \\
\hline No overtime & $\rightarrow$ no overtime & 339 & 1.00 (ref) & 1.00 (ref) \\
\hline No overtime & $\rightarrow$ overtime & 49 & $1.62[0.77-3.39]$ & $1.47[0.64-3.38]$ \\
\hline Overtime & $\rightarrow$ no overtime & 149 & $2.32[1.43-3.76]$ & $1.96[1.04-3.69]$ \\
\hline \multirow[t]{3}{*}{ Overtime } & $\rightarrow$ overtime & 68 & $0.47[0.17-1.33]$ & $0.44[0.15-1.27]$ \\
\hline & & \multicolumn{3}{|c|}{ Psychological distress case } \\
\hline & & $\mathrm{n}$ & $\mathrm{OR}^{\mathrm{a}}[95 \% \mathrm{Cl}]$ & $\mathrm{OR}^{\mathrm{b}}[95 \% \mathrm{Cl}]$ \\
\hline No overtime & $\rightarrow$ no overtime & 357 & 1.00 (ref) & 1.00 (ref) \\
\hline No overtime & $\rightarrow$ overtime & 57 & $1.15[0.62-2.13]$ & $0.81[0.40-1.62]$ \\
\hline Overtime & $\rightarrow$ no overtime & 199 & $1.20[0.81-1.77]$ & $1.00[0.63-1.59]$ \\
\hline Overtime & $\rightarrow$ overtime & 86 & $0.88[0.49-1.55]$ & $0.69[0.37-1.29]$ \\
\hline
\end{tabular}

\footnotetext{
Uncorrected

${ }^{b}$ Corrected for age (continuous), education, occupational mobility, psychological job demands, decision latitude, supervisory support, co-worker support and physical demands
}

\section{Discussion}

The present study examined the association between transitions in various types of work time arrangements and changes in self-reported health outcomes in order to gain more insight into a possible causal relationship between working time arrangements and health. This study showed that transitions in work time arrangements are prospectively related to changes in several self-reported health outcomes. The results varied for different transitions and the different health outcomes studied. Moreover, considerable gender differences were observed. Substantial and significant relationships were found between transitions in work schedule and the incidence of prolonged fatigue and need 
for recovery among men. Moreover, transitions in working hours affected the need for recovery in men, while they influenced both self-reported general health and psychological distress in women. Finally, transitions in overtime were significantly associated with a change in need for recovery among men and women. As studying transitions is fairly complicated, several methodological and conceptual issues should be addressed.

In our study, a follow-up period of one year was chosen. Shorter measurement periods would have probably resulted in a clearer insight into the time course of cause and effect 37. Despite the frequent sampling (every four months) in the large-scale Maastricht Cohort Study, we were not able to study transitions that took place within these short periods of time, as items on specific work time arrangements were only assessed in the extensive questionnaires that were sent out annually. Therefore, the specific time period in which the transition took place could not be clearly defined. We do know, however, that the transition took place presumably after an average of six months after the baseline measurement. As we do not exactly know when the transition took place, it is also not clear whether the health effect of the transition had not yet occurred or whether the effect had already faded away. For instance, the women changing to fewer hours per week might not yet have adapted to their new working hours and consequently no effect was found (yet). A related issue is that the time span within which an effect can occur is probably related to the health outcome under study. Some outcomes may react faster to a certain transition than others. As was indicated by Jansen et al. ${ }^{3}$, it is possible that the effects of shift work on fatigue develop relatively soon after starting to work in a shift work job, while the effects on other health outcomes have not yet occurred. In addition, the differences found for the separate health outcomes may also have been due to our choice of arbitrary cut-off points. To date, there are no existing cut-off points for classifying employees with a marked need for recovery that would put them at risk for future health problems. In our study, the upper tertile was used to define employees with a considerable need for recovery from work, the so-called need-for-recovery cases. So far, this appeared to be a good method since the distribution of need for recovery in the cohort covered the whole range of the scale and showed no cut-off points or peculiarities.

In our study, the employees were already in the middle of an ongoing process both with regard to work time arrangements and health. In this respect, our first measurement was not a true baseline measurement. Previous work time arrangements and transitions that had taken place in the past may have already had their influence on the health of the respondents before our actual baseline measurement. Consequently, a selection bias may have already occurred before our first measurement. People working overtime may have stopped working overtime before baseline due to mental health problems. This possibility may be an explanation for the fact that men working overtime both at the time 
of the baseline measurement and at the time of the follow-up measurement reported a significantly lower need for recovery and less psychological distress than men not working overtime. A specific type of selection bias is the healthy worker effect. For example, it is possible that only employees able to withstand the effects that accompany shift work start working in shifts or remain in shift work. This could be an explanation for the fact that the transition from day work to shift work in our study was not significantly associated with a change in self-reported health outcomes like perceived general health, need for recovery and psychological distress. Moreover, the fact that employees who started working overtime did not experience a significant deterioration in health may have also been due to this healthy worker effect. In this study, we minimized the selection effects by studying individual changes in work time arrangements in relation to individual changes in health.

The results of our study indicate that transitions that were hypothesized to have positive health effects were not always associated with a positive change in mental health. For example, when women changed their working hours to $<36$ hours per week, the change did not prevent them from becoming psychologically distressed, a finding which was not in line with our hypothesis. This effect could have been due to other changes in the work or home situation that we did not control for in the analyses. With respect to work-family conflict, Jansen et al. ${ }^{38}$ found that fulltime working women with a high work-home interference had a substantially higher probability of changing their working hours over time, than those reporting a lower work-home interference. In this respect, it is possible that, despite a reduction in working hours, the women in this study still experienced the negative effects of a double burden and therefore became psychologically distressed. In this view, a potentially important confounder is whether changes in work time arrangements were forced upon the employee, more likely leading to negative effects, or whether they were the worker's own choice, possibly leading to more positive effects 39,40 . For example, an obligation to reduce the amount of working hours because of company restructuring can be an important source of psychological distress. Although an item in the questionnaire specifically asked whether or not the change in working hours was at the employee's own request, we were unable to make this distinction due to the low number of participants responding to this item. For the same reason, in this study, no further distinction could be made regarding the amount of overtime or the size of the change in working hours. It is possible, however, that a limited amount of overtime or a small change in working hours has a limited influence on health and that more severe levels of overtime or larger changes in working hours must be reached before health consequences appear. Regarding the external validity of our study, it should be mentioned that this study only applied to full time employees. Mechanisms and choices related to work time arrangements will probably differ for part-time workers, for whom several selection processes may have already taken place. 
Another issue concerns the correction for confounding in our study. As was already mentioned in the introduction, the relationship between work time arrangements and health may be confounded by several factors that we controlled for in the analyses. Work-related factors, like job demands, are very interrelated with work time arrangements. For example, it is possible that shift workers perceive their job as more demanding than day workers do. As such, controlling for these work-related factors may have led to over-control and hence to an underestimation of the observed relationships.

Contrary to our hypothesis, quitting overtime was associated with an elevated need for recovery among both men and women compared to not working overtime. Our explanation for this counterintuitive result stems from Kristensen et al. ${ }^{41}$, who suggested that the pressure for increased productivity may result in a mismatch between the amount of work that needs to be done and the time available to do it. This mismatch leads to pressure for both a faster work pace (intensity of work) and longer working hours (extensity of work). It goes without saying that both could lead to a deterioration of health. What might have happened in our study is that these people had already intensified their work and, in consequence, they experienced a higher need for recovery at that point in time. When they subsequently extensified their work by working overtime the need for recovery may have increased even more. Quitting overtime may then only have reduced the need for recovery to the level of the effect that the intensification already had on the need for recovery.

To our knowledge, this is the first prospective study examining the relation between transitions in various work time arrangements and changes in four self-reported health outcomes (self-reported general health, need for recovery, prolonged fatigue, and psychological distress) in a general working population. Although this study used a longitudinal approach, it was methodologically not possible to draw any conclusions about causality as the change in exposure was measured at the same time as a change in the outcome measures. This study clearly showed that individual transitions in working time arrangements are related to individual changes in self-reported health outcomes. As the transition creates a new situation, consequently enabling a direct change in health to be studied, we do think that studying transitions may be an important means by which to gain more insight into a possible causal relationship between employment and health. Given the considerable impact of work time arrangements on the individual worker, employers, and society, and the high frequency in which transitions within work time arrangements can occur, these findings underline the need for interventions addressing work time arrangements in order to prevent, or at least reduce, their impact on the health of the working population. Moreover, it is important to pay substantial attention to employees' expressed requests for changing their work time arrangements, as they can be an antecedent of a future change in health, as well as an effect of already changed health. 


\section{REFERENCES}

1. Harrington JM. Shift work and health--a critical review of the literature on working hours. Ann Acad Med Singapore. 1994;23(5):699-705.

2. Harrington JM. Health effects of shift work and extended hours of work. Occup Environ Med. 2001:58:68-72.

3. Jansen NWH, van Amelsvoort LGPM, Kristensen TS, van den Brandt PA, Kant 1. Work schedules and fatigue: a prospective cohort study. Occup Environ Med. 2003;60 Suppl 1:14753.

4. Sparks K, Cooper C, Fried Y, Shirom A. The effects of hours of work on health: A metaanalytic review. J Occup Organ Psych. 1997;70:391-408.

5. Spurgeon $\mathrm{A}$, Harrington $\mathrm{JM}$, Cooper $\mathrm{CL}$. Health and safety problems associated with long working hours: a review of the current position. Occup Environ Med. 1997;54(6):367-75.

6. van der Hulst M. Long workhours and health. Scand J Work Environ Health. 2003;29(3):17188.

7. van Amelsvoort LG, Schouten EG, Kok FJ. Impact of one year of shift work on cardiovascular disease risk factors. J Occup Environ Med. 2004;46(7):699-706.

8. Arrow JO. Estimating the influence of health as a risk factor on unemployment: a survival analysis of employment durations for workers surveyed in the German Socio-Economic Panel (1984-1990). Soc Sci Med. 1996;42(12):1651-9.

9. Béland F, Birch S, Stoddart G. Unemployment and health: contextual-level influences on the production of health in populations. Soc Sci Med. 2002;55(11):2033-52.

10. Claussen B. Health and re-employment in a five-year follow-up of long-term unemployed. Scand J Public Health. 1999;27(2):94-100.

11. Schaufeli WB. Youth unemployment and mental health: some Dutch findings. J Adolesc. 1997;20(3):281-92.

12. Ross CE, Mirowsky J. Does employment affect health? J Health Soc Behav. 1995;36(3):23043.

13. Virtanen $\mathrm{P}$, Koivisto AM. Wellbeing of professionals at entry into the labour market: a follow up survey of medicine and architecture students. J Epidemiol Community Health. 2001;55(11):831-5.

14. Hammarström A. Health consequences of youth unemployment-review from a gender perspective. Soc Sci Med. 1994;38(5):699-709.

15. Gordis L. From association to causation: deriving inferences from epidemiologic studies. In: Gordis L, editor. Epidemiology. Philadelphia, PA: W.B. Saunders Company; 1996.

16. Rothman KJ, Greenland S. Causation and causal inference in epidemiology. Am J Public Health. 2005;95 Suppl 1:S144-50.

17. Shieids M. Long working hours and health. Health Rep. 1999;11(2):33-48.

18. Bøggild $H$, Burr $H$, Tüchsen $F$, Jeppesen HJ. Work environment of Danish shift and day workers. Scand J Work Environ Health. 2001;27(2):97-105.

19. Jansen NWH, Kant I, van Amelsvoort LGPM, Nijhuis FJN, van den Brandt PA. Need for recovery from work: evaluating short-term effects of working hours, patterns and schedules. Ergonomics. 2003;46(7):664-80. 
20. Kant I, Bültmann U, Schroer KAP, Beurskens AJHM, Van Amelsvoort LGPM, Swaen GMH. An epidemiological approach to study fatigue in the working population: the Maastricht Cohort Study. Occup Environ Med. 2003;60 Suppl 1:i32-9.

21. Aaronson NK, Mulier M, Cohen PD, Essink-Bot ML, Fekkes $M$, Sanderman $R$, et al. Translation, validation, and norming of the Dutch language version of the SF-36 Health Survey in community and chronic disease populations. J Clin Epidemiol. 1998;51(11):105568.

22. Ala-Mursula L, Vahtera J, Kivimäki M, Kevin MV, Pentti J. Employee control over working times: associations with subjective health and sickness absences. J Epidemiol Community Health. 2002;56(4):272-8.

23. Artazcoz L, Borrell C, Rohlfs I, Beni C, Moncada A, Benach J. Trabajo doméstico, género y salud en población ocupada [Housework, gender and health in the working population]. Gac Sanit. 2001;15(2):150-3.

24. Chandola $T$, Bartley $M$, Wiggins $R$, Schofield $P$. Social inequalities in health by individual and household measures of social position in a cohort of healthy people. $J$ Epidemiol Community Health. 2003;57(1):56-62.

25. Dalstra JA, Kunst AE, Geurts JJ, Frenken FJ, Mackenbach JP. Trends in socioeconomic health inequalities in the Netherlands, 1981-1999. J Epidemiol Community Health. 2002;56(12):927-34.

26. Van Veldhoven M, Meijman TF. Het meten van psychosociale arbeidsbelasting met een vragenlijst: de vragenlijst beleving en beoordeling van de arbeid (VBBA) The measurement of psychosocial job demands with a questionnaire (VBBA)]. Amsterdam, NL: Netherlands Institute for the Working Environment NIA-TNO; 1994.

27. Van Veldhoven $M$, Broersen $S$. Measurement quality and validity of the "need for recovery scale". Occup Environ Med. 2003;60 Suppl 1:i3-9.

28. Vercoulen JH, Swanink CM, Fennis JF, Galama JM, van der Meer JW, Bleijenberg $G$. Dimensional assessment of chronic fatigue syndrome. J Psychosom Res. 1994;38(5):383-92.

29. Bültmann U, de Vries M, Beurskens AJ, Bleijenberg G, Vercoulen JH, Kant I. Measurement of prolonged fatigue in the working population: determination of a cutoff point for the checklist individual strength. J Occup Health Psychol. 2000;5(4):411-6.

30. Goldberg DP, Williams P. The user's guide to the General Health Questionnaire. Windsor, UK: NFER-Nelson; 1991.

31. Koeter MWJ, Ormel J. General Health Questionnaire, Handleiding Nederlandse bewerking [General Health Questionnaire, Manual Dutch version]. Lisse, NL: Swets \& Zeitlinger; 1991.

32. Karasek R, Brisson C, Kawakami N, Houtman I, Bongers P, Amick B. The Job Content Questionnaire (JCQ): an instrument for internationally comparative assessments of psychosocial job characteristics. J Occup Health Psychol. 1998;3(4):322-55.

33. Karasek RA. The Job Content Questionnaire and User's Guide (version 1.1). Los Angeles, CA: Department of Industrial and Systems Engineering, University of Southern California; 1985.

34. Grundemann RMW, Smulders PGW, de Winter CR. Vragenlijst Arbeid en Gezondheid (VAG) [Questionnaire on Work and Health]. Lisse: Swets \& Zeitlinger; 1993.

35. SAS Institute Inc. SAS version 9.1. Cary, NC: SAS Institute Inc.; 2003.

36. SAS Institute Inc. SAS OnlineDoc® 9.1.2. Cary, NC: Sas Institue Inc.; 2004. 
37. Frese $M$, Zapf $D$. Methodological issues in the study of work stress: Objective vs subjective measurement of work stress and the question of longitudinal studies. In: Cooper CL, Payne $R$, editors. Causes, Coping and Consequences of Stress at Work. Chichester, UK: Wiley; 1988. p. 375-411.

38. Jansen NWH, Kant I, Nijhuis FJN, Swaen GMH, Kristensen TS. Impact of worktime arrangements on work-home interference among Dutch employees. Scand $\mathrm{J}$ Work Environ Health. 2004;30(2):139-48.

39. Barton J, Smith L, Totterdell P, Spelten E, Folkard S. Does Individual Choice Determine Shift System Acceptability. Ergonomics. 1993;36(1-3):93-9.

40. Gartner J. Conflicts between employee preferences and ergonomic recommendations in shift scheduling: regulation based on consent is not sufficient. Revista De Saude Publica. 2004;38:65-71.

41. Kristensen TS, Bjorner JB, Christensen KB, Borg V. The distinction between work pace and working hours in the measurement of quantitative demands at work. Work Stress. 2004;18(4):305-22. 


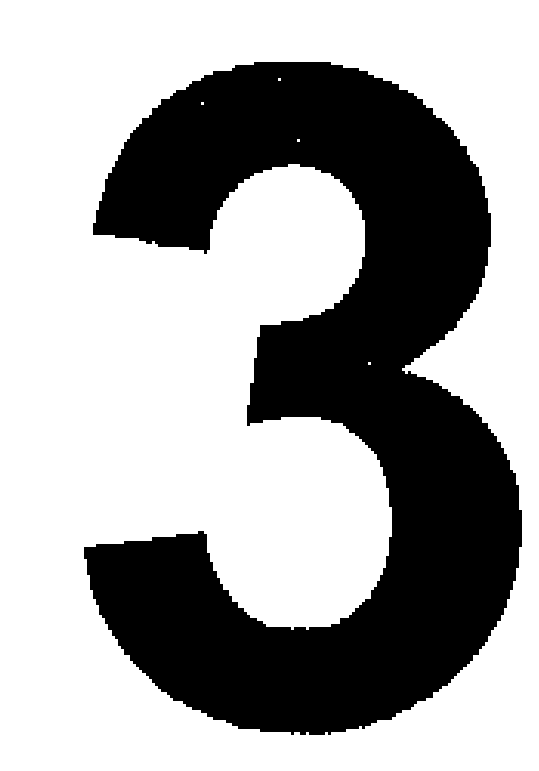

\section{Mental health effects of changes in psychosocial work characteristics: A prospective cohort study}

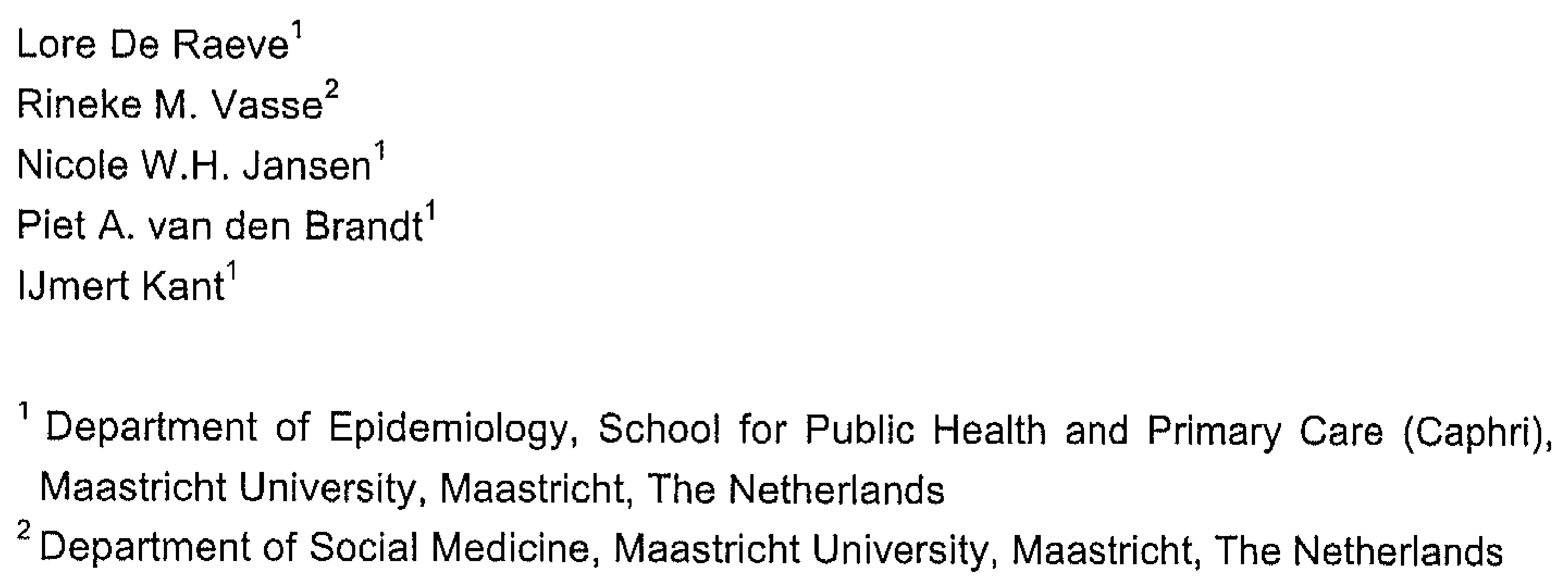

Journal of Occupational and Environmental Medicine 2007; 49(8):890-899 


\section{ABSTRACT}

Objectives: To explore a possible causal relationship between psychosocial work characteristics and mental health.

Methods: Using longitudinal data from the Maastricht Cohort Study on "Fatigue at Work" $(n=2332$ ), the effects of changes in job demands and decision latitude on subsequent changes in need for recovery and prolonged fatigue were studied.

Results: Increasing job demands were a significant predictor of a subsequent increase in need for recovery $(\beta=0.063)$ and prolonged fatigue $(\beta=0.057)$. An increase in decision latitude predicted a subsequent decrease in need for recovery $(\beta=-0.078)$ and prolonged fatigue $(\beta=-0.063)$. After adjusting for changes in other work characteristics, the effects on changes in prolonged fatigue were no longer significant.

Conclusions: These findings support a possible causal relationship between work characteristics and mental health and can be used for designing effective prevention and intervention strategies. 


\section{INTRODUCTION}

Psychosocial work characteristics have previously been associated with a variety of adverse health effects, including cardiovascular health ${ }^{1-3}$, musculoskeletal disorders ${ }^{4-6}$, mental disorders ${ }^{7-10}$ and fatigue ${ }^{11-13}$, but also with poor self-reported health ${ }^{14-16}$, sickness absence ${ }^{17,18}$ and a number of behavioral risk factors ${ }^{19-21}$. A leading conceptual model to describe the psychosocial work environment is the model described by Karasek ${ }^{22}$. The initial model identifies two crucial components of the psychosocial work environment: job demands and job control (or decision latitude). Numerous studies have shown that both high job demands as well as low decision latitude are associated with adverse health outcomes ${ }^{23}, 24$. The majority of the studies examining the relationship between psychosocial work characteristics and mental health is based on a cross-sectional design ${ }^{25}$. Consequently, no causal inferences can be drawn on the relationship between work characteristics and health. Some studies, however, did examine the prospective relationship between psychosocial work characteristics and mental health outcomes. A recent meta-analysis ${ }^{10}$ provides evidence that high demands and low decision latitude are prospective risk factors for common mental disorders and suggests that the psychosocial work environment is important for mental health. Despite their longitudinal design, previous prospective studies did not always succeed in disentangling the cause and effect relationship between psychosocial work characteristics and mental health. Two important methodological limitations, that is (1) the dynamic nature of the psychosocial work environment is not taken into account and (2) a change in the work environment was not measured before a change in mental health outcome, often prevent researchers from establishing a cause and effect relationship.

With respect to the first issue, existing longitudinal studies often use a so-called time lag model in which psychosocial work characteristics are modeled prior in time to the outcome variable. An important disadvantage of these studies is that they often ignore the rather dynamic nature of certain work characteristics. Only few previous studies have examined the relationship between changes in job demands and job control and changes in mental health outcomes ${ }^{25}$. A study of Janssen and Nijhuis ${ }^{13}$ showed that a decrease in job demands and an increase in decision latitude were associated with decreases in fatigue, emotional exhaustion, and psychological distress. Another previous prospective study ${ }^{26}$ found that increasing demands were associated with an increase in emotional exhaustion and that increases in aspects of job control (skill discretion and decision authority) were associated with a higher level of job satisfaction. Moreover, they also found evidence for a reversed effect of changes in health and well-being on changes in work conditions. The changes in work conditions and changes in health seemed to mutually influence each other. Another longitudinal study ${ }^{27}$ found that the 
recent onset of job stress was strongly associated with the incidence of depression, anxiety, and chronic fatigue. Although these studies all applied a longitudinal design, the change in work characteristics was measured simultaneously with the change in the outcome measures, which brings us to the second methodological limitation, namely that a change in the work environment was not measured before a change in mental health outcome. Therefore, no conclusions could be drawn regarding a possible causal relationship and normal and reversed effects could not be disentangled. After all, a prerequisite for examining causality is that the change in exposure is measured before the actual change in the health outcome ${ }^{28,29}$. To our knowledge, a study examining the relationship between changes in psychosocial work characteristics and subsequent changes in mental health has not been conducted yet.

To date, there is little information available on the time course of cause and effect between psychosocial work characteristics and mental health ${ }^{30-32}$. In this respect, it might be questioned whether changes in job demands and control occur rather simultaneously with or before changes in mental health outcomes. In this study, two mental health outcomes were used that might react differently in the course of time ${ }^{33}$. Need for recovery represents the short-term effects of a working day and has previously been associated with several work-related factors ${ }^{33-35}$. Moreover, previous prospective studies have shown that need for recovery is associated with the development of cardiovascular disease ${ }^{36}$, subjective health complaints ${ }^{34}$, and sickness absence ${ }^{34}$ Prolonged fatigue in contrast represents long-term effects and has previously been associated with work schedules ${ }^{37}$, psychosocial work characteristics ${ }^{11}$, long-term illness ${ }^{38}$, sick leave ${ }^{39}$ and work disability ${ }^{40}$.

The net effect of changes in psychosocial work characteristics on mental health can only be determined by controlling for other factors that could disturb their actual relationship. When studying the effect of changes in job demands and control it is important to minimize selection bias, for example by excluding employees with a long-term illness, and to rule out the effect of changes in other characteristics of the job, such as changes in job function, working time arrangements and other work characteristics ${ }^{23}$. In this respect, it must be noticed that studying changes reduces the possibility that any observed associations are spurious as a result of confounding by unobserved stable personality characteristics ${ }^{41}$.

Elaborating on previous studies ${ }^{8,13,26}$, this study examines the longitudinal association between changes in psychological job demands and decision latitude within one year of follow-up and changes in need for recovery and prolonged fatigue within the same period of time. The primary goal of this study, however, is to gain more insight into a possible causal relationship between psychosocial work characteristics and mental health by examining the effects of changes in psychological job demands and decision latitude on 
subsequent changes in need for recovery and prolonged fatigue, while controlling for potential confounding factors. A detailed insight into a possible causal relationship between psychosocial work characteristics and mental health is indispensable for designing effective prevention and intervention strategies ${ }^{42}$.

\section{METHODS}

\section{Study population}

This study is based on data from the Maastricht Cohort Study, a prospective study on fatigue at work ${ }^{43}$, in which employees from 45 different companies (both blue-collar and white-collar jobs) were followed by means of self-administered questionnaires, which they received at four-month intervals. Once a year, in May, employees received an extensive questionnaire with items on work and non-work-related factors, demographics, and health factors. Twice a year (in September and in January) employees received a short questionnaire, capturing mainly outcome measures. In May 1998, the baseline questionnaire was sent out to 26,978 employees. Altogether, 12,161 employees completed and returned the baseline questionnaire (response rate of $45 \%$ ). Twenty-one questionnaires were excluded from analysis because of technical reasons. The baseline (T0) cohort thus consisted of 12,140 people. Employees who had completed the baseline questionnaire and at least one of the following two short questionnaires (T1 and/or T2) received the one-year follow-up questionnaire (T3) in May 1999 (response rate $79.5 \%, n=9655$ ). The consecutive short questionnaire (T4) was sent out in September 1999 (response rate 73.8\%, n=8956). Non-response analyses at baseline yielded no significant differences between respondents and non-respondents regarding demographic characteristics. Non-respondents were somewhat less likely to report fatigue complaints. A non-response analysis after one year of follow-up revealed that dropouts during the first year of follow-up were likely to report more fatigue complaints at baseline than were respondents. Further details on the sectors and trades represented in the Maastricht Cohort Study, the procedure, and the non-response have been reported elsewhere ${ }^{37,43-45}$.

Changes in psychosocial work characteristics (psychological job demands and decision latitude) were assessed between baseline (TO) and one-year follow-up (T3; Fig. 1). 


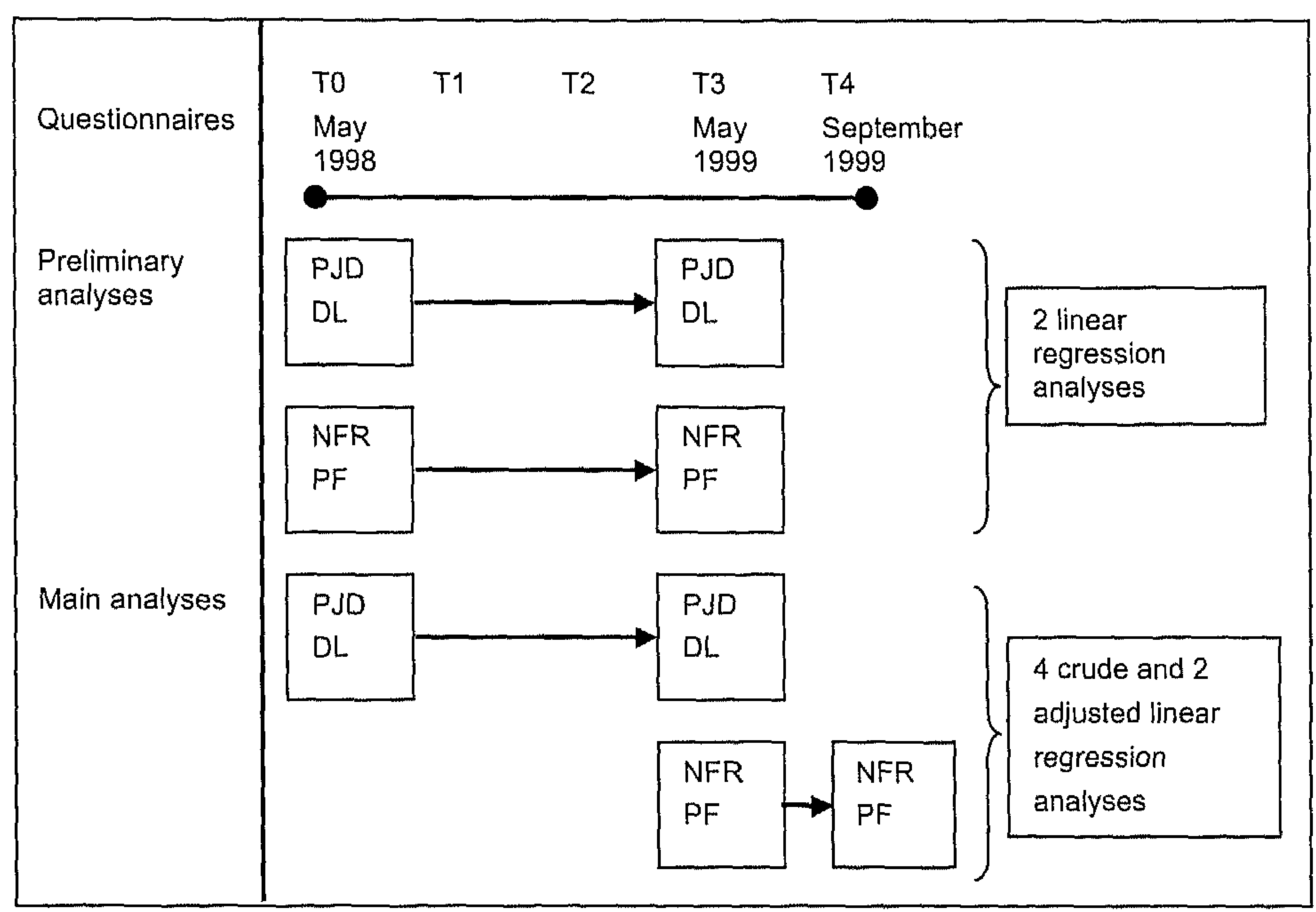

Figure 1 Questionnaires, preliminary and main analyses in the present study $(n=2332)$ as part of the Maastricht Cohort Study. $P J D=$ psychological job demands; $D L=$ decision latitude; NFR= Need for recovery; $P F=$ Prolonged fatigue

As earlier analyses showed that changes in work schedule (day work versus shift work) and changes in working hours (part time versus full time) were prospectively related to changes in mental health ${ }^{37,46}$, only employees involved in day work for at least 36 $\mathrm{hrs} / \mathrm{wk}$ at both TO and T3 were selected. Moreover, as a previous study ${ }^{46}$ showed that increasing working hours from 36 to $40 \mathrm{hrs} / \mathrm{wk}$ to more than $40 \mathrm{hrs} / \mathrm{wk}$ increased the odds of developing self-reported health problems within one year of follow-up, employees who changed between working 36 to $40 \mathrm{hrs} / \mathrm{wk}$ and more than $40 \mathrm{hrs} / \mathrm{wk}$ were also excluded from this study. This selection resulted in 3830 employees who were comparable with respect to working hours and in whom interdependency between changes in psychosocial work characteristics and changes in work time arrangements could be ruled out. From this selection, employees with multiple jobs at T0 or T3 ( $n=175)$ were also excluded, because information about the content and the characteristics of the other job was lacking. Moreover, employees who reported themselves to be absent from work because of illness or reported working under modified conditions related to former sickness absence (e.g., fewer hours, modified tasks or other functions) at the time of administering the T0 or the T3 questionnaire $(n=448)$ were excluded from the analyses as they might have a distorted view of their work situation because of sickness absence. 
Finally, employees with a long-term illness at TO or T3 $(n=875)$ were excluded from the analyses. These exclusions resulted in a final study population of 2332 employees. Baseline characteristics of the study population are presented in Table 1.

Table 1 Baseline characteristics of the study population and frequencies of changes in psychosocial work characteristics from T0 to T3

\begin{tabular}{ll}
\hline Total study population, $\mathrm{n}$ & 2332 \\
Gender, male (\%) & 88.1 \\
Age, mean (SD) & $42.32(8.45)$ \\
Occupational mobility (\%) & 16.9 \\
Prolonged fatigue $(0.93)^{*}[20-140]^{\dagger}$, mean (SD) & $51.04(20.77)$ \\
Need for recovery $(0.77)^{\star}[0-100]^{\dagger}$, mean (SD) & $32.91(24.98)$ \\
Psychological job demands $(0.67)^{*}[12-48]^{\dagger}$, mean (SD) & $33.14(5.32)$ \\
Decreasing job demands (\%) & 44.0 \\
Stable job demands $(\%)$ & 15.2 \\
Increasing job demands (\%) & 40.8 \\
Decision latitude $(0.77)^{\star}[24-96]^{\dagger}$, mean (SD) & $75.66(9.60)$ \\
Decreasing decision latitude (\%) & 45.8 \\
Stable decision latitude $(\%)$ & 13.4 \\
Increasing decision latitude (\%) & 40.8 \\
\hline
\end{tabular}

* Cronbach's a in this study

${ }^{\dagger}$ Scale range

\section{Measures}

\section{Psychosocial work characteristics}

A validated Dutch version of the self-administered Job Content Questionnaire (JCQ) was used to measure psychological job demands, decision latitude and social support at work 47. 48. Psychological job demands were assessed by the sum of five items. Decision latitude consisted of two subscales: skill discretion (six items on the amount of skill used in the job) and decision authority (three items on the opportunity to make decisions concerning the job). For each item, the response options varied from "strongly disagree" to "strongly agree" on a four-point scale. Social support was measured with two scales (co-worker support and supervisor support), each consisting of four items. For each scale, the total score was calculated by adding the response scores to the items. Physical demands were assessed with a one-item question "would you consider your work to be physically demanding? (yes/no)" Mental demands were assessed using a one-item question "would you consider your work to be mentally demanding? (yes/no)". The latter two questions were derived from the Dutch questionnaire on Work and Health 49. 
Change scores of the work characteristics were calculated by subtracting the To score from the T3 score. For psychological job demands, a differential score above zero implied a negative change, i.e., an increase in psychological job demands. For decision latitude, a differential score above zero implied a positive change, i.e., an increase in decision latitude. Higher absolute differential scores implied more change, whereas differential scores approaching zero could be considered as approximately equalling a stable work situation. The frequency of changes in psychological job demands or decision latitude is also described in Table 1.

\section{Mental health outcomes}

The need for recovery from work was assessed using an 11-item scale from the Dutch Questionnaire on the Experience and Evaluation of Work [Dutch abbreviation, VBBA] ${ }^{35}$, 50. The items represent short-term effects of a day of work (e.g. "it is difficult for me to relax at the end of a working day"). Responses (no/yes) to the 11 items were summed up and standardized to generate a total score ranging from 0 to 100 . Higher scores indicate a higher need for recovery. Prolonged fatigue was measured with the Checklist Individual Strength (CIS), a 20 -item questionnaire developed to measure several aspects of prolonged fatigue ${ }^{51}$. Whereas the need for recovery scale measures the recuperation period after one day of work and thus represents short-term effects, the CIS asks employees how they felt during the past two weeks. The CIS is a self-report instrument consisting of four subscales: subjective experience of fatigue (eight items, e.g. "I feel tired"), concentration (five items, e.g. "I have trouble concentrating"), motivation (four items, e.g. "I feel no desire to do anything") and physical activity level (three items, e.g. "I don't do much during the day"). The responses to each statement are scored on sevenpoint Likert scales ranging from "yes, that is true", to "no, that is not true". Higher scores indicate a higher degree of fatigue, lower levels of concentration, reduced motivation, or less activity. A composite CIS-total score, ranging from 20 to 140 , was constructed by adding the individual's scores on the four factors. Change scores on the need for recovery scale and the fatigue scale were calculated by subtracting the T0 score from the T3 score (preliminary analyses) or by subtracting the T3 score from the T4 score (main analyses). A differential score above zero implied a negative change, i.e., an increase in need for recovery or fatigue.

\section{Occupational mobility}

Within the first year of follow-up (between T0 and T3), employees were asked every four months whether they changed their job function in the past four months. These scores were combined into the variable occupational mobility, which was defined as a change in job function between TO and T3 and which was included as a confounder in the model. As such, it was possible to study the health effects of changes in psychosocial work characteristics independent of changes in job function. 


\section{Statistical analysis}

The analyses in this study can be divided into preliminary and main analyses (Fig. 1). In the preliminary analyses, the longitudinal relationship between changes in psychological job demands and decision latitude within one year of follow-up and changes in mental health outcomes within the same period of time was examined (secondary goal of the study). In the main analyses, a possible causal relationship was examined between changes in psychological job demands and decision latitude and subsequent changes in need for recovery and prolonged fatigue after four months (main goal of the study).

In the preliminary analyses, the longitudinal relationship between a change in psychological job demands and decision latitude between T0 and T3 and a change in need for recovery and prolonged fatigue between TO and T3 was examined using two stepwise linear regression analyses. In the first step of the regression analyses, we controlled for occupational mobility. The To score of the dependent variable involved was added in the second step. The third step of the regression analysis was to control for the work characteristics at TO. Finally, changes in other work characteristics between TO and T3 were controlled for in the fourth step.

In the main analyses, four linear regression analyses were performed to examine the effects of changes in psychological job demands and decision latitude between TO and T3 on subsequent changes in need for recovery and prolonged fatigue between T3 and T4. In this case, the change in work characteristics occurs before the change in need for recovery or fatigue and a possible causal relationship might be detected. To gain insight into a rather crude effect, two linear regression analyses were performed to study the relationship between changes in psychological job demands between T0 and T3 and changes in need for recovery and prolonged fatigue between $\mathrm{T} 3$ and $T 4$, while stepwise controlling for occupational mobility (step 1), the T3 value of the respective outcome variable (step 2), and the baseline psychological job demands (step 3). Two analogous linear regression analyses were performed for the change in decision latitude between TO and T3. Finally, to gain insight into the net effect of changes in psychological job demands and decision latitude, two linear regression analyses were performed, while stepwise controlling for occupational mobility (step 1), the T3 value of the respective outcome variable (step 2), baseline work characteristics (step 3), and changes in other work characteristics between TO and T3 (step 4). By controlling for the previous measurement of both the dependent as well as the independent variables in the regression analyses, we were able to control for regression to the mean, floor and ceiling effects, which are the most important artifacts of the statistical analysis of change scores 52-54. The focus of all the analyses in this study is the effect of the change in psychological job and the change in decision latitude in the last step of the analyses. All analyses were performed using the SPSS 13.0 statistical packages ${ }^{55}$. 


\section{RESULTS}

Table 1 shows that a rather extensive part of the study population experienced a change in psychological job demands and decision latitude in the first year of follow-up. A decrease in psychological job demands occurred in $44 \%$ of the study population whereas $40.8 \%$ experienced an increase in demands between TO and T3. Almost $46 \%$ encountered a decrease in decision latitude whereas about $41 \%$ experienced an increase in decision latitude.

Table 2 presents the results of the preliminary analyses, i.e., two stepwise regression analyses for the longitudinal relationship between changes in psychological job demands and decision latitude and changes in fatigue and need for recovery in the same follow-up period. The standardized $\beta$ values of the end model are presented. Results show that increasing psychological job demands are significantly associated with increases in need for recovery $(\beta=0.173)$ and prolonged fatigue $(\beta=0.108)$. An increase in decision latitude is significantly associated with lower levels of need for recovery $(\beta=-0.088)$ and with less prolonged fatigue $(\beta=-0.134)$.

Table 2 Stepwise regression analyses for changes in psychosocial work characteristics between $\mathrm{TO}$ and $\mathrm{T} 3$ and changes in fatigue and need for recovery between TO and T3

\begin{tabular}{|c|c|c|c|c|}
\hline & \multicolumn{2}{|c|}{$\begin{array}{l}\Delta \text { Need for recovery } \\
\qquad(n=1973)\end{array}$} & \multicolumn{2}{|c|}{$\begin{array}{c}\Delta \text { Prolonged fatigue } \\
\qquad(n=1952)\end{array}$} \\
\hline & $\Delta \mathrm{R}^{2}$ & $\beta$ & $\Delta \mathrm{R}^{2}$ & $\beta$ \\
\hline Occupational mobility T0-T3 & 0.001 & -0.010 & 0.001 & -0.022 \\
\hline Need for recovery/Fatigue $\mathrm{TO}^{\mathrm{a}}$ & $0.006^{\star *}$ & $-0.178^{\star \star *}$ & $0.137^{\star \star \star}$ & $-0.427^{\star \star \star \star}$ \\
\hline Physical demands TO & $0.008^{*}$ & $0.077^{\star *}$ & $0.007^{*}$ & 0.041 \\
\hline Mental demands T0 & & $0.168^{\star \star \star}$ & & $0.095^{\star \star \star}$ \\
\hline Co-worker social support T0 & & -0.022 & & -0.023 \\
\hline Supervisor social support To & & $-0.052^{\star}$ & & -0.015 \\
\hline Psychological job demands T0 & & $0.125^{* * *}$ & & $0.097^{* * *}$ \\
\hline Decision latitude TO & & -0.035 & & $-0.133^{* * *}$ \\
\hline$\Delta$ Physical demands & $0.103^{* * *}$ & $0.093^{* * *}$ & $0.061^{\star \star \star}$ & $0.089^{* * *}$ \\
\hline$\Delta$ Mental demands & & $0.238^{\star \star \star}$ & & $0.145^{* * *}$ \\
\hline$\Delta$ Co-worker social support & & -0.030 & & -0.023 \\
\hline$\Delta$ Supervisor social support & & $-0.075^{\star *}$ & & $-0.072^{\star *}$ \\
\hline$\Delta$ Psychological job demands & & $0.173^{\star \star \star}$ & & $0.108^{* * *}$ \\
\hline$\Delta$ Decision latitude & & $-0.088^{* *}$ & & $-0.134^{* * *}$ \\
\hline Total $R^{2}$ & $0.117^{\star * *}$ & & $0.206^{\star \star \star}$ & \\
\hline Adj. $R^{2}$ & 0.110 & & 0.200 & \\
\hline
\end{tabular}

${ }^{a}$ Need for recovery and prolonged fatigue at To were added as covariates in the analysis with $\Delta$ need for recovery and $\Delta$ prolonged fatigue as outcome measures, respectively

${ }^{*} p<0.05,{ }^{* *} p<0.01,{ }^{* * *} p<0.001$ 
The results from the main analyses of this study are presented in Tables 3 and 4. Table 3 presents the effects of changes in psychological job demands and decision latitude on subsequent changes in need for recovery and prolonged fatigue without correcting for other work characteristics. After correction for occupational mobility, fatigue at T3 and baseline psychological job demands, increasing psychological job demands are a significant predictor of a subsequent increase in the level of need for recovery $(\beta=0.063)$ and prolonged fatigue $(\beta=0.057)$. Moreover, Table 3 shows that an increase in decision latitude predicts a subsequent decrease in need for recovery $(\beta=-0.078)$ and prolonged fatigue $(\beta=-0.063)$.

Table 3 Stepwise regression analyses for changes in psychosocial work characteristics between T0 and T3 and a subsequent change in fatigue and need for recovery between T3 and T4

\begin{tabular}{|c|c|c|c|c|}
\hline & \multicolumn{2}{|c|}{$\Delta$ Need for recovery } & \multicolumn{2}{|c|}{$\Delta$ Prolonged fatigue } \\
\hline & $\Delta \mathrm{R}^{2}$ & $\beta$ & $\Delta R^{2}$ & $\beta$ \\
\hline Occupational mobility TO-T3 & 0.001 & -0.030 & 0.001 & -0.043 \\
\hline Need for recovery/ Fatigue $T 3^{\mathrm{a}}$ & $0.126^{\star \star *}$ & $-0.384^{* * *}$ & $0.074^{\star \star \star}$ & $-0.284^{\star \star \star}$ \\
\hline Psychological job demands TO & $0.003^{* *}$ & $0.087^{\star \star}$ & 0.001 & $0.061^{*}$ \\
\hline$\Delta$ Psychological job demands & $0.003^{*}$ & $0.063^{*}$ & $0.003^{*}$ & $0.057^{*}$ \\
\hline Total $R^{2}$ & $0.132^{\star \star *}$ & & $0.079^{\star \star *}$ & \\
\hline Adj. $R^{2}$ & 0.130 & & 0.077 & \\
\hline$n$ & 1919 & & 1886 & \\
\hline Occupational mobility TO-T3 & 0.001 & -0.017 & 0.001 & -0.032 \\
\hline Need for recovery/ Fatigue $T 3^{\mathrm{a}}$ & $0.125^{\star \star *}$ & $-0.360^{\star * *}$ & $0.076^{\star * *}$ & $-0.292^{\star \star \star}$ \\
\hline Decision latitude T0 & 0.001 & $-0.070^{\star \star}$ & 0.002 & $-0.073^{\star \star}$ \\
\hline$\Delta$ Decision latitude & $0.005^{\star *}$ & $-0.078^{* *}$ & $0.003^{*}$ & $-0.063^{\star}$ \\
\hline Total $\mathrm{R}^{2}$ & $0.132^{\star \star \star}$ & & $0.082^{* * *}$ & \\
\hline Adj. $R^{2}$ & 0.130 & & 0.080 & \\
\hline$n$ & 1972 & & 1938 & \\
\hline
\end{tabular}

${ }^{a}$ Need for recovery and prolonged fatigue at T3 were added as covariates in the analysis with $\Delta$ need for recovery and $\Delta$ prolonged fatigue as outcome measures, respectively

${ }^{*} p<0.05,{ }^{* *} p<0.01,{ }^{* * *} p<0.001$

Table 4 presents the effects of changes in psychological job demands and decision latitude on subsequent changes in need for recovery and prolonged fatigue, adjusted for other work characteristics. Results show that changes in psychological job demands and decision latitude have no significant effect on subsequent changes in the level of prolonged fatigue. The corresponding p-values are 0.065 for psychological job demands and 0.060 for decision latitude. Increasing psychological job demands are a significant predictor of a subsequent increase in the need for recovery $(\beta=0.077)$. An increase in decision latitude is a significant predictor of subsequent decreasing levels of need for recovery $(\beta=-0.079)$. 
Table 4 Stepwise regression analyses for changes in psychosocial work characteristics between TO and T3 and a subsequent change in fatigue and need for recovery between T3 and T4

\begin{tabular}{|c|c|c|c|c|}
\hline & \multicolumn{2}{|c|}{$\begin{array}{c}\Delta \text { Need for recovery } \\
\quad(n=1851)\end{array}$} & \multicolumn{2}{|c|}{$\begin{array}{l}\Delta \text { Prolonged fatigue } \\
\qquad(n=1821)\end{array}$} \\
\hline & $\Delta R^{2}$ & $\beta$ & $\Delta R^{2}$ & $\beta$ \\
\hline Occupational mobility T0-T3 & 0.001 & -0.019 & 0.001 & -0.026 \\
\hline Need for recovery/ Fatigue $T 3^{a}$ & $0.127^{\star * *}$ & $-0.403^{* * *}$ & $0.076^{\star * *}$ & $-0.324^{* * *}$ \\
\hline Physical demands TO & $0.012^{\star \star \star}$ & -0.015 & $0.011^{* *}$ & 0.009 \\
\hline Mental demands T0 & & 0.014 & & 0.046 \\
\hline Co-worker social support To & & -0.026 & & -0.025 \\
\hline Supervisor social support To & & $-0.072^{\star \star}$ & & $-0.101^{\star * *}$ \\
\hline Psychological job demands TO & & $0.087^{\star \star}$ & & 0.034 \\
\hline Decision latitude TO & & $-0.072^{* *}$ & & -0.054 \\
\hline$\Delta$ Physical demands & $0.010^{* *}$ & -0.022 & $0.009^{\star \star}$ & -0.010 \\
\hline$\Delta$ Mental demands & & -0.034 & & 0.005 \\
\hline$\Delta$ Co-worker social support & & -0.013 & & -0.036 \\
\hline$\triangle$ Supervisor social support & & -0.008 & & $-0.056^{*}$ \\
\hline$\Delta$ Psychological job demands & & $0.077^{\star \star}$ & & 0.049 \\
\hline$\Delta$ Decision latitude & & $-0.079^{\star \star}$ & & -0.051 \\
\hline Total $\mathrm{R}^{2}$ & $0.150^{\star \star \star}$ & & $0.097^{\star \star \star}$ & \\
\hline Adj. $R^{2}$ & 0.144 & & 0.090 & \\
\hline
\end{tabular}

${ }^{a}$ Need for recovery and prolonged fatigue at T3 were added as covariates in the analysis with $\Delta$ need for recovery and $\Delta$ prolonged fatigue as outcome measures, respectively

${ }^{*} p<0.05,{ }^{\star \star} p<0.01,{ }^{* \star *} p<0.001$

\section{Discussion}

This study confirms and extends the results of earlier studies, which have indicated that changes in psychosocial work characteristics are associated with employees' health and well-being ${ }^{8,13,56}$. The results of this study show a significant longitudinal relationship between changes in psychological job demands and decision latitude within one year of follow-up and changes in need for recovery and prolonged fatigue within the same period of time. These results were in line with previous research ${ }^{13,26}$. Nevertheless, it was still not possible to fully disentangle a possible cause and effect relationship. In this study, we therefore tried to extend previous research in this field by measuring changes in mental health outcomes within a relatively short time span (four months) after a change in psychological job demands or decision latitude. When changes in other work characteristics were not controlled for, a significant effect was found for psychological job demands and decision latitude on both the subsequent need for recovery and subsequent prolonged fatigue. When controlling for changes in other work characteristics, increasing psychological job demands were a significant predictor of a subsequent increase in need for recovery, whereas an increase in decision latitude 
significantly predicted a decrease in subsequent levels of need for recovery. After including other work characteristics as confounders in the model, the effects of psychological job demands and decision latitude on subsequent levels of prolonged fatigue were no longer significant. All relationships were in the expected direction.

The results of this study suggest that the impact of changes in psychological job demands and decision latitude depends rather strongly on the time course of cause and effect between psychosocial work characteristics and mental health outcomes. Frese and Zapf ${ }^{30}$ describe two models of how a stressor can affect ill health in the course of time. First, in the exposure time model, the incidence of ill health increases with the duration of exposure to a stressor. According to the stress reaction model, a specific type of the exposure time model, the impact of a stressor increases and leads to psychological dysfunction after a certain time. Once the stressor is removed, there is an improvement in psychological functioning. In the second model, ill-health can be considered a rather immediate response to the shock of being exposed to a stressor, and has the tendency to reduce over time. This model is also known as the initial impact model. As changes in mental health outcomes were measured within a relatively short period of time (four months) following a change in psychological job demands and decision latitude, the results of this study might be an indication of a rather immediate effect of changes is psychosocial work characteristics on subsequent changes in need for recovery and prolonged fatigue, in other words, an initial impact. Nevertheless, it can also be questioned whether the impact was actually initially being measured in this study. Despite frequent sampling in the Maastricht cohort study, items on psychosocial work characteristics were only measured in the questionnaires that were sent out annually. Consequently, the change in psychological job demands and decision latitude was measured over the one-year period from baseline (T0) to one-year follow-up (T3). As such, we do not exactly know when the change in job demands and decision latitude took place. Therefore, according to the initial impact model, it is possible that the initial effects had already reduced at the time the outcomes were measured and that only a residual effect, that is an underestimation of the actual effect, was measured. Future research might profit from using shorter time intervals for measuring changes in psychosocial work characteristics. On the other hand it is also possible that, in line with the stress reaction model, the impact of a change in, for example, psychological job demands has not reached its peak yet. Therefore, future research might also benefit from using different time lags for measuring mental health outcomes. However, we do think that time lags should not be too long, as work characteristics can change again within this period.

A frequent flaw in previous research on psychosocial work characteristics is that it often ignores the rather dynamic nature of certain work characteristics. For example, job demands are studied at a particular point in time, whereas health outcomes are studied 
one year afterwards. As such, the fact that job demands seem to change rather frequently over time is often neglected. Hence, when comparing employees with low demands with employees with high demands at a particular time and examining the health of these two groups one year afterwards, a serious misclassification might occur, because a rather extensive part of the total population already experienced a change in demands within this year of follow-up. As in this study a rather dynamic work environment was observed, studying individual changes in work characteristics in relation to individual changes in mental health outcomes over time is essential and allows us to gain more insight into the causal relationship between work characteristics and health.

Besides the fact that changes in exposure need to be measured before a change in the outcome, the existence of a possible causal relationship cannot be established without ruling out other plausible explanations. In this study, several attempts have been made to minimize the influence of selection bias and possible confounding factors. First, selection bias was minimized by selecting a rather homogenous study population ${ }^{23}$. For example, by selecting only employees involved in stable day work for at least 36 hrs/wk at both $T 0$ and $T 3$, we were able to study the effects of changes in psychological job demands and decision latitude independently of changes in work schedule or working hours. Although this increases the internal validity of the study, it may limit the ability to generalize the findings. Additionally, some exclusion criteria could also have resulted in over-control and hence in an underestimation of the actual effects. Despite our attempts to minimize selection bias, it is rather unlikely that we were able to eliminate all selection effects. In this respect, it can be argued that our first measurement is not a true baseline measurement. The employees in this study were already in the middle of an ongoing process with regard to both psychosocial work characteristics as well as health. The preexisting work environment and changes that have already taken place in the past might have already influenced the health of the respondents before our actual baseline measurement. For example, employees experiencing high psychological job demands might have undertaken some kind of action to reduce the demands (e.g. working fewer hours) and the hazards this might bring to their health. In other words, a selection bias might have already occurred before our first measurement. Second, studying individual changes in exposure in relation to individual changes in health over time cancels out the possibility that observed associations are due to confounding by unobserved stable characteristics ${ }^{41}$. If change scores are computed by subtracting two measurements of the same variable, then both measurements are affected equally by stable variables and relationships between intra-individual changes are not affected ${ }^{57}$. Third, in this study, the influence of possible confounding factors was minimized. In the analyses, the baseline level of both the dependent as well as the independent variables was controlled for. Although the highly significant inverse relationship between, for example, baseline prolonged fatigue and the change in prolonged fatigue seems to indicate regression 
towards the mean, this possibility was largely ruled out in this study. As change scores of the outcome variables were used, while correcting for the initial value of the outcome variable, it was possible to control for regression to the mean and for floor and ceiling effects ${ }^{52-54}$. Additionally, we controlled for changes in other work characteristics. Compared with a cruder model, these adjustments resulted in smaller $\beta$ values for prolonged fatigue and the results for prolonged fatigue became insignificant. Nevertheless, the $\beta$ values were still in the expected direction and the corresponding $p$ values $(0.065$ for psychological job demands and 0.060 for decision latitude) showed that the relationship was borderline significant. These results might be an indication of the fact that changes in psychosocial work characteristics coincide with one another and that it is rather difficult to study changes in psychological job demands irrespective of changes in, for example, social support. We further examined whether changes in health behaviors, such as smoking, drinking, physical activity and BMI caused a relevant change in the regression coefficient, but as they did not, they were left out of the analyses.

Although this study showed that changes in psychological job demands and decision latitude were often statistically significant, in general the observed effects were rather small. Therefore, clinical relevance might be questioned. Some methodological features of this study might have had an impact on the strength of the effects found. First, as change scores in psychological job demands and decision latitude were measured in this study, it is possible that even a small change has resulted in increasing levels of, for example, prolonged fatigue. Increasing the contrast in the independent variables through, for example, changes to the highest tertile of the scale would probably have resulted in a larger effect and clinically more relevant changes in, for example, prolonged fatigue. Second, linear data analysis might have resulted in an underestimation of the true effect of changes in work characteristics on changes in mental health outcomes ${ }^{32}$. In this study, the change score of, for example, psychological job demands contained both positive as well as negative changes on the job demands scale, thereby automatically assuming that increases in demands would have the same impact as decreases in demands, only the direction of the association should be reversed ${ }^{32}$. It is, however, possible that the strength of the effect of increasing demands is not the same as the strength of the effect of decreasing demands and that separate analyses for increasing and decreasing demands would induce a larger contrast, perhaps resulting in higher or lower $\beta$ values. Third, the baseline response of $45 \%$ and the loss to follow-up over time might raise the question of selective participation of employees and selective dropout, which may have biased the findings in this study. Non-response analyses ${ }^{43}$ revealed that fatigue complaints were lower among non-respondents at the baseline measurement, but higher during follow-up compared with the respondents. This selective drop-out may have resulted in an underestimation of the findings in this study. Fourth, both psychosocial work characteristics as well as mental health outcomes were 
measured by means of questionnaire data. The findings could thus reflect common method variance, which may lead to an overestimation of the strength of the association between the psychosocial work characteristics and mental health. Including some objective measures of the work environment and health outcomes as well might be interesting for future research.

The results of this study clearly show that changes in psychosocial work characteristics are prospectively related to statistically significant changes in need for recovery and prolonged fatigue. In this study, the dynamic nature of the work characteristics was thoroughly taken into account, selection bias was restrained, and the influence of possible confounding factors was minimized. Moreover, changes in exposure were measured before changes in mental health outcomes. Therefore, these findings support a possible causal relationship between changes in psychosocial work characteristics and changes in mental health outcomes. Given the considerable impact of changes in psychological job demands and decision latitude on the employee and the high frequency in which these changes can occur, these findings underline the need for interventions addressing psychosocial work characteristics.

\section{REFERENCES}

1. Peter R, Siegrist J. Psychosocial work environment and the risk of coronary heart disease. Int Arch Occup Environ Health. 2000;73 Suppl:S41-5.

2. Schnall PL, Landsbergis PA, Baker D. Job Strain and Cardiovascular-Disease. Ann Rev Publ Health. 1994;15:381-411.

3. Guimont $C$, Brisson $C$, Dagenais GR, Milot A, Vezina M, Masse $B$, et al. Effects of job strain on blood pressure: a prospective study of male and female white-collar workers. Am J Public Health. 2006;96(8):1436-43.

4. Buckle P. Upper limb disorders and work: the importance of physical and psychosocial factors. J Psychosom Res. 1997;43(1):17-25.

5. Davis KG, Heaney CA. The relationship between psychosocial work characteristics and low back pain: underlying methodological issues. Clin Biomech. 2000;15(6):389-406.

6. Clays $E$, De Bacquer D, Leynen F, Kornitzer M, Kittel F, De Backer $G$. The impact of psychosocial factors on low back pain: longitudinal results from the Belstress study. Spine. 2007;32(2):262-8.

7. Niedhammer I, Goldberg M, Leclerc A, Bugel I, David S. Psychosocial factors at work and subsequent depressive symptoms in the Gazel cohort. Scand $J$ Work Environ Health. 1998;24(3):197-205.

8. Stansfeld SA, Fuhrer R, Shipley MJ, Marmot MG. Work characteristics predict psychiatric disorder: prospective results from the Whitehall II Study. Occup Environ Med. 1999;56(5):302-7. 
9. Sanne B, Mykletun A, Dah! AA, Moen BE, Tell GS. Testing the Job Demand-Control-Support model with anxiety and depression as outcomes: the Hordaland Health Study. Occup Med. 2005;55(6):463-73.

10. Stansfeld S, Candy B. Psychosocial work environment and mental health - a meta-analytic review. Scand J Work Environ Health. 2006;32(6):443-62.

11. Bültmann U, Kant I, Van den Brandt PA, KasI SV. Psychosocial work characteristics as risk factors for the onset of fatigue and psychological distress: Prospective results from the Maastricht Cohort Study. Psychol Med. 2002;32(2):333-45.

12. Bültmann U, Kant IJ, Schroer CAP, KasI SV. The relationship between psychosocial work characteristics and fatigue and psychological distress. Int Arch Occup Environ Health. 2002;75(4):259-66.

13. Janssen $N$, Nijhuis FJ. Associations between positive changes in perceived work characteristics and changes in fatigue. J Occup Environ Med. 2004;46(8):866-75.

14. Borg $V$, Kristensen TS, Burr $H$. Work environment and changes in self-rated health: $A$ five year follow-up study. Stress Medicine. 2000;16(1):37-47.

15. Niedhammer I, Chea M. Psychosocial factors at work and self reported health: comparative results of cross sectional and prospective analyses of the French GAZEL cohort. Occup Environ Med. 2003;60(7):509-15.

16. Rahkonen $O$, Laaksonen M, Martikainen P, Roos E, Lahelma E. Job control, job demands, or social class? The impact of working conditions on the relation between social class and health. J Epidemiol Community Health. 2006;60(1):50-4.

17. Niedhammer I, Bugel I, Goldberg M, Leclerc A, Gueguen A. Psychosocial factors at work and sickness absence in the Gazel cohort: a prospective study. Occup Environ Med. 1998;55(11):735-41.

18. North FM, Syme SL, Feeney A, Shipley M, Marmot M. Psychosocial work environment and sickness absence among British civil servants: The Whitehall II Study. Am J Public Health. 1996;86(3):332-40.

19. Brisson C, Larocque $B$, Moisan J, Vezina M, Dagenais GR. Psychosocial factors at work, smoking, sedentary behavior, and body mass index: A prevalence study among 6995 white collar workers. J Occup Environ Med. 2000;42(1):40-6.

20. Hellerstedt WL, Jeffery RW. The association of job strain and health behaviours in men and women. Int J Epidemiol. 1997;26(3):575-83.

21. Tsutsumi A, Kayaba K, Yoshimura M, Sawada M, Ishikawa $S$, Sakai K, et al. Association between job characteristics and health behaviors in Japanese rural workers. Int J Behav Med. 2003;10(2):125-42.

22. Karasek RA. Job demands, job decision latitude, and mental strain: implications for job redesign. Adm Sci Q. 1979;24:285-308.

23. de Jonge J. A critical examination of the demand-control-support model from a work psychological perspective. Int J Stress Manag. 1997;4(4):235-58.

24. de Lange AH, Taris TW, Kompier MA, Houtman IL, Bongers PM. "The very best of the millennium": longitudinal research and the demand-control-(support) model. $J$ Occup Health Psychol. 2003;8(4):282-305.

25. Van der Doef M, Maes S. The Job Demand-Control(-Support) model and psychological wellbeing: a review of 20 years of empirical research. Work Stress. 1999;13(2):87-114. 
26. Gelsema Tl, van der Doef M, Maes S, Janssen M, Akerboom S, Verhoeven C. A longitudinal study of job stress in the nursing profession: causes and consequences. J Nurs Manag. 2006;14(4):289-99.

27. Godin I, Kittel F, Coppieters $Y$, Siegrist J. A prospective study of cumulative job stress in relation to mental health. BMC Public Health. 2005;5(1):67.

28. Lilienfeld DE, Stolley PD. Foundations of Epidemiology. 3th ed. New York: Oxford University Press; 1994.

29. Rothman KJ, Greenland S. Causation and causal inference in epidemiology. Am J Public Health. 2005;95 Suppl 1:S144-50.

30. Frese M, Zapf D. Methodological issues in the study of work stress: Objective vs subjective measurement of work stress and the question of longitudinal studies. In: Cooper CL, Payne $\mathrm{R}$, editors. Causes, Coping and Consequences of Stress at Work. Chichester, UK: Wiley; 1988. p. 375-411.

31. Taris TW, Kompier M. Challenges in longitudinal designs in occupational health psychology. Scand J Work Environ Health. 2003;29(1):1-4.

32. Zapf $D$, Dormann $C$, Frese M. Longitudinal studies in organizational stress research: a review of the literature with reference to methodological issues. J Occup Health Psychol. 1996;1(2):145-69.

33. Jansen NWH, Kant I, van den Brandt PA. Need for recovery in the working population: description and associations with fatigue and psychological distress. Int J Behav Med. 2002;9(4):322-40.

34. Sluiter JK, de Croon EM, Meijman TF, Frings-Dresen MHW. Need for recovery from work related fatigue and its role in the development and prediction of subjective health complaints. Occup Environ Med. 2003;60:62-70.

35. Van Veldhoven M, Broersen S. Measurement quality and validity of the "need for recovery scale". Occup Environ Med. 2003;60 Suppl 1:i3-9.

36. van Amelsvoort LGPM, Kant IJ, Bültmann U, Swaen GMH. Need for recovery after work and the subsequent risk of cardiovascular disease in a working population. Occup Environ Med. 2003;60(Supp I)::83-7.

37. Jansen NWH, van Amelsvoort LGPM, Kristensen TS, van den Brandt PA, Kant I. Work schedules and fatigue: a prospective cohort study. Occup Environ Med. 2003;60 Suppl 1:14753.

38. Franssen PML, Bultmann U, Kant I, van Amelsvoort LGPM. The association between chronic diseases and fatigue in the working population. J Psychosom Res. 2003;54(4):339-44.

39. Janssen N, Kant IJ, Swaen GMH, Janssen PPM, Schroer CAP. Fatigue as a predictor of sickness absence: results from the Maastricht cohort study on fatigue at work. Occup Environ Med. 2003;60:71-6.

40. van Amelsvoort LGPM, Kant IJ, Beurskens AJHM, Schroer CAP, Swaen GMH. Fatigue as a predictor of work disability. Occup Environ Med. 2002;59(10):712-3.

41. Head J, Kivimaki M, Martikainen $P$, Vahtera J, Ferrie JE, Marmot MG. Influence of change in psychosocial work characteristics on sickness absence: The Whitehall II Study. J Epidemiol Community Health. 2006;60(1):55-61.

42. Reynolds S. Psychological well-being at work: is prevention better than cure? J Psychosom Res. 1997;43(1):93-102. 
43. Kant I, Bültmann U, Schroer KAP, Beurskens AJHM, Van Amelsvoort LGPM, Swaen GMH. An epidemiological approach to study fatigue in the working population: the Maastricht Cohort Study. Occup Environ Med. 2003;60 Suppl 1:132-9.

44. Bültmann U, Kant I, Kasi SV, Beurskens AJ, van den Brandt PA. Fatigue and psychological distress in the working population: psychometrics, prevalence, and correlates. $J$ Psychosom Res. 2002;52(6):445-52.

45. Kant I, Beurskens AJ, Schroër C, Nijhuis F, van Schayck CP. De Maastrichtse Cohort Studie naar langdurige psychische vermoeidheid in de arbeidssituatie [The Maastricht Cohort Study of prolonged fatigue at work]. Tijdschr Bedr-Verzek Geneeskd (TBV). 2000;8:226-32.

46. De Raeve $L$, Jansen NWH, Kant I. Health effects of transitions in work schedule, workhours and overtime in a prospective cohort study. Scand J Work Environ Health. 2007;33(2):10513.

47. Karasek R, Brisson C, Kawakami N, Houtman I, Bongers $P$, Amick B. The Job Content Questionnaire (JCQ): an instrument for internationally comparative assessments of psychosocial job characteristics. J Occup Health Psychol. 1998;3(4):322-55.

48. Karasek RA. The Job Content Questionnaire and User's Guide (version 1.1). Los Angeles, CA: Department of Industrial and Systems Engineering, University of Southern California; 1985.

49. Grundemann RMW, Smulders PGW, de Winter CR. Vragenlijst Arbeid en Gezondheid (VAG) [Questionnaire on Work and Health]. Lisse: Swets \& Zeitlinger; 1993.

50. Van Veldhoven M, Meijman TF. Het meten van psychosociale arbeidsbelasting met een vragenlijst: de vragenlijst beleving en beoordeling van de arbeid (VBBA) [The measurement of psychosocial job demands with a questionnaire (VBBA)]. Amsterdam, NL: Netherlands Institute for the Working Environment NIA-TNO; 1994.

51. Vercoulen JH, Swanink CM, Fennis JF, Galama JM, van der Meer JW, Bleijenberg G. Dimensional assessment of chronic fatigue syndrome. J Psychosom Res. 1994;38(5):383-92.

52. Taris TW. A Primer in Longitudinal Data-Analysis. London, UK: Sage; 2000.

53. Twisk JWR. Applied Longitudinal Data Analysis for Epidemiology. A Practical Guide. Cambridge, UK: Cambridge University Press; 2003.

54. Rogosa DR. Myths and methods: myths about longitudinal research plus supplemental questions. In: Gottman JM, editor. The Analysis of Change. Mahwah, NJ: Lawrence Erlbaum; 1996. p. 3-66.

55. SPSS. SPSS Base 13.0. Chicago, III: SPSS Inc.; 2005.

56. de Jonge J, Le Blanc PM, Schaufeli WB, van der Linden S. Verandering in werkkenmerken in relatie tot verandering in burnout en arbeidstevredenheid [Changes in job characteristics as related to changes in burnout and job satisfaction]. Gedrag en Organisatie. 1998;11:121-34.

57. Rodgers WL. Comparison of alternative approaches to the simple causal models from panel data. In: Kasprzyk D, Duncan G, Kalton G, Singh MP, editors. Panel Surveys. New York: Wiley; 1989. p. 432-56. 


\section{4}

\section{Risk factors for interpersonal conflicts at work}

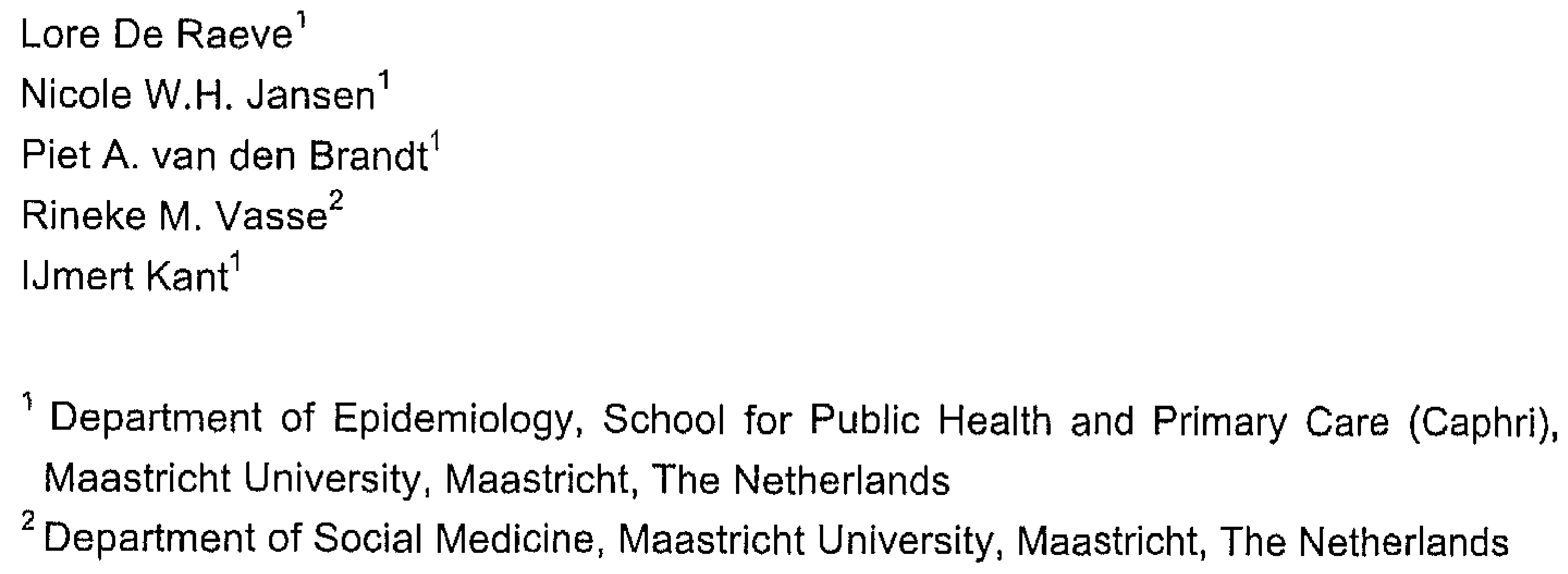




\section{ABSTRACT}

Objectives: The main goal of this study is to identify work-related risk factors for the onset of interpersonal conflicts at work.

Methods: Longitudinal data from the Maastricht Cohort Study on fatigue at work $(n=9241)$ were used. After respondents who reported an interpersonal conflict at baseline were excluded, logistic regression analyses were used to determine the role of several work-related risk factors at baseline in the onset of a conflict with co-workers or supervisors after one year of follow-up.

Results: Higher psychological job demands, higher levels of role ambiguity, the presence of physical demands, higher musculoskeletal demands, a poorer physical work environment, shift work, overtime, and higher levels of job insecurity significantly predicted the onset of both a co-worker conflict and a supervisor conflict. Higher levels of co-worker and supervisor social support, more autonomy concerning the terms of employment, good overall job satisfaction, monetary gratification, and esteem reward significantly protected against the onset of both a co-worker conflict and a supervisor conflict. Higher levels of decision latitude and more career opportunities also significantly protected against the onset of a supervisor conflict.

Conclusions: Several factors in the work environment are related to the onset of interpersonal conflicts at work. Given the rather serious consequences of interpersonal conflicts at work with respect to health and well-being, the observed risk factors can serve as a starting point for effective prevention and intervention strategies in the workplace. 


\section{INTRODUCTION}

Interpersonal conflicts have often been identified as a leading source of stress in occupational settings ${ }^{1-3}$. On the basis of a review of the literature, Barki and Hartwick ${ }^{4}$ defined interpersonal conflict as "a dynamic process that occurs between interdependent parties as they experience negative emotional reactions to perceived disagreements and interference with the attainment of their goals". In the present study, interpersonal conflicts were limited to conflicts experienced at work, i.e., conflicts with co-workers or supervisors. Interpersonal conflicts at work have a negative impact on the job satisfaction and well-being of employees ${ }^{5,6}$ and have previously been shown to be associated with work disability ${ }^{7}$ and with several mental health outcomes, like psychiatric morbidity ${ }^{8}$, depression ${ }^{9}$, and fatigue and psychological distress ${ }^{10}$. In the light of the rather serious consequences of interpersonal conflicts with respect to health and well being, conflict mediation is more and more becoming a hot topic for managers and employers ${ }^{11,12}$. It is, however, not always clear what groups or situations need to be targeted in the prevention and management of conflicts. For example, do conflicts occur more often among shift workers than among day workers? Or do they mainly occur in a work situation in which job demands are high? A previous cross-sectional study using the Finnish Twin Cohort ${ }^{13}$ found that monotonous work and hectically paced work, white-collar status, hostility and neuroticism were significantly associated with interpersonal conflicts. So far, evidence from cross-sectional studies describing high-risk groups for interpersonal conflicts at work is scarce. In addition, to our knowledge, longitudinal evidence identifying important work-related risk factors for the development of interpersonal conflicts with co-workers and supervisors is almost non-existent. Nevertheless, both cross-sectional and longitudinal insight into the etiology of interpersonal conflicts is important and may serve as a starting point for designing effective prevention and intervention strategies in the workplace.

The present study focuses on work-related risk factors for interpersonal conflicts with supervisors or co-workers. Various factors in the work environment may play a role in the onset of interpersonal conflicts at work. The pressure to produce more and to work faster with fewer resources may result in irritability, frustration, and anger. This may especially be the case when the demands of the job interfere with demands at home. For example, shift work, or regular overtime may not always be compatible with being a parent, with running a household, or with leisure time activities. Employees may then become irritated or fatigued, which may influence relationships at work. Moreover, if there are perceived disagreements about tasks, if there are ambiguities in role definitions, or if the responsibilities are unclear, the stage is set for interpersonal friction between the persons involved. Perceived inequities between a person's own work situation and that of fellow workers may also result in conflicting situations. For example, employees may 
become irritated because their colleagues have better work conditions, do not have to work as hard, get more respect, or earn more money. A conflict may also arise when employees perceive an imbalance between their own career aspirations and the career opportunities within the company, or when there is strong competition to get a particular job.

Risk factors contributing to the onset of interpersonal conflicts at work may thus originate from different domains of the work situation, such as the content of the job, work conditions, work relations, the conditions of employment, and the employees' evaluation of their work. As so far, little is actually known about the etiology of interpersonal conflicts at work, we tentatively hypothesized that poor work relations (i.e., low levels of social support), and a job content that is characterized by high psychological job demands, low decision latitude, or high role ambiguity constitute a higher risk of developing interpersonal conflicts at work. Moreover, we hypothesized that a highly demanding work environment (e.g., high physical demands or poor physical work environment) constitutes a higher risk for the onset of interpersonal conflicts. We also expect that certain conditions of employment, such as shift work and overtime, but also few career opportunities, imply an elevated risk of developing interpersonal conflicts at work. Finally, we hypothesized that poor overall job satisfaction or high effort-reward imbalance increase the risk of developing an interpersonal conflict. The purpose of this study was not to provide clear insight into the pathways through which work-related factors may contribute to the onset of an interpersonal conflict at work, but rather to explore a broad range of work-related factors that may contribute to the onset of a conflict at work. As such, this study may contribute to future theorizing and research on interpersonal conflicts at work.

Although previous research on this issue is rather scarce, it is important to keep in mind some considerations stemming from prior research on the outcomes of interpersonal conflicts. First, the impact of work-related interpersonal conflicts may depend on the source of the conflict. Previous research has found differential outcomes for conflicts with co-workers and conflicts with supervisors ${ }^{5,14}$. Therefore, in this study, the risk factors for conflicts with co-workers and supervisors were studied separately. Second, the relationship between interpersonal conflicts and social support has not been thoroughly examined in previous research. Does the existence of an interpersonal conflict necessarily imply a lack of social support? Or are they unrelated concepts? A previous study ${ }^{15}$ found that conflicts with co-workers and conflicts with supervisors were significantly associated with depersonalization and emotional exhaustion, respectively, while neither co-worker nor supervisor social support were significantly associated with any of the dimensions of burnout. Finally, when examining the relationship between work-related factors and the onset of interpersonal conflicts at work, the influence of possible confounding factors, such as demographic factors or living situation, should be 
taken into account, as they may be related to characteristics of the work situation, as well as to the onset of an interpersonal conflict.

The first goal of this study was to gain insight into the prevalence and incidence of interpersonal conflicts and to describe the overlap between interpersonal conflicts with and social support from co-workers and supervisors. The second and main goal of this study was to use longitudinal data to examine the role of several work-related factors at baseline as risk factors for the development of interpersonal conflicts with co-workers or supervisors after one year of follow-up.

\section{MetHODS}

\section{Study population}

This study was based on data from the Maastricht Cohort Study, a prospective study on fatigue at work ${ }^{16}$, in which employees from 45 different companies (both blue-collar and white-collar jobs) were followed by means of self-administered questionnaires, which they received at four-month intervals. Once a year, in May, employees received an extensive questionnaire with items on work- and non-work-related factors, demographics, and health factors. Twice a year (in September and in January) employees received a short questionnaire that mainly captured health outcome measures. In May 1998, the baseline questionnaire was sent out to 26,978 employees. A total of 12,161 employees completed and returned the baseline questionnaire (response rate of $45 \%$ ). Twenty-one respondents were excluded from the analysis for technical reasons. The baseline (TO) cohort thus consisted of 12,140 people and captured both blue-collar and white-collar workers. Non-response analyses at baseline yielded no significant differences between the respondents and non-respondents regarding demographic characteristics such as age, gender and education ${ }^{17}$. Further details on the non-response, the procedure, and the sectors and trades represented in the Maastricht Cohort Study have been reported elsewhere ${ }^{16,18}$. Employees who had completed the baseline questionnaire and at least one of the following two short questionnaires (T1 and T2) received the one-year follow-up questionnaire (T3) in May 1999 (response rate $79.5 \%, n=9655$ ). Non-response analyses at one-year follow-up revealed that the nonrespondents were likely to report more interpersonal conflicts with co-workers at baseline than the respondents $\left(8.6 \%\right.$ vs. $\left.7.1 \%, \chi^{2}=6.07, p<0.05\right)$. Moreover, the non-respondents at one-year follow-up were likely to report more interpersonal conflicts with supervisors at baseline than the respondents $\left(12.2 \%\right.$ vs. $\left.9.7 \%, \chi^{2}=11.99, p<0.01\right)$. 
Only the employees who completed the TO and T3 questionnaires were included in this study ( $n=9655)$. Moreover, employees with multiple jobs at baseline $(n=414)$ were excluded because information about the content and the characteristics of the other job was lacking. This selection resulted in a final study population of 9241 employees, consisting of $73.1 \%$ men and $26.9 \%$ women. Descriptive characteristics of the study population at baseline are presented in table 1 , separately for conflicts with co-workers and supervisors.

\section{Measures}

Interpersonal conflicts

Two items from the Dutch Questionnaire on the Experience and Evaluation of Work (Dutch abbreviation, VBBA) ${ }^{19}$ were used to measure conflicts with co-workers and supervisors. Conflicts with co-workers were assessed with the question "Do you have conflicts with your co-workers? (no/yes)". Conflicts with supervisors were assessed with the question "Do you have conflicts with your daily supervisor? (no/yes)".

\section{Work-related risk factors}

Several possible work-related risk factors for interpersonal conflicts with co-workers or supervisors were assessed at baseline (TO). The work-related factors were divided into the following five domains: job content, work conditions, work relations, terms of employment and the evaluation of work.

Job content

Psychological job demands and decision latitude were measured at baseline with a validated Dutch version of the Job Content Questionnaire ${ }^{20,21}$. Psychological job demands were assessed by the sum of five items (Cronbach's $\alpha=0.70$ ). Decision latitude (Cronbach's $\alpha=0.80$ ) consisted of the following two subscales: skill discretion (six items on the amount of skill used in the job) and decision authority (three items on the opportunity to make decisions concerning the job). For each item, the response options were as follows: $1=$ strongly disagree, $2=$ disagree, $3=$ agree, $4=$ strongly agree. For each scale, the total score was calculated by summing the response scores of the items. Higher scores indicated more psychological job demands and more decision latitude. Role ambiguity was measured by two items from the Dutch Questionnaire on the Experience and Evaluation of Work ${ }^{19}$ : "Is it clear to you what you are responsible for in your work? (no/yes)" and "Has it been clearly specified what your tasks are at work? (no/yes)". The scores of the items were summed to generate a total score ranging from 0 to 2 (Cronbach's $\alpha=0.72$ ). Higher scores indicated more role ambiguity or, in other words, less role clarity. 


\section{Work conditions}

Physical demands were assessed with a one-item question, which was derived from the Dutch Questionnaire on Work and Health ${ }^{22}$ : "Would you consider your work to be physically demanding? (no/yes)". Musculoskeletal demands were measured using the sum of one item (physically demanding work) from the Dutch Questionnaire on Work and Health ${ }^{22}$ and four items (work that requires the same posture over a long time, difficult postures, repeated movements over a long time, and carrying or lifting heavy weights) from a questionnaire on musculoskeletal load and health complaints, which had previously been validated for Dutch employees ${ }^{23,24}$. The response option for each item was nolyes. The five items were summed to generate a total score, ranging from 0 to 5 (Cronbach's $\alpha=0.67$ ), with higher scores indicating higher musculoskeletal demands. The physical work environment was measured using four items from the Dutch Questionnaire on Work and Health ${ }^{22}$ on whether employees were bothered with heat or cold, lack of fresh air, noise and a nasty smell (no/yes). A sum score was generated (Cronbach's $a=0.70$ ) with higher scores indicating a poorer physical work environment.

\section{Work relations}

Social support from co-workers and supervisors was measured at baseline with a validated Dutch version of the Job Content Questionnaire ${ }^{20,21}$. Social support was measured with the following two scales, each consisting of four items: co-worker support (e.g., "My colleagues take an interest in me"; "My colleagues are friendly"; Cronbach's $\alpha=0.76$ ) and supervisor support (e.g., "My supervisor is concerned with his or her employees"; "My supervisor is helpful in getting the job done"; Cronbach's $\alpha=0.85$ ). For each item, the response options were as follows: 1=strongly disagree, $2=$ disagree, $3=$ agree, $4=$ strongly agree. For each scale the total score was calculated by summing the response scores of the items. Higher scores indicated more social support from either co-workers or supervisors.

\section{Terms of employment}

Work schedule captured day work versus shift work. In this study, day work comprised normal working hours between 7 am and $7 \mathrm{pm}$. Shift work captured three-shift, four-shift, five-shift, and irregular shift work, all including frequent night work ${ }^{18}$. Overtime work was assessed by asking employees whether they frequently worked overtime (no/yes). It was also measured whether the participants occupied a supervisory function (no/yes). Autonomy with respect to the terms of employment was measured by six items on autonomy with respect to work pace, working hours, holidays, leaving the workplace, and taking breaks, from the Dutch monitor on stress and physical load ${ }^{25}$. The items were summed to generate a total score ranging from 0 to 6 (Cronbach's $\alpha=0.78$ ), with higher scores indicating more autonomy concerning the terms of employment. Career opportunities were measured by two items from the Dutch Questionnaire on the Experience and Evaluation of Work ${ }^{19}$ (possibilities to take extra courses or training, 
possibilities for personal growth and development) and one item (sufficiency of career opportunities) from a survey on living conditions in the Netherlands ${ }^{26}$. Items were summed to generate a total score ranging from 0 to 3 (Cronbach's $\alpha=0.72$ ), with higher scores indicating more career opportunities. Job insecurity was measured by one item from the Dutch Questionnaire on the Experience and Evaluation of Work ${ }^{19}$ ("Do you fear losing your job on short notice? no/yes"), and one item from the Questionnaire on Work and Health ${ }^{22}$ ("Does this work environment offer you enough security? no/yes"). Items were summed up to generate a total score ranging from 0 to 2 (Cronbach's $\alpha=0.67$ ), with higher scores indicating more job insecurity.

\section{Evaluation of work}

Overall job satisfaction was measured with one item on how employees would describe their overall job satisfaction. The response options were as follows: 1=good, $2=$ reasonable, $3=$ moderate, $4=$ not good. The response options were recoded to a scale ranging from 0 to 3 , with higher scores indicating more job satisfaction. The employees' evaluation of the balance between their efforts and rewards was assessed with two items derived from a validated Dutch version of the Effort-Reward Imbalance Questionnaire ${ }^{27}$.

${ }^{28}$. These items assessed monetary gratification ("Do you think that, considering all your efforts and achievements, your salary is adequate?") and esteem reward ("Do you think that, considering all your efforts and achievements, you receive the respect you deserve at work?"). Answering options were "no", "yes" and "I don't know". The last option was recoded as "missing".

\section{Possible confounding factors}

In the analyses, we corrected for age, educational level, living situation, and the presence of a long-term illness as these variables might be related to both the work situation and the onset of an interpersonal conflict. Moreover, we examined interactions between every work-related factor and gender. However, as none of these interactions was significant, the analyses in this study were not stratified for gender. Gender was then included as a possible confounder in the analyses. Information on age, gender, educational level, living situation ("Do you live alone?" no/yes) and the presence of a long-term illness ("Do you have a long-term illness?" no/yes) was obtained through selfreport in the baseline (TO) questionnaire.

\section{Statistical analysis}

Chi square tests (for categorical variables) and independent sample t-tests (for continuous variables) were conducted to examine whether employees who did and did not experience a conflict differed significantly with respect to several personal characteristics and work-related factors. 
Multivariate logistic regression analyses were conducted to examine the role of several work-related factors at baseline in the onset of a conflict with co-workers or supervisors after one year of follow-up. Logistic regression analyses were first conducted for each work-related factor separately. The onset of a conflict was estimated between baseline and one year of follow-up. Therefore, when the incidence of co-worker conflict was examined, all employees reporting a conflict with co-workers at baseline were excluded. When the incidence of supervisor conflict was examined, all employees reporting a conflict with their supervisor at baseline were excluded. As such, odds ratios (OR) and $95 \%$ confidence intervals $(95 \% \mathrm{Cls}$ ) were calculated separately for co-worker conflict and supervisor conflict. All the regression analyses were corrected for gender, age, education, living situation, and the presence of a long-term illness.

Subsequently, the work-related risk factors in the domains of job content, work conditions, work relations and the terms of employment that showed a significant effect on the onset of an interpersonal conflict in the previous regression analyses were entered into a multivariate model in order to examine the simultaneous effect of these baseline risk factors on the onset of interpersonal conflicts at work after one year of follow-up. These domains were chosen as they contain modifiable factors that can be subject to change if necessary or requested. Separate analyses were conducted for coworker and supervisor conflict and corrected for gender, age, education, living situation, and the presence of a long-term illness. All analyses in this study were performed using the SPSS 13.0 statistical packages ${ }^{29}$.

\section{REsULtS}

\section{Prevalence of conflicts at baseline and incidence after one-year follow-up}

The baseline prevalence of interpersonal conflicts in this study was $7.11 \%(n=651)$ for co-worker conflict and $9.71 \%(n=885)$ for supervisor conflict. In this study, the Phi (Ф) correlation coefficient (i.e., a Pearson correlation between two dichotomous variables) for co-worker and supervisor conflict was $0.244(p<0.001)$. A minority $(2.5 \%)$ of the total study population reported a conflict with both co-workers and their supervisor at baseline. About $7.2 \%$ reported a conflict with their supervisor, but not with co-workers, and $4.6 \%$ had a conflict with co-workers, but not with their supervisor. The remaining $85.7 \%$ reported no conflicts at baseline. When conflicts at baseline were excluded, the incidence of a co-worker conflict after one year of follow-up (T3) was $3.9 \%(n=325)$. The incidence of a supervisor conflict after one year of follow-up (T3) was $5.3 \%(n=429)$. 
Table 1 Baseline descriptive characteristics of the study population according to conflicts with coworkers and supervisors

\begin{tabular}{|c|c|c|}
\hline & \multicolumn{2}{|c|}{ Baseline co-worker conflict } \\
\hline & No $(n=8505)$ & Yes $(n=651)$ \\
\hline Age, mean (SD) & $41.54(8.77)$ & $40.72(8.49)^{\star}$ \\
\hline Gender (\% male) & 72.7 & $78.2^{\star *}$ \\
\hline Education (\% low) & 19.0 & $23.0^{\star \star}$ \\
\hline (\% medium) & 45.0 & 46.4 \\
\hline (\% high) & 35.9 & 30.7 \\
\hline Living alone (\%yes) & 9.2 & $14.4^{\star \star \star}$ \\
\hline Long-term illness (\% yes) & 23.7 & $28.2^{\star}$ \\
\hline \multicolumn{3}{|l|}{ Job content } \\
\hline Psychological job demands $[12-48]^{\dagger}$, mean (SD) & $33.10(5.59)$ & $35.15(6.12)^{\star \star \star}$ \\
\hline Decision latitude $[24-96]^{\dagger}$, mean (SD) & $72.16(11.13)$ & $69.50(11.90)^{\star \star \star}$ \\
\hline Role ambiguity $[0-2]^{\dagger}$, mean (SD) & $0.40(0.70)$ & $0.65(0.83)^{\star \star \star}$ \\
\hline \multicolumn{3}{|l|}{ Work conditions } \\
\hline Physical demands (\% yes) & 23.5 & $32.7^{\star \star \star}$ \\
\hline Musculoskeletal demands $[0-5]^{\dagger}$, mean (SD) & $1.57(1.46)$ & $1.98(1.61)^{* * *}$ \\
\hline Poor physical work environment $[0-4]^{\dagger}$, mean (SD) & $1.18(1.30)$ & $1.71(1.41)^{\star * *}$ \\
\hline \multicolumn{3}{|l|}{ Work relations } \\
\hline Co-worker social support $[4-16]^{\dagger}$, mean (SD) & $11.97(1.52)$ & $10.51(1.94)^{\star * *}$ \\
\hline Supervisor social support $[4-16]^{\dagger}$, mean (SD) & $10.50(2.29)$ & $9.44(2.49)^{\star \star \star}$ \\
\hline \multicolumn{3}{|l|}{ Terms of employment } \\
\hline Work schedule (\% shift work) & 27.2 & $38.1^{* * *}$ \\
\hline Overtime (\% yes) & 45.3 & $51.3^{\star \star}$ \\
\hline Supervisory function ( $\%$ yes) & 24.4 & $27.2^{\mathrm{ns}}$ \\
\hline Autonomy $[0-6]^{\dagger}$, mean (SD) & $4.29(1.80)$ & $3.86(1.92)^{\star \star \star}$ \\
\hline Career opportunities $[0-3]^{\dagger}$, mean (SD) & $1.87(1.14)$ & $1.49(1.16)^{\star * *}$ \\
\hline Job insecurity $[0-2]^{\dagger}$, mean (SD) & $0.23(0.55)$ & $0.45(0.73)^{\star * *}$ \\
\hline \multicolumn{3}{|l|}{ Evaluation of work } \\
\hline Overall job satisfaction $[0-3]^{\dagger}$, mean (SD) & $2.42(0.72)$ & $1.97(0.87)^{\star \star \star}$ \\
\hline Monetary gratification (\% yes) & 51.8 & $39.55^{\star * \star}$ \\
\hline Esteem reward (\% yes) & 53.0 & $27.3^{\star \star \star}$ \\
\hline \multicolumn{3}{|c|}{$\begin{array}{l}\text { Continuous variables are presented as mean (SD) with corresponding } p \text {-values from independen } \\
\text { samples t-tests; categorical variables are presented as } \% \text { of total with corresponding } p \text {-values from } \\
\text { chi }^{2} \text {-tests; Significance levels apply to the difference with no co-worker conflict; }{ }^{*} p<0.05,{ }^{* *} p<0.01 \\
{ }^{* * *} p<0.001,{ }^{\text {ns }} \text { not significant } \\
{ }^{\dagger} \text { scale range }\end{array}$} \\
\hline
\end{tabular}


Table 1 (continued)

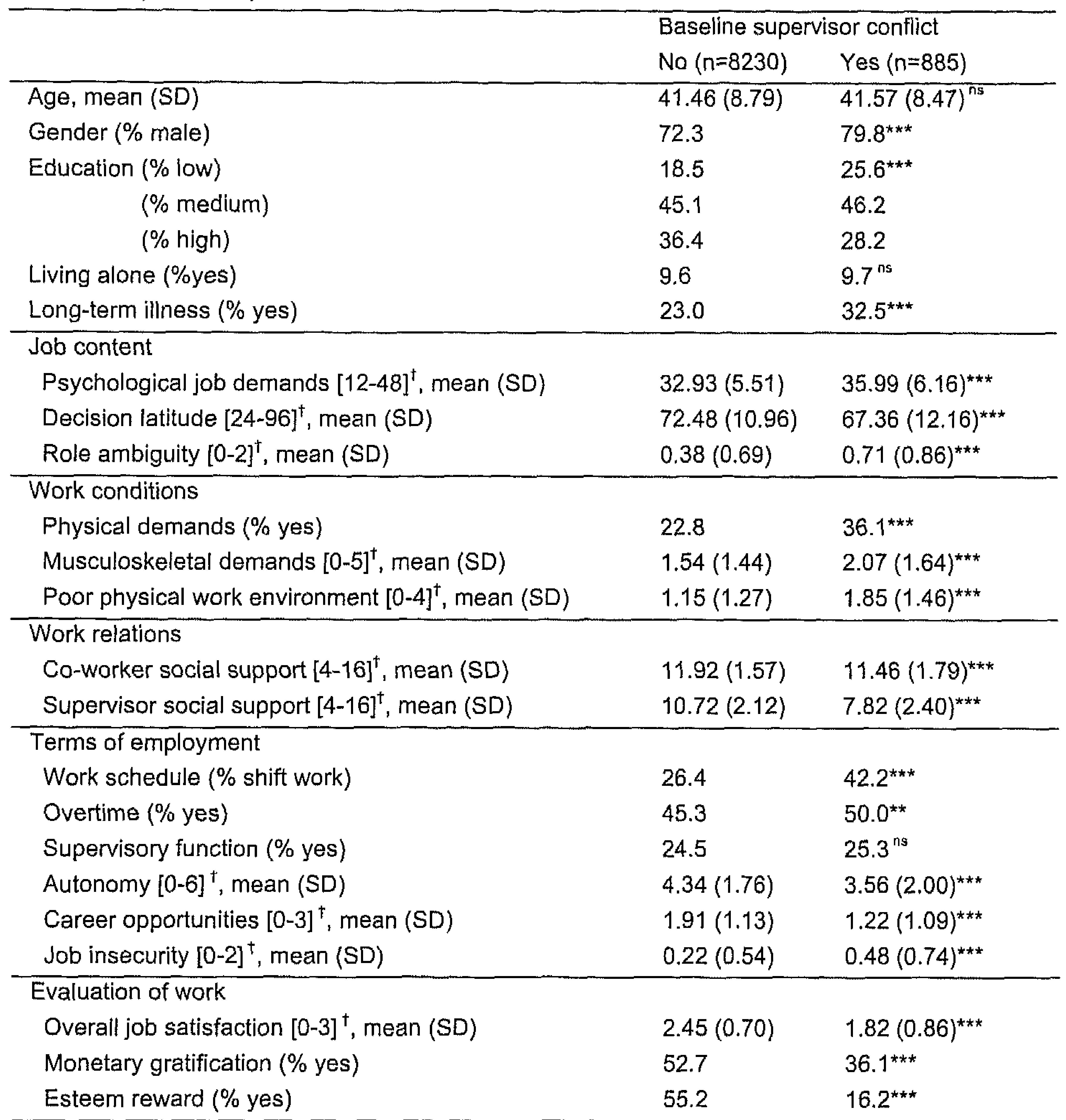

Continuous variables are presented as mean (SD) with corresponding p-values from independent samples t-tests; categorical variables are presented as $\%$ of total with corresponding $p$-values from chi $^{2}$-tests; Significance levels apply to the difference with no supervisor conflict; ${ }^{*} p<0.05,{ }^{* *} p<0.01$, *** $p<0.001,{ }^{\text {ns }}$ not significant

${ }^{\dagger}$ scale range 


\section{Baseline descriptive characteristics of the study population}

Table 1 shows the descriptive characteristics of the study population at baseline. The table shows that conflicts with co-workers and with supervisors relatively more often occurred among the men, employees with a low level of education, and people with a long-term illness. Moreover, co-worker conflict relatively more often occurred among employees who lived alone. Furthermore, the employees who experienced a conflict with their co-workers were on average somewhat younger that those who did not experience a co-worker conflict.

With regard to job content, the employees experiencing interpersonal conflicts at work reported significantly higher levels of psychological job demands, lower levels of decision latitude and more role ambiguity. With respect to the work conditions, the employees with interpersonal conflicts at work reported significantly more physical demands, higher levels of musculoskeletal demands and a poorer physical work environment. This was the case for both co-worker and supervisor conflicts. Regarding work relations, table 1 shows that employees reporting interpersonal conflict with either co-workers or their supervisor reported significantly lower levels of social support from both their co-workers and their supervisor. As regards the terms of employment, it appears from table 1 that both conflicts with co-workers and supervisors occurred significantly more often among the shift workers and employees working overtime. Furthermore, the respondents with an interpersonal conflict reported lower levels of autonomy with respect to their working conditions, fewer career opportunities, and more job insecurity. Concerning the evaluation of their work, the employees reporting a conflict with either a co-worker or a supervisor reported a worse overall job satisfaction, and they less often considered their efforts and achievements at work to be in balance with their income and the respect they received at work.

\section{Overlap between interpersonal conflicts and social support}

The Pearson correlation coefficient for co-worker conflict and co-worker social support (continuous) was $-0.234(p<0.01)$. The Pearson correlation coefficient for supervisor conflict and supervisor social support (continuous) was $-0.371(p<0.01)$. To examine the overlap between interpersonal conflicts and social support in more detail, we dichotomized the total scores for social support at the median, with scores above the median indicating high co-worker or supervisor social support. Among the employees reporting a conflict with their co-workers, $65.8 \%$ also reported low co-worker social support. Nevertheless, 34.2\% reported high co-worker social support. Among the employees with a conflict with their supervisor, $86.4 \%$ reported low support from their supervisor, while only $13.6 \%$ reported high social support from their supervisor. 


\section{Risk factors for interpersonal conflicts with co-workers and supervisors}

The prospective relationships between several work-related factors at baseline and the onset of a conflict with either a co-worker or a supervisor after one year of follow-up are shown in table 2 . Odds ratios were calculated for each risk factor separately and were controlled for gender, age, education, living situation, and the presence of a long-term illness.

Table 2 Work-related risk factors at baseline as risk factors for interpersonal conflicts with coworkers and supervisors after one-year of follow-up

\begin{tabular}{|c|c|c|c|}
\hline Risk factors ${ }^{b}$ & & $\begin{array}{l}\text { Co-worker conflict } \\
\mathrm{OR}^{\mathrm{a}}[95 \% \mathrm{Cl}]\end{array}$ & $\begin{array}{l}\text { Supervisor conflict } \\
\mathrm{OR}^{\mathrm{a}}[95 \% \mathrm{Cl}]\end{array}$ \\
\hline \multicolumn{4}{|l|}{ Job content } \\
\hline Psychological job demands $[12-48]^{\dagger}$ & & $1.04[1.02-1.06]^{\star \star \star}$ & $1.05[1.04-1.07]^{* * *}$ \\
\hline Decision latitude $[24-96]^{\dagger}$ & & $1.00[0.99-1.01]^{\mathrm{ns}}$ & $0.98[0.97-0.99]^{* * \star}$ \\
\hline Role ambiguity $[0-2]^{\dagger}$ & & $1.41[1.21-1.64]^{\star \star \star}$ & $1.60[1.40-1.82]^{\star \star *}$ \\
\hline \multicolumn{4}{|l|}{ Work conditions } \\
\hline \multirow[t]{2}{*}{ Physical demands } & No & 1.00 (ref) & 1.00 (ref) \\
\hline & Yes & $1.53[1.16-2.01]^{\star *}$ & $1.69[1.33-2.16]^{\star \star \star *}$ \\
\hline Musculoskeletal demands $[0-5]^{\dagger}$ & & $1.16[1.07-1.26]^{\star \star}$ & $1.14[1.06-1.23]^{\star \star \star}$ \\
\hline Poor physical work environment $[0-4]^{\dagger}$ & & $1.26[1.15-1.38]^{\star \star *}$ & $1.27[1.17-1.37]^{\star \star \star}$ \\
\hline \multicolumn{4}{|l|}{ Work relations } \\
\hline Co-worker social support [4-16] $]^{\dagger}$ & & $0.84[0.78-0.91]^{\star * *}$ & $0.88[0.82-0.93]^{* * *}$ \\
\hline Supervisor social support $[4-16]^{\dagger}$ & & $0.93[0.89-0.98]^{* *}$ & $0.80[0.77-0.84]^{* * *}$ \\
\hline \multicolumn{4}{|l|}{ Terms of employment } \\
\hline \multirow[t]{2}{*}{ Work schedule } & Day work & 1.00 (ref) & 1.00 (ref) \\
\hline & Shift work & $1.41[1.02-1.95]^{*}$ & $1.79[1.35-2.37]^{* * *}$ \\
\hline \multirow[t]{2}{*}{ Overtime } & No & 1.00 (ref) & 1.00 (ref) \\
\hline & Yes & $1.29[1.02-1.64]^{*}$ & $1.35[1.10-1.67]^{\star \star}$ \\
\hline \multirow[t]{2}{*}{ Supervisory function } & No & $1.00(\mathrm{ref})$ & 1.00 (ref) \\
\hline & Yes & $1.21[0.92-1.59]^{\mathrm{ns}}$ & $1.18[0.93-1.49]^{\mathrm{ns}}$ \\
\hline Autonomy $[0-6]^{\dagger}$ & & $0.93[0.87-0.99]^{*}$ & $0.84[0.80-0.89]^{\star * *}$ \\
\hline Career opportunities $[0-3]^{\dagger}$ & & $0.91[0.82-1.00]^{\mathrm{ns}}$ & $0.70[0.64-0.76]^{\star \star \star}$ \\
\hline Job insecurity $[0-2]^{\dagger}$ & & $1.23[1.02-1.49]^{*}$ & $1.62[1.40-1.88]^{* * *}$ \\
\hline \multicolumn{4}{|l|}{ Evaluation of work } \\
\hline Overall job satisfaction $[0-3]^{\dagger}$ & & $0.74[0.64-0.85]^{\star \star \star}$ & $0.57[0.50-0.64]^{\star * *}$ \\
\hline \multirow[t]{2}{*}{ Monetary gratification } & No & 1.00 (ref) & $1.00(\mathrm{ref})$ \\
\hline & Yes & $0.72[0.56-0.92]^{*}$ & $0.62[0.49-0.77]^{\star * *}$ \\
\hline \multirow[t]{2}{*}{ Esteem reward } & No & 1.00 (ref) & 1.00 (ref) \\
\hline & Yes & $0.60[0.46-0.77]^{\star \star \star}$ & $0.36[0.29-0.46]^{\star * *}$ \\
\hline
\end{tabular}

${ }^{a} \mathrm{OR}$ corrected for gender, age, education, living situation, and the presence of a long-term illness

${ }^{b}$ The odds ratios (OR) for the continuous independent variables refer to a 1 point increase on the total scale; ${ }^{*} p<0.05,{ }^{* *} p<0.01,{ }^{* * *} p<0.001,{ }^{n s}$ not significant

${ }^{\dagger}$ scale range 
Higher psychological job demands, higher levels of role ambiguity, the presence of physical demands, higher musculoskeletal demands, a poorer physical work environment, shift work, overtime, and higher levels of job insecurity significantly predicted the onset of both a co-worker and a supervisor conflict. Higher levels of social support from co-workers and supervisors, more autonomy concerning the terms of employment, good overall job satisfaction, monetary gratification, and esteem reward significantly protected against the onset of both a co-worker and a supervisor conflict. In addition, higher levels of decision latitude and more career opportunities also significantly protected against the onset of a supervisor conflict.

Table 3 Multivariate model of work-related risk factors at baseline for interpersonal conflicts with co-workers and supervisors after one-year of follow-up

\begin{tabular}{|c|c|c|c|}
\hline Risk factors ${ }^{b}$ & & $\begin{array}{l}\text { Co-worker conflict } \\
\mathrm{OR}^{\mathrm{a}}[95 \% \mathrm{Cl}]\end{array}$ & $\begin{array}{l}\text { Supervisor conflict } \\
\mathrm{OR}^{\mathrm{a}}[95 \% \mathrm{Cl}]\end{array}$ \\
\hline \multicolumn{4}{|l|}{ Job content } \\
\hline \multicolumn{2}{|l|}{ Psychological job demands [12-48] $]^{\dagger}$} & $1.02[0.99-1.04]^{\mathrm{ns}}$ & $1.02[1.00-1.04]^{\mathrm{ns}}$ \\
\hline \multicolumn{2}{|l|}{ Decision latitude $[24-96]^{\dagger}$} & . & $1.00[0.99-1.01]^{\mathrm{ns}}$ \\
\hline \multicolumn{2}{|l|}{ Role ambiguity $[0-2]^{\dagger}$} & $1.26[1.06-1.51]^{\star \star}$ & $1.39[1.19-1.62] * * *$ \\
\hline \multicolumn{4}{|l|}{ Work conditions } \\
\hline \multirow[t]{2}{*}{ Physical demands } & No & 1.00 (ref) & 1.00 (ref) \\
\hline & Yes & $1.12[0.71-1.75]^{\mathrm{ns}}$ & $1.22[0.81-1.82]^{\mathrm{ns}}$ \\
\hline \multicolumn{2}{|l|}{ Musculoskeletal demands $[0-5]^{\dagger}$} & $1.05[0.92-1.21]^{\mathrm{ns}}$ & $0.96[0.85-1.09]^{\mathrm{ns}}$ \\
\hline \multicolumn{2}{|l|}{ Poor physical work environment $[0-4]^{\dagger}$} & $1.16[1.03-1.30]^{*}$ & $1.10[0.99-1.22]^{\mathrm{ns}}$ \\
\hline \multicolumn{4}{|l|}{ Work relations } \\
\hline \multicolumn{2}{|l|}{ Co-worker social support [4-16] ${ }^{\dagger}$} & $0.87[0.80-0.95]^{* \star}$ & $0.94[0.87-1.01]^{\mathrm{ns}}$ \\
\hline \multicolumn{2}{|l|}{ Supervisor social support $[4-16]^{\dagger}$} & $0.99[0.93-1.05]^{\mathrm{ns}}$ & $0.87[0.83-0.93]^{* * *}$ \\
\hline \multicolumn{4}{|l|}{ Terms of employment } \\
\hline \multirow[t]{2}{*}{ Work schedule } & Day work & 1.00 (ref) & $1.00($ ref $)$ \\
\hline & Shift work & $1.25[0.84-1.87]^{\mathrm{ns}}$ & $1.37[0.96-1.96]^{\text {ns }}$ \\
\hline \multirow{2}{*}{ Overtime } & No & 1.00 (ref) & 1.00 (ref) \\
\hline & Yes & $1.23[0.92-1.63]^{\mathrm{ns}}$ & $1.35[1.04-1.75]^{*}$ \\
\hline \multicolumn{2}{|l|}{ Autonomy $[0-6]^{\dagger}$} & $1.02[0.93-1.12]^{\mathrm{ns}}$ & $0.95[0.88-1.04]^{\mathrm{ns}}$ \\
\hline \multicolumn{2}{|l|}{ Career opportunities $[0-3]^{\dagger}$} & & $0.87[0.77-0.98]^{\star}$ \\
\hline \multicolumn{2}{|l|}{ Job insecurity $[0-2]^{\dagger}$} & $0.99[0.79-1.25]^{\mathrm{ns}}$ & $1.20[0.99-1.44]^{\mathrm{ns}}$ \\
\hline \multicolumn{4}{|c|}{$\begin{array}{l}\text { "The odds ratios }(O R) \text { for the continuous independent variables, refer to a } 1 \text { point increase on the } \\
\text { total scale; }{ }^{*} p<0.05,{ }^{* *} p<0.01,{ }^{* * *} p<0.001,{ }^{n s} \text { not significant } \\
\text { - These factors were not added to the multivariate model as they did not have a significant impact in }\end{array}$} \\
\hline
\end{tabular}




\section{Multivariate model of risk factors for interpersonal conflicts}

All work-related factors in the domains of job content, work conditions, work relations, and the terms of employment that significantly predicted the onset of an interpersonal conflict in the previous regression analyses were entered simultaneously into a multivariate model using a logistic regression analysis in order to examine the simultaneous effect of these baseline risk factors on the incidence of interpersonal conflicts at work after one year of follow-up, while correcting for gender, age, education, living situation, and the presence of a long-term illness. The multivariate model revealed that higher levels of role ambiguity and a poor physical work environment significantly predicted the onset of a co-worker conflict (see table 3). Higher levels of co-worker social support significantly protected against the onset of a co-worker conflict. Furthermore, higher levels of role ambiguity and overtime significantly predicted the onset of a supervisor conflict after one year of follow-up in the multivariate model. Higher levels of social support from supervisors and more career opportunities significantly protected against the onset of a supervisor conflict. Although not statistically significant, shift work and higher levels of job insecurity also seemed to increase the odds for the onset of a supervisor conflict.

\section{DIscussion}

The objectives of this study were to gain insight into the prevalence and incidence of interpersonal conflicts at work and to examine the role of several work-related risk factors at baseline as risk factors for the development of interpersonal conflicts with coworkers or supervisors after one year of follow-up. In this study, the prevalence of an interpersonal conflict at baseline was $7.1 \%$ for co-worker conflict and $9.7 \%$ for supervisor conflict. Among participants who reported no conflicts at baseline, the incidence of an interpersonal conflict after one year of follow-up was $3.9 \%$ for co-worker conflict and $5.3 \%$ for supervisor conflict. Regarding the baseline characteristics of the study population, differences between the employees who did and did not experience a conflict were statistically significant in most cases. This finding may partly be due to the high number of respondents in this study. Some rather large differences could be observed for some groups, such as respondents with a long-term illness and employees working in shifts or working overtime. Furthermore, this study showed prospective relationships between several work-related risk factors and conflicts with co-workers or supervisors over time. This study showed that various factors in the work environment, such as job content, work conditions, work relations, terms of employment, and employees' evaluations of work may play a role in the onset of interpersonal conflicts at work. Overall, our tentative hypotheses were confirmed. 
The results of this study also showed that conflicts with supervisors seem to occur more often than conflicts with co-workers. Moreover, the rather low correlation between the conflict variables in this study seems to indicate different concepts of conflict. In addition, odds ratios for the onset of a supervisor conflict seemed larger than those for the onset of a co-worker conflict. It is possible that workers feel that their supervisor is responsible for issues that arise in the workplace. When the supervisor is called to account for the problems an employee encounters, a conflict may result. The results of this study suggest that, for future research on interpersonal conflicts at work, it is important to differentiate between co-worker conflict and supervisor conflict, as risk factors for interpersonal conflicts at work may vary according to the source of the conflict, i.e., conflict with co-workers or supervisors. In this study, gender was not a moderator of the relationship between work-related factors and interpersonal conflicts, suggesting that risk factors for interpersonal conflicts at work were not statistically different between men and women. Furthermore, the results in this study were adjusted for gender, age, education, living situation, and the presence of a long-term illness. Compared with the results of a crude model, the odds ratios decreased somewhat, but they remained in the expected direction and stayed statistically significant in most cases.

When significant risk factors for interpersonal conflicts were combined in an overall multivariate model, the results showed that higher levels of role ambiguity and a poor physical work environment significantly predict the onset of a co-worker conflict, while higher levels of co-worker social support significantly protect against the onset of a coworker conflict. Conflict with the supervisor was predicted by higher levels of role ambiguity and by overtime, while higher levels of social support from supervisors and more career opportunities significantly protected against the onset of a supervisor conflict. Compared with the earlier analyses in this study, in the overall multivariate model, odds ratios decreased and often became non-significant. This finding may be explained by the fact that predictors were often highly correlated. This high correlation may have some implications for the prevention of interpersonal conflicts at work Preventive efforts aimed at one particular risk factor may also influence other risk factors, either positively or negatively. Ideally, effective preventive measures aim at highly prevalent risk factors with a high impact. Moreover, from a practical point of view, it is useful to take modifiable factors as a starting point for developing preventive measures. Results from this study indicate that attempts can be made to decrease role ambiguity, to enhance the physical work environment, and to increase social support in order to reduce the possibility for developing interpersonal conflicts. Moreover, improving the factors within the domain of the terms of employment, such as reducing the amount of overtime or improving workers' career opportunities may prevent the onset of a conflict with the supervisor. 
The results of this study showed that employees are able to experience both interpersonal conflicts and high social support simultaneously. However, social support and interpersonal conflicts with co-workers were only modestly related in this study, while the overlap with social support was somewhat larger for supervisor conflict. This finding may be explained by the source of the conflict (co-worker or supervisor conflict). For example, one particular co-worker may cause a conflict, while most co-workers may provide social support. This situation is, however, more unusual when it applies to conflicts with and support from the supervisor, and may therefore explain why the amount of overlap is somewhat larger for conflicts with and support from the supervisor. For future research, it may be useful to examine whether employees, who experience both high social support and interpersonal conflicts, are able to benefit from social support as it is undermined by interpersonal conflicts. In other words, do the negative effects of interpersonal conflicts outweigh the positive effects of high social support ${ }^{30}$ ?

Although this study showed that many factors were statistically significantly related to the onset of conflicts at work, in general, the observed effects were rather small. Therefore, clinical relevance may be questioned. Some of the methodological features of this study might have had an impact on the strength of the effects found. First, where possible, the continuous scores of the scales for the independent variables were used. As such, even a small change (e.g., 1 point increase on the psychological job demands scale with a range from 12 to 48 ) significantly predicted the onset of a conflict. Increasing the contrast in the independent variables by using, for example, the upper tertile to define a contrast between employees with and without high demands resulted in a larger effect and higher odds ratios for the onset of a conflict in this study. In addition, the risk factors in this study were highly prevalent. Consequently, even though risk factors may show a rather small effect in terms of odds ratios, the effect may be clinically relevant, because the risk factors are highly prevalent. Second, it is possible that the time frame used in this study was not adequate to detect the largest effect. We used work-related risk factors at baseline to predict the onset of an interpersonal conflict after one year of follow-up. It is, however, possible that the work environment changed within that year. Moreover, our first measurement was not a true baseline measurement as the employees were already in the middle of an ongoing process, both with regard to the work-related factors as with respect to the course of the conflict. It is possible that a conflict was recurring or was already latent at our baseline measurement due to previous levels of, for example, high job demands. Moreover, despite frequent sampling (every four months) in the large-scale Maastricht Cohort Study, we were not able to study the incidence of interpersonal conflicts within these short periods of time, as conflicts were only assessed in the extensive questionnaires that were sent out annually. Therefore, we do not exactly know when a conflict developed or how long the conflict situation lasted. It is possible that a conflict resulting from high job demands was already resolved after one year of follow-up or that the conflict we observed at one-year follow-up was already the second or third 
conflict. For future research, it might be interesting to use shorter time lags to measure the incidence of conflicts.

The following issues should be kept in mind when interpreting the results of this study. First, although we found several work-related factors to be risk factors in the onset of interpersonal conflicts at work, it is also possible that these factors were outcomes rather than risk factors. For example, poor overall job satisfaction may not only have been a risk factor for the development of a conflict, but it may also have been the result of an interpersonal conflict. For future studies, it is important to keep in mind a possible reciprocal relationship between work-related factors and interpersonal conflicts. Second, in this study, the influence of negative affectivity in the relationship between work-related risk factors and the onset of interpersonal conflicts was examined, but, as in most cases, it did not influence this relationship, it was left out of the analyses. Not including negative affectivity as a confounder is consistent with Spector and colleagues ${ }^{31}$ who stated that negative affectivity should not be considered a bias in need of statistical control. Third, both co-worker and supervisor conflict were measured with one item asking employees whether they had conflicts with their co-workers or their supervisor. Especially when the construct being measured is multidimensional, single item measures may raise concern with respect to the validity of the study. A previous study ${ }^{32}$, however, obtained very high correlations between individuals' global assessments of interpersonal conflicts and a multidimensional measure of interpersonal conflicts based on assessments of disagreement, interference, and negative emotion. Although our study did not provide an in-depth look at the underpinnings of the construct of interpersonal conflicts, and future research might benefit from using a multi-item scale for measuring interpersonal conflicts at work, we do think that our overall assessment of interpersonal conflicts is useful and valuable. In fact, our measures did not only show the expected relationships with several work-related factors in a large study population, they also differentiated between coworker and supervisor conflict, which was an important shortcoming of previous studies. Fourth, baseline prevalence data may have been somewhat biased because of the initial response rate of $45 \%$. Moreover, it is possible that the prevalence and incidence of supervisor conflict were somewhat underestimated, as the item on supervisor conflict referred to conflict with the daily supervisor and potential conflict with other or higher managers was not included in this item. Fifth, all work-related factors, as well as the presence of interpersonal conflict, were measured by means of questionnaire data. The findings could thus have reflected common method variance, which may lead to an overestimation of the strength of the association between the work-related risk factors and the incidence of an interpersonal conflict. For future research, it might be interesting to include some objective measures of the work environment as well. Finally, although we corrected for possible confounding factors in this study, the potential existence of unidentified confounding factors cannot be ruled out. 
Although these limitations should be kept in mind when interpreting the results of this study, several strengths of the study should be mentioned as well. The results of this study were based on data from a large-scale, prospective cohort study that enabled us to study the prospective relationship between a broad range of work-related factors and the onset of interpersonal conflicts over a one-year follow-up period. This study showed that various factors in the work environment play a role in the onset of interpersonal conflicts at work and may contribute to future theorizing and research on the antecedents of interpersonal conflicts at work. Moreover, given the rather serious consequences of interpersonal conflicts at work for health and well being, the results of this study may serve as a starting point for designing effective prevention and intervention strategies in the workplace.

\section{REFERENCES}

1. Spector PE, Jex SM. Development of four self-report measures of job stressors and strain: Interpersonal Conflict at Work Scale, Organizational Constraints Scale, Quantitative Workload Inventory, and Physical Symptoms Inventory. J Occup Health Psychol. 1998;3(4):356-67.

2. Narayanan L, Menon S, Spector P. A cross-cultural comparison of job stressors and reactions among employees holding comparable jobs in five countries. Int $J$ Stress Manage. 1999;6(3):197-212.

3. Keenan A, Newton TJ. Stressful events, stressors, and psychological strains in young professional engineers. J Occup Behav. 1985;6:151-6.

4. Barki $\mathrm{H}$, Hartwick J. Conceptualizing the construct of interpersonal conflict. Int $\mathrm{J}$ Confl Manage. 2004;15(3):216-44.

5. Frone MR. Interpersonal conflict at work and psychological outcomes: testing a model among young workers. J Occup Health Psychol. 2000;5(2):246-55.

6. Cooper $\mathrm{CL}$, Marshall J. Occupational sources of stress: a review of the literature relating coronary heart disease and mental ill health. J Occup Organ Psychol. 1976;49:11-28.

7. Appelberg $K$, Romanov $K$, Heikkilä $K$, Honkasalo ML, Koskenvuo M. Interpersonal conflict as a predictor of work disability: a follow-up study of 15,348 Finnish employees. J Psychosom Res. 1996;40(2):157-67.

8. Romanov K, Appelberg K, Honkasalo ML, Koskenvuo M. Recent interpersonal conflict at work and psychiatric morbidity: A prospective study of 15,530 employees aged 24-64. J Psychosom Res. 1996;40(2):169-76.

9. Hagerty BM, Williams RA. The effects of sense of belonging, social support, conflict, and Ioneliness on depression. Nurs Res. 1999;48(4):215-9.

10. Bültmann U, Kant I, Van den Brandt PA, Kasl SV. Psychosocial work characteristics as risk factors for the onset of fatigue and psychological distress: Prospective results from the Maastricht Cohort Study. Psychol Med. 2002;32(2):333-45.

11. Hyde M, Jappinen $P$, Theorell $T$, Oxenstierna G. Workplace conflict resolution and the health of employees in the Swedish and Finnish units of an industrial company. Soc Sci Med. 2006;63(8):2218-27. 
12. Lipcamon JD, Mainwaring BA. Conflict resolution in healthcare management. Radiol Manag. $2004 ; 26(3): 48-51$

13. Appelberg K, Romanov K, Honkasalo ML, Koskenvuo M. Interpersonal conflicts at work and psychosocial characteristics of employees. Soc Sci Med. 1991;32(9):1051-6.

14. Bruk-Lee V, Spector PE. The social stressors-counterproductive work behaviors link: Are conflicts with supervisors and coworkers the same? J Occup Health Psychol. 2006;11(2):14556

15. Fujiwara K, Tsukishima E, Tsutsumi A, Kawakami N, Kishi R. Interpersonal conflict, social support, and burnout among home care workers in Japan. J Occup Health. 2003;45(5):31320.

16. Kant I, Bültmann U, Schroer KAP, Beurskens AJHM, Van Amelsvoort LGPM, Swaen GMH. An epidemiological approach to study fatigue in the working population: the Maastricht Cohort Study. Occup Environ Med. 2003;60 Suppl 1:i32-9.

17. Mohren D, Jansen NW, Van Amelsvoort LG, Kant I. An Epidemiological Approach of Fatigue and Work. Experiences from the Maastricht Cohort Study. Maastricht, NL: Programma Epidemiologie van Arbeid en Gezondheid; 2007.

18. Jansen NWH, van Amelsvoort LGPM, Kristensen TS, van den Brandt PA, Kant I. Work schedules and fatigue: a prospective cohort study. Occup Environ Med. 2003;60 Suppl 1:i47. 53.

19. Van Veldhoven M, Meijman TF. Het meten van psychosociale arbeidsbelasting met een vragenlijst: de vragenlijst beleving en beoordeling van de arbeid (VBBA) [The measurement of psychosocial job demands with a questionnaire (VBBA)]. Amsterdam, NL: Netherlands Institute for the Working Environment NIA-TNO; 1994.

20. Karasek R, Brisson C, Kawakami N, Houtman I, Bongers P, Amick B. The Job Content Questionnaire (JCQ): an instrument for internationally comparative assessments of psychosocial job characteristics. J Occup Health Psychol. 1998;3(4):322-55.

21. Karasek RA. The Job Content Questionnaire and User's Guide (version 1.1). Los Angeles, CA: Department of Industrial and Systems Engineering, University of Southern California; 1985.

22. Grundemann RMW, Smulders PGW, de Winter CR. Vragenlijst Arbeid en Gezondheid (VAG) [Questionnaire on Work and Health]. Lisse: Swets \& Zeitlinger; 1993.

23. Hildebrandt VH, Bongers PM, van Dijk FJ, Kemper HC, Dul J, Dutch Musculoskeletal Questionnaire: description and basic qualities. Ergonomics. 2001;44(12):1038-55.

24. Kuorinka 1, Jonsson B, Kilbom A, Vinterberg H, Biering-Sorensen $F$, Andersson $G$, et al. Standardised Nordic questionnaires for the analysis of musculoskeletal symptoms. Appl Ergon. 1987;18(3):233-7.

25. Houtman IL, Goudswaard A, Dhondt S, van der Grinten MP, Hildebrandt VH, van der Poel EG. Dutch monitor on stress and physical load: risk factors, consequences, and preventive action. Occup Environ Med. 1998;55(2):73-83.

26. Statistics Netherlands. Doorlopend Leefsituatie Onderzoek [Ongoing Survey on Living Conditions]. Voorburg/Heerlen: Statistics Netherlands; 1996.

27. Hanson EK, Schaufeli W, Vrijkotte T, Plomp NH, Godaert GL. The validity and reliability of the Dutch Effort-Reward Imbalance Questionnaire. J Occup Health Psychol. 2000;5(1):142-55.

28. Siegrist J. Adverse health effects of high-effort/low-reward conditions. J Occup Health Psychol. 1996;1(1):27-41.

29. SPSS. SPSS Base 13.0. Chicago, III: SPSS Inc.; 2005. 


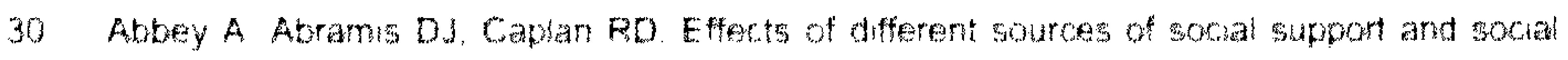

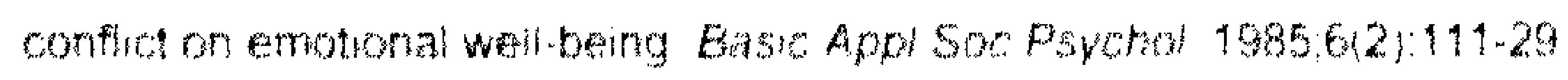

31. Spector PE Zarf D. Chen PY. Frese M. Why negatuvaffertuty stould not be controled in

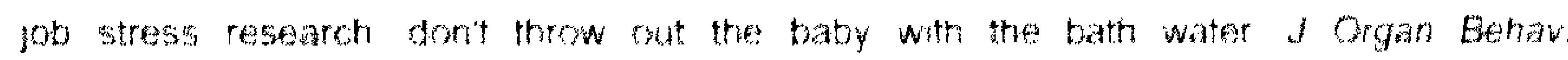
$2000: 2111) 79.95$

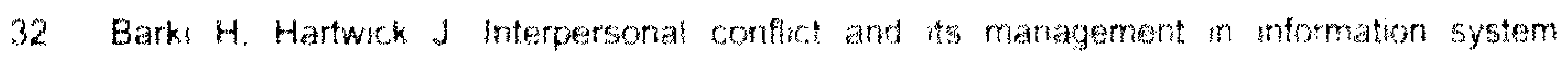
development MIS Q 20012512, 19522. 


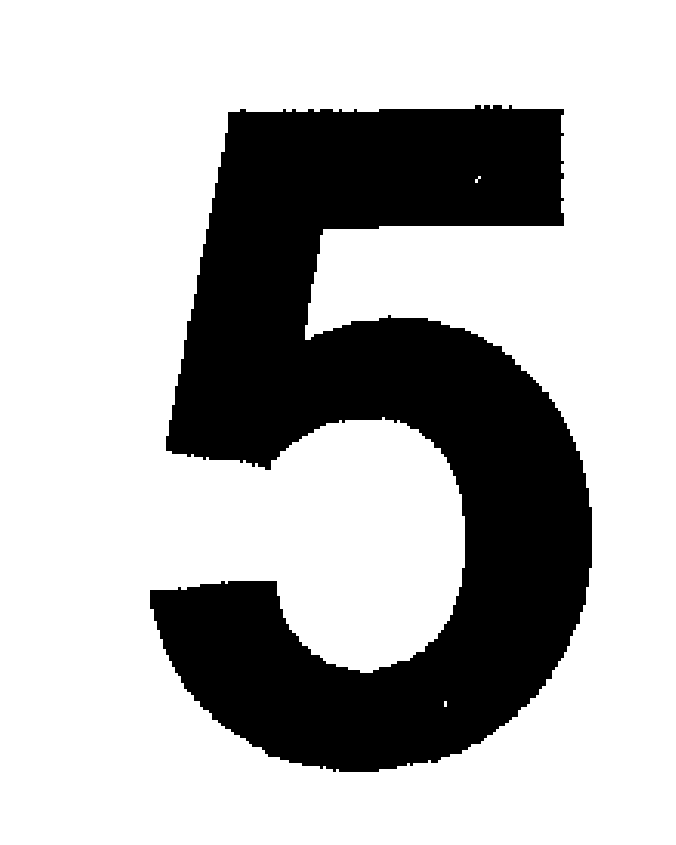

\section{Interpersonal conflicts at work as a predictor of self-reported health outcomes and occupational mobility}

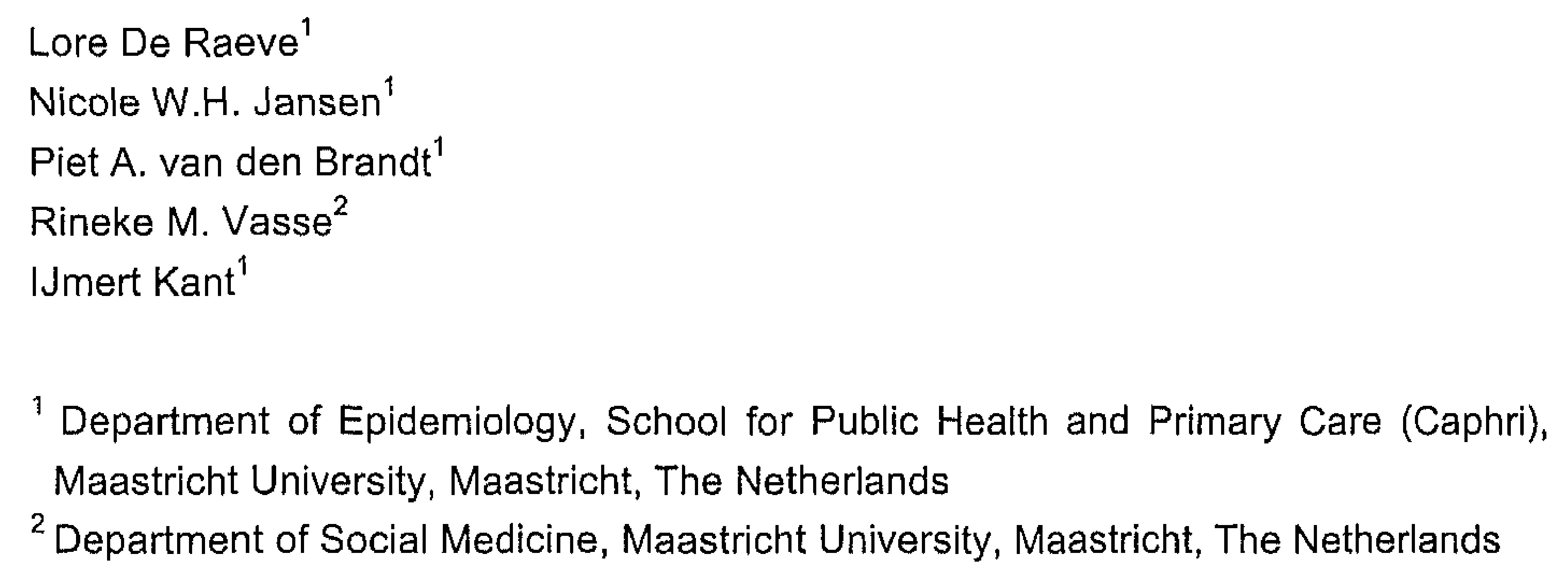




\section{ABSTRACT}

Objectives: The goal of this prospective study was to examine the relationship between interpersonal conflicts at work and subsequent self-reported health outcomes (selfreported general health, need for recovery, and prolonged fatigue) and occupational mobility (internal mobility, i.e., changing job function, and external mobility, i.e., changing employers).

Methods: Data from the Maastricht Cohort Study on fatigue at work ( $n=5582$ for coworker conflict; $n=5530$ for supervisor conflict) were used. Interpersonal conflict with either co-workers or supervisors was assessed between baseline and one-year followup. Outcomes were studied every four months between one-year and two-year follow-up. Logistic regression analyses using generalized estimating equations were conducted for each of the dichotomous outcomes, while controlling for demographic factors, the presence of a long-term illness, other workplace stressors, coping, and outcome at baseline. Analyses were conducted for men only.

Results: At baseline, conflicts with co-workers occurred in $7.2 \%$ of the study population, while conflicts with supervisors occurred in $9.5 \%$ of the study population. In general, this study showed that co-worker conflict was a statistically significant risk factor for the onset of an elevated need for recovery, prolonged fatigue, poor general health and external occupational mobility. Supervisor conflict was a significant risk factor for the onset of an elevated need for recovery, prolonged fatigue, external occupational mobility, and internal occupational mobility.

Conclusions: The results of this study indicate a possible causal relationship between interpersonal conflicts at work and self-reported health and occupational mobility. Given the considerable impact of interpersonal conflicts at work on the individual worker and on the organization, and the fact that interpersonal conflicts at work are highly prevalent, these findings underline the need for interventions aimed at preventing the occurrence of interpersonal conflicts at work, or at least reducing the harmful effects on both the employee and the organization. 


\section{INTRODUCTION}

Interpersonal conflicts are highly prevalent ${ }^{1}$ and have often been identified as a leading source of stress in the occupational setting ${ }^{2-4}$. Interpersonal conflicts at work have previously been associated with health-related outcomes, such as a poor sleep quality ${ }^{5}$, ${ }^{6}$, the use of tranquilizers and hypnotics ${ }^{7}$, psychiatric morbidity ${ }^{8}$, burnout ${ }^{9,10}$, anxiety, frustration, and depression 2,11, 12, and with organizational outcomes such as job dissatisfaction ${ }^{10,13,14}$, turnover intention ${ }^{13}$, intention to quit ${ }^{2,11,15}$, and work disability ${ }^{1}$.

The majority of studies examining effects of interpersonal conflicts at work on the individual is based on a cross-sectional design, and therefore they do not allow any causal inferences to be made. Some studies did, however, examine the effects of interpersonal confilicts at work using a longitudinal design. Two studies that used data collected in the 1980's found that conflicts constituted an elevated risk for work disability among women ${ }^{1}$ and for psychiatric morbidity among men and women ${ }^{8}$. A more recent prospective study by Bültmann et al. ${ }^{16}$ found that interpersonal conflicts at baseline predicted the onset of prolonged fatigue and psychological distress at one year followup.

Even when using a longitudinal design, previous prospective studies did not always succeed in disentangling the cause and effect relationship between interpersonal conflicts and health and organizational outcomes. Insight into this causal relationship is, however, a prerequisite for designing and implementing interventions in the workplace aimed at preventing or at least reducing the negative effects of interpersonal conflicts at work. Methodological limitations, such as small study populations and the inability to control for the initial value of the outcome measure often prevent researchers from providing evidence regarding the causal effects of interpersonal conflicts at work. Moreover, the onset of an interpersonal conflict needs to be measured before the onset of a certain outcome, because a prerequisite for examining causality is that the change in exposure is measured before the actual change in the outcome ${ }^{17}$. Furthermore, the net effects of interpersonal conflicts at work can only be determined by controlling for possible confounding factors that have shown to be associated with both exposure and outcome.

Once these methodological requirements are fulfilled, several other considerations need to be taken into account. First, the impact of work-related interpersonal conflicts may depend on the source of the conflict. Previous research has found differential outcomes for conflicts with co-workers and conflicts with supervisors ${ }^{9,13,18}$. Second, interpersonal conflicts at work might have different effects, depending on the outcome studied. Moreover, when looking at different outcomes, one also has to consider the time lag that 
is needed to find the strongest effect. For example, it is possible that effects on health outcomes occur rather quickly in response to a conflict. However, it might take longer for an individual to actually change jobs because of this conflict. Previous research has often used long time lags between exposure and outcome. Consequently, it is possible that initial effects have already taken place in an earlier stage and that therefore, at the time of actual outcome measurement, only a residual effect, that is, an underestimation of the actual effect, was measured ${ }^{19}$. Finally, previous studies found gender differences in the effects of interpersonal conflicts at work ${ }^{1,20.21}$. However, existing literature was not always consistent ${ }^{8}$. The analyses in this study were conducted for men only.

Taken into account the above methodological and conceptual considerations, the goal of this prospective study is to gain insight into the negative effects of interpersonal conflicts with co-workers and supervisors within a large cohort of male employees. This study examines the effects of interpersonal conflicts at work between baseline and one-year follow-up on three self-reported health outcomes (self-reported general health, need for recovery, and prolonged fatigue) and on organizational outcomes (occupational mobility) between one-year and two-year follow-up, while controlling for demographic factors, the presence of a long-term illness, other workplace stressors and coping.

\section{Methods}

\section{Study population}

This study is based on data from the Maastricht Cohort Study, a prospective study on fatigue at work ${ }^{22}$, in which employees from 45 different companies were followed by means of ten consecutive self-administered questionnaires, which they received at fourmonth intervals. Once a year, in May, the employees received an extensive questionnaire with items on work and non-work-related factors, demographics, and health factors. Twice a year (in September and January) the employees received a short questionnaire, capturing mainly outcome measures. In May 1998, the baseline questionnaire was sent out to 26,978 employees. Altogether, 12,161 employees completed and returned the baseline questionnaire (response rate of $45 \%$ ). Twenty-one questionnaires were excluded from analysis due to technical problems. The baseline (TO) cohort thus consisted of 12,140 people and captured both blue-collar and whitecollar workers. Non-response analyses at baseline yielded no significant differences between respondents and non-respondents regarding demographic characteristics. Nonrespondents were somewhat less likely to report fatigue complaints. Further details on non-response, the procedure, and sectors and trades represented in the Maastricht Cohort Study have been reported elsewhere ${ }^{22-25}$. Employees who had completed the baseline questionnaire and at least one of the following two short questionnaires ( $\mathrm{T} 1$ and 
T2), received the one-year follow-up questionnaire (T3) in May 1999 (response rate $79.5 \%, n=9655$ ). The employees who returned the questionnaire at $T 3$ and at least one of the consecutive short questionnaires (T4 and $\mathrm{T} 5$ ) also received the extensive questionnaire (T6) in May 2000 (response rate 66.5\%, $n=8070$ ). For this study, data from T0, T3, T4, T5 and T6 were used. Questionnaires at baseline (TO) and one-year follow-up (T3) were used to determine the onset of an interpersonal conflict at work. Questionnaires at T3 (May 1999), T4 (September 1999), T5 (January 2000), and T6 (May 2000) were used to assess the outcomes; see figure 1.

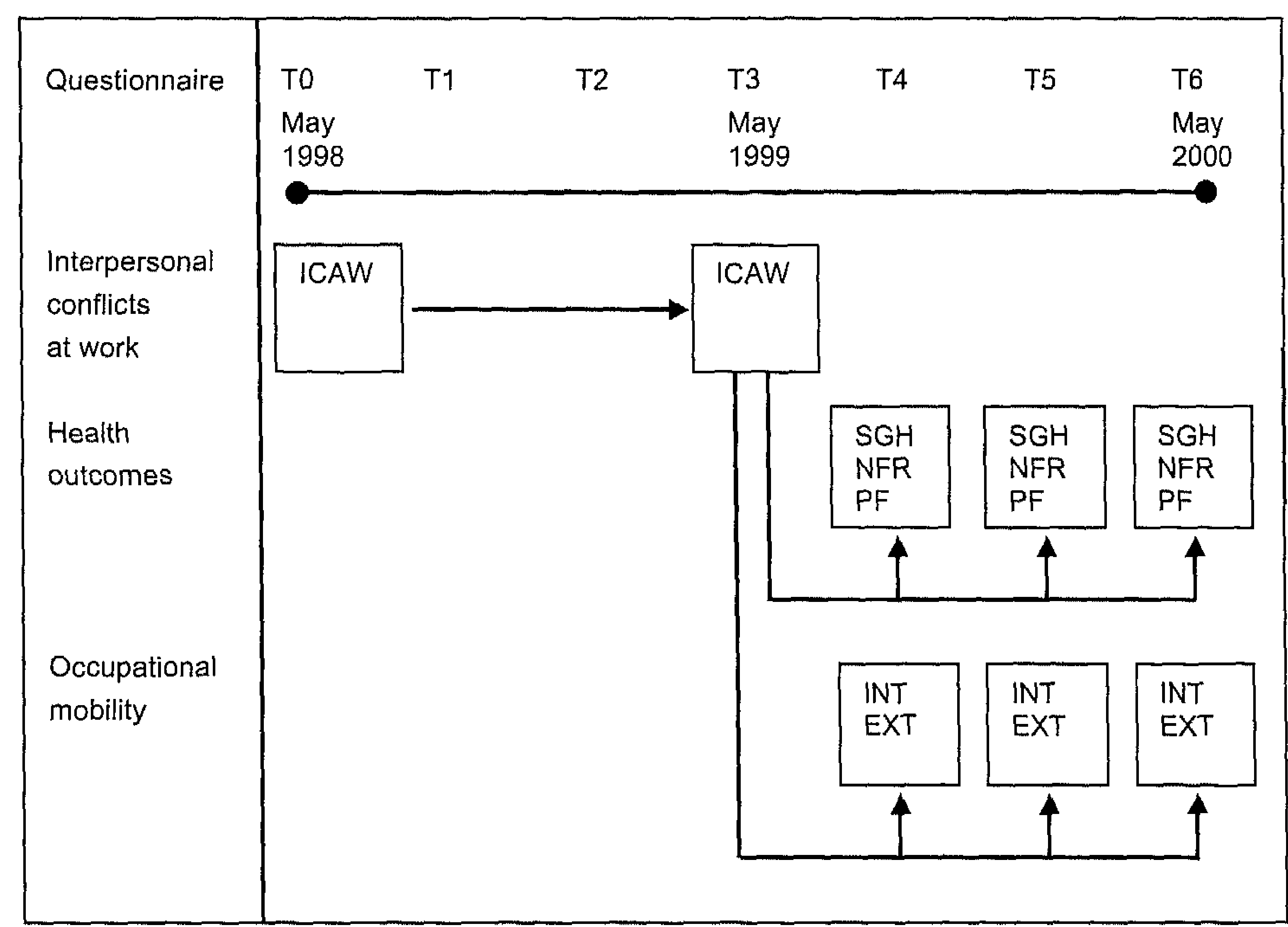

Figure 1 Questionnaires, analyses, and main variables in the present study ( $n=5582$ for co-worker conflict; $n=5530$ for supervisor conflict) as part of the Maastricht Cohort Study. ICAW= interpersonal conflicts at work; $S G H=$ Self-reported general health; NFR= Need for recovery; $P F=$ Prolonged fatigue; $I N T=$ Internal occupational mobility; EXT= External occupational mobility

Employees on whom at least baseline and one-year follow-up data were available were considered for this study ( $n=9655$ ). As it is possible that the effects of interpersonal conflict are different for men and women, and because of the limited amount of women that was available for the longitudinal analyses in this study, women were excluded $(n=2606)$ and the analyses in this study were conducted for men only. Employees with multiple jobs at TO or T3 were excluded $(n=427)$, because information on the other job was lacking. Moreover, employees who reported themselves to be absent from work because of illness or reported working under modified conditions related to former 
sickness absence (e.g., fewer hours, modified tasks or other functions) at the time of administering the TO or the T3 questionnaire were excluded from the analyses ( $n=943$ ) as they might have a distorted view of their work situation because of sickness absence. After exclusion of employees with missing data on the exposure of interest $(97$ missings on co-worker conflict and 149 missings on supervisor conflict) co-worker conflict could be studied in 5582 employees, and supervisor conflict could be studied in 5530 employees. Baseline characteristics of these final study populations are presented in table 1.

\section{Measures}

Interpersonal conflicts at work

Conflicts with co-workers and supervisors were measured with two items from the Dutch Questionnaire on the Experience and Evaluation of Work (Dutch abbreviation, VBBA) ${ }^{26}$. Conflicts with co-workers were assessed with the question "Do you have conflicts with your co-workers? (no/yes)". Supervisor conflict was assessed with the question "Do you have conflicts with your daily supervisor? (no/yes)". Information on interpersonal conflicts was gathered once a year in the extensive questionnaires.

\section{Self-reported health outcomes}

Self-reported general health was measured using one item adapted from the SF- $36{ }^{27}$, giving an overall rating of health on a five-point scale ( $1=$ excellent, $2=$ very good, $3=$ good, 4=moderate, $5=$ bad). In line with several other studies ${ }^{28-31}$, this measure was dichotomized by grouping response scores $1-3$ into the category of good general health and scores 4-5 into the category of poor general health. Self-reported general health was assessed every four months. The need for recovery from work was assessed every four months using an 11-item scale from the Dutch Questionnaire on the Experience and Evaluation of Work [Dutch abbreviation, VBBA] ${ }^{26,32,33}$. The items represent short-term effects of a day of work. Responses (no/yes) to the 11 items were summed up to generate a total score ranging from 0 to 100 (Cronbach's $\alpha=0.78$ ). As no cut-off point existed for classifying persons with a high score on the total scale, we used the upper tertile to define employees with a considerable need for recovery from work. Prolonged fatigue was measured every four months with the 20-item self-reported Checklist Individual Strength (CIS), which has been described extensively elsewhere ${ }^{34}, 35$. A composite CIS-total score, ranging from 20 to 140 (Cronbach's $\alpha=0.93$ ), was constructed by adding the item scores. A cut-off point of $\mathrm{ClS}$ total $>76$ was used for case classification. This cut-off point was established in a separate pilot study by means of defined samples with differences in fatigue levels ${ }^{34}$. Persons scoring $>76$ on the CIStotal were designated as probable cases of prolonged fatigue. Whereas the need for recovery scale measures the recuperation period after one day of work and thus represents short-term effects, the CIS asked employees how they felt during the past two weeks. 


\begin{abstract}
Occupational mobility
Occupational mobility was assessed every four months from T1 onwards and can be divided into internal mobility and external mobility. Internal mobility was defined as a job change within the company and was assessed with one item asking employees whether they changed their job function in the past four months (no/yes). External mobility was defined as a change in jobs from one employer to another and was assessed with one item asking employees whether they changed employers in the past four months (no/yes).
\end{abstract}

\title{
Confounding factors
}

Self-reported data were available on age (continuous), living situation (living alone no/yes), and the presence of a long-term illness (no/yes). Educational level was measured according to the highest level of education the person completed and was recoded in three categories: low (primary and lower vocational school), medium (lower secondary school, intermediate vocational school, and secondary school), and high (higher vocational school and university). Moreover, as psychological job demands, decision latitude, social support and coping behavior have previously shown to be related to both interpersonal conflicts as well as to the outcome measures, they were treated as possible confounders in this study. Psychological job demands, decision latitude, and social support were measured with a validated Dutch version of the selfadministered Job Content Questionnaire (JCQ) ${ }^{36,37}$. Coping was measured by the $15-$ item Utrecht Coping List ${ }^{38}$ and consisted of two subscales: problem-focused coping (an active way of altering the problem causing stress), and emotion-focused coping (the regulation of the emotional response to a stressful situation). Because information on coping style was not available in our baseline questionnaire, but since this factor is often seen as a stable characteristic, we used the one-year follow-up (T3) measurement to assess coping style.

\section{Statistical analysis}

The onset of interpersonal conflicts was assessed between baseline (TO) and one-year follow-up (T3). Employees reporting conflicts at work were divided into four groups because the duration, the settlement and/or the recurrence of a conflict might influence the strength of the effects. This classification was made both for co-worker conflict and for supervisor conflict. The reference group (group 1) consisted of employees reporting neither a conflict at baseline (TO) nor at one-year follow-up (T3). The second group consisted of employees reporting a conflict at baseline but not at follow-up. The third group consisted of employees who reported no conflict at baseline, but who did report a conflict at one-year follow-up. The fourth group consisted of employees who reported a conflict both at baseline and at one-year follow-up. 
Table 1 Baseline descriptive characteristics of the study populations

\begin{tabular}{|c|c|c|c|c|}
\hline \multirow[t]{3}{*}{ Co-worker conflict $(n=5582)$} & Group 1 & Group 2 & Group 3 & Group 4 \\
\hline & TO: no & TO: yes & TO: no & TO: yes \\
\hline & T3: no & T3: no & T3: yes & T3: yes \\
\hline Total, $n$ & 4971 & 262 & 209 & 140 \\
\hline \multirow[t]{2}{*}{ Age, mean (SD) } & 42.60 & 41.69 & 40.89 & 41.26 \\
\hline & $(8.50)$ & $(8.15)$ & $(8.01)$ & $(8.50)^{\star \star}$ \\
\hline \multicolumn{5}{|l|}{ Education (\%) } \\
\hline Low & 19.3 & 25.9 & 26.4 & $23.0^{\star}$ \\
\hline Medium & 41.5 & 40.4 & 40.4 & 45.3 \\
\hline High & 39.3 & 33.7 & 33.2 & 31.7 \\
\hline Living alone yes (\%) & 8.4 & 11.9 & 10.5 & $11.5^{\mathrm{ns}}$ \\
\hline Long-term illness yes (\%) & 19.0 & 19.8 & 32.3 & $25.5^{\star \star \star}$ \\
\hline \multirow[t]{2}{*}{ Psychological job demands $[12-48]^{\dagger}$, mean (SD) } & 33.06 & 34.58 & 34.77 & 35.39 \\
\hline & $(5.52)$ & $(6.09)$ & (5.59) & $(6.36)^{\star \star \star}$ \\
\hline \multirow[t]{2}{*}{ Decision latitude $[24-96]^{\dagger}$, mean $(\mathrm{SD})$} & 73.57 & 72.06 & 72.66 & 70.54 \\
\hline & $(10.89)$ & $(10.95)$ & $(11.72)$ & $(12.00)^{\star *}$ \\
\hline \multirow[t]{2}{*}{ Co-worker social support [4-16] ${ }^{\dagger}$, mean (SD) } & 11.94 & 10.77 & 11.63 & 10.24 \\
\hline & $(1.46)$ & $(1.93)$ & $(1.66)$ & $(1.91)^{\star \star \star}$ \\
\hline \multirow[t]{2}{*}{ Supervisor social support $[4-16]^{\dagger}$, mean (SD) } & 10.51 & 9.74 & 10.10 & 9.43 \\
\hline & $(2.23)$ & $(2.31)$ & $\langle 2.48)$ & $(2.75)^{\star \star \star}$ \\
\hline \multirow[t]{2}{*}{ Problem-focused coping $[10-40]^{\dagger}$, mean (SD) } & 25.45 & 25.57 & 25.05 & 25.41 \\
\hline & $(3.86)$ & $(3.90)$ & $(4.25)$ & $(4.38)^{n s}$ \\
\hline \multirow[t]{2}{*}{ Emotion-focused coping $[5-20]^{\dagger}$, mean (SD) } & 9.50 & 9.85 & 10.00 & 10.08 \\
\hline & $(2.10)$ & (2.29) & $(2.46)$ & $(2.30)^{\star \star \star *}$ \\
\hline
\end{tabular}

Continuous variables are presented as mean (SD) with corresponding p-values from one-way analyses of variance; categorical variables are presented as $\%$ of total with corresponding p-values from $\mathrm{chi}^{2}$-tests; Significance levels apply to differences between the four groups; ${ }^{*} p<0.05$, ${ }^{\star *} p<0.01,{ }^{* \star *} p<0.001,{ }^{\text {ns }}$ not significant

${ }^{\dagger}$ scale range

When a causal relationship exists between an exposure variable and an outcome variable in a study, then a change in exposure (i.e., the onset of a conflict) must be followed by a change in the outcome over time. To examine whether there is a causal relationship in this study, we examined the effect of the onset of a conflict between baseline (TO) and one-year follow-up (T3) on subsequent changes in the outcome measures between one-year follow-up (T3) and two-year follow-up (T6). Therefore, first, all prevalent cases from the involved dependent variable at one-year follow-up (T3) were excluded and incident cases for each outcome were studied at T4, T5, and T6. We used logistic regression analyses for repeated measurements (generalized estimating equations, GEE) to examine the relationship between the onset of an interpersonal conflict and subsequent changes in self-reported health outcomes and occupational mobility. GEE can be used as a method for dealing with correlated data arising from repeated measurements ${ }^{39}$. 
Interpersonal conflicts as predictor of health and occupational mobility

Table 1 (continued)

\begin{tabular}{|c|c|c|c|c|}
\hline Supervisor conflict ( $n=5530$ ) & $\begin{array}{l}\text { Group } 1 \\
\text { TO: no } \\
\text { T3: no }\end{array}$ & $\begin{array}{l}\text { Group } 2 \\
\text { T0: yes } \\
\text { T3: no }\end{array}$ & $\begin{array}{l}\text { Group } 3 \\
\text { T0: no } \\
\text { T3: yes }\end{array}$ & $\begin{array}{l}\text { Group } 4 \\
\text { T0: yes } \\
\text { T3: yes }\end{array}$ \\
\hline Total, $n$ & 4731 & 329 & 280 & 190 \\
\hline Age, mean $(S D)$ & $\begin{array}{l}42.42 \\
(8.52)\end{array}$ & $\begin{array}{l}42.09 \\
(8.46)\end{array}$ & $\begin{array}{l}42.81 \\
(7.99)\end{array}$ & $\begin{array}{l}43.12 \\
(7.89)^{\mathrm{ns}}\end{array}$ \\
\hline Education (\%) & & & & \\
\hline Low & 18.8 & 23.7 & 24.7 & $30.4^{\star \star \star}$ \\
\hline Medium & 40.8 & 43.8 & 49.5 & 40.8 \\
\hline High & 40.3 & 32.5 & 25.8 & 28.8 \\
\hline Living alone yes (\%) & 8.7 & 10.7 & 8.6 & $5.8^{\text {ns }}$ \\
\hline Long-term illness yes (\%) & 18.6 & 25.5 & 20.4 & $32.3^{\star \star \star}$ \\
\hline Psychological job demands $[12-48]^{\dagger}$, mean (SD) & $\begin{array}{l}32.85 \\
(5.43)\end{array}$ & $\begin{array}{l}35.67 \\
(6.15)\end{array}$ & $\begin{array}{l}34.48 \\
(5.68)\end{array}$ & $\begin{array}{l}36.51 \\
(6.02)^{\star \star \star}\end{array}$ \\
\hline Decision latitude $[24-96]^{\dagger}$, mean (SD) & $\begin{array}{l}74.09 \\
(10.65)\end{array}$ & $\begin{array}{l}69.35 \\
(12.06)\end{array}$ & $\begin{array}{l}71.02 \\
(11.33)\end{array}$ & $\begin{array}{l}68.27 \\
(12.25)^{\star \star \star}\end{array}$ \\
\hline Co-worker social support [4-16] ${ }^{\dagger}$, mean (SD) & $\begin{array}{l}11.88 \\
(1.50)\end{array}$ & $\begin{array}{l}11.60 \\
(1.80)\end{array}$ & $\begin{array}{l}11.52 \\
(1.69)\end{array}$ & $\begin{array}{l}11.44 \\
(1.72)^{* * *}\end{array}$ \\
\hline Supervisor social support $[4-16]^{\dagger}$, mean (SD) & $\begin{array}{l}10.77 \\
(2.04)\end{array}$ & $\begin{array}{l}8.11 \\
(2.42)\end{array}$ & $\begin{array}{l}9.60 \\
(2.22)\end{array}$ & $\begin{array}{l}7.46 \\
(2.40)^{\star \star \star}\end{array}$ \\
\hline Problem-focused coping $[10-40]^{\dagger}$, mean (SD) & $\begin{array}{l}25.48 \\
(3.84)\end{array}$ & $\begin{array}{l}25.68 \\
(3.60)\end{array}$ & $\begin{array}{l}25.15 \\
(4.21)\end{array}$ & $\begin{array}{l}24.96 \\
(4.57)^{\mathrm{ns}}\end{array}$ \\
\hline Emotion-focused coping [5-20] ${ }^{\dagger}$, mean (SD) & $\begin{array}{l}9.51 \\
(2.08)\end{array}$ & $\begin{array}{l}9.54 \\
(2.16)\end{array}$ & $\begin{array}{l}9.8 \\
(2.41)\end{array}$ & $\begin{array}{l}10.26 \\
(2.58)^{\star \star \star}\end{array}$ \\
\hline
\end{tabular}

Continuous variables are presented as mean (SD) with corresponding p-values from one-way analyses of variance; categorical variables are presented as $\%$ of total with corresponding $p$-values from $\mathrm{chi}^{2}$-tests; Significance levels apply to differences between the four groups; ${ }^{*} p<0.05$, ${ }^{* \star} p<0.01,{ }^{* \star \star} p<0.001,{ }^{\text {ns }}$ not significant

${ }^{\dagger}$ scale range

Separate logistic regression models were fitted for each of the dichotomized outcome measures: self-reported general health, prolonged fatigue, need for recovery, internal mobility, and external mobility. Odds ratios (OR) and $95 \%$ confidence intervals $(95 \% \mathrm{Cl})$ were calculated separately for co-worker conflict and supervisor conflict. In the analyses, we corrected for age, education, living situation, the presence of a long-term illness, psychological job demands, decision latitude, social support from co-workers or supervisors and coping behavior. Moreover, when health outcomes were studied, we also corrected for the dichotomous baseline (TO) value of the respective health outcomes to rule out a possible reversed effect of health status on the onset of a conflict. All analyses were performed using SPSS $13.0^{40}$ and STATA $9.2^{41}$ statistical packages. 


\section{RESULTS}

At baseline, conflicts with co-workers occurred in $7.2 \%$ of the study population for coworker conflict ( $n=5582$ ), while conflicts with supervisors occurred in $9.5 \%$ of the study population for supervisor conflict $(n=5530)$. When employees experiencing a co-worker conflict at baseline were excluded, the incidence of a co-worker conflict at one-year follow-up was $4.0 \%(n=209)$. When employees experiencing a supervisor conflict at baseline were excluded, the incidence of a supervisor conflict at one-year follow-up was $5.6 \%(n=280)$.

Table 1 presents the descriptive characteristics of the study populations at baseline (TO) for conflicts with co-workers and supervisors within one year of follow-up. In general, compared to the first group, the second, third, and fourth group were less educated and they more often experienced a long-term illness. Moreover, the groups reporting conflicts reported higher levels of psychological job demands, lower levels of decision latitude, less social support from co-workers or supervisors, and higher levels of emotion-focused coping.

Table 2 presents the percentages of employees reporting caseness of the available outcomes at baseline (TO) and at one-year follow-up (T3) within each of the four groups. Both at $\mathrm{TO}$ and at $\mathrm{T} 3$, unhealthy cases are least prevalent in the group reporting no conflicts. Except for the association between co-worker conflict and the need for recovery at $\mathrm{T} 3$, the largest percentage of unhealthy cases on the three health outcomes was observed in the group reporting conflicts at TO and T3. In the longitudinal GEEanalyses, employees reporting caseness at $\mathrm{T} 3$ were excluded from the analyses and outcomes were controlled for at T0. Furthermore, the prevalence of occupational mobility was relatively high in the group reporting a conflict at T0 but not at T3 (group 2). In the other groups, the percentage of employees reporting occupational mobility at T3, especially external mobility, was rather low.

Table 3 presents the results from the logistic GEE-analyses for the self-reported health outcomes, after control for possible confounders. Results indicate that, compared to employees reporting no conflict at T0 or T3 (group 1) the onset of a co-worker conflict (group 3) was a statistically significant risk factor for the onset of prolonged fatigue and poor general health within one-year of follow-up. The onset of a supervisor conflict significantly predicted an elevated need for recovery and more prolonged fatigue. A coworker conflict reported at baseline but not at follow-up (group 2), was associated with a significantly higher need for recovery. A co-worker conflict reported at both TO and T3 (group 4) increased the odds of developing self-reported poor general health, while a supervisor conflict in group 4 increased the odds of developing a high need for recovery and prolonged fatigue. 
Interpersonal conflicts as predictor of health and occupational mobility

Table 2 Prevalence of outcomes in the study populations at TO and T3

\begin{tabular}{|c|c|c|c|c|}
\hline \multirow[t]{3}{*}{ Co-worker conflict ( $n=5582$ ) } & Group 1 & Group 2 & Group 3 & Group 4 \\
\hline & T0: no & TO: yes & To: no & T0: yes \\
\hline & T3: no & T3: no & T3: yes & T3: yes \\
\hline Total, $n$ & 4971 & 262 & 209 & 140 \\
\hline \multicolumn{5}{|l|}{ Cases of outcomes at TO } \\
\hline Poor general health (\%) & 10.3 & 16.9 & 18.4 & $20.0^{\star \star \star}$ \\
\hline Need for recovery (\%) & 23.6 & 38.7 & 42.8 & $47.2^{\star \star \star}$ \\
\hline Prolonged fatigue (\%) & 17.3 & 28.1 & 27.5 & $33.3^{\star * *}$ \\
\hline \multicolumn{5}{|l|}{ Cases of outcomes at $\mathrm{T}^{\dagger}$} \\
\hline Poor general health (\%) & 11.9 & 18.0 & 21.6 & $27.3^{\star \star \star}$ \\
\hline Need for recovery $(\%)$ & 29.5 & 43.6 & 59.8 & $56.2^{\star \star \star}$ \\
\hline Prolonged fatigue (\%) & 18.3 & 27.9 & 38.0 & $38.7^{* \star \star}$ \\
\hline External mobility (\%) & 1.3 & 3.1 & 0.5 & $0.0^{\star}$ \\
\hline Internal mobility (\%) & 6.4 & 11.9 & 2.9 & $6.5^{\star \star}$ \\
\hline \multirow[t]{3}{*}{ Supervisor conflict $(n=5530)$} & Group 1 & Group 2 & Group 3 & Group 4 \\
\hline & To: no & TO: yes & To: no & T0: yes \\
\hline & T3: no & T3: no & T3: yes & T3: yes \\
\hline Total, $n$ & 4731 & 329 & 280 & 190 \\
\hline \multicolumn{5}{|l|}{ Cases of outcomes at T0 } \\
\hline Poor general health (\%) & 10.1 & 18.3 & 13.4 & $23.2^{\star \star *}$ \\
\hline Need for recovery (\%) & 22.8 & 39.3 & 36.6 & $52.8^{* \star \star}$ \\
\hline Prolonged fatigue $(\%)$ & 16.80 & 27.2 & 22.7 & $36.5^{\star \star \star}$ \\
\hline \multicolumn{5}{|l|}{ Cases of outcomes at $\mathrm{T} 3^{\dagger}$} \\
\hline Poor general health $(\%)$ & 11.4 & 18.9 & 22.7 & $27.0^{\star \star \star}$ \\
\hline Need for recovery (\%) & 28.6 & 42.1 & 51.2 & $60.6^{\star \star \star}$ \\
\hline Prolonged fatigue (\%) & 17.9 & 25.9 & 32.3 & $41.7^{\star \star *}$ \\
\hline External mobility (\%) & 1.3 & 2.4 & 1.1 & $0.0^{\mathrm{ns}}$ \\
\hline Internal mobility (\%) & 6.6 & 10.1 & 4.3 & $3.2^{* *}$ \\
\hline
\end{tabular}

Table 4 presents the results from the logistic GEE-analyses for internal and external mobility, after control for possible confounding factors. A co-worker conflict resulted in significantly higher odds of changing jobs from one employer to another in groups 2,3 , and 4. The effect of a co-worker conflict on internal mobility was not statistically significant. The onset of a supervisor conflict (group 3) was a significant risk factor both internal and external mobility. A supervisor conflict reported both at baseline and oneyear follow-up (group 4) also resulted in higher odds of changing jobs, both internally and externally. 
Table 3 Interpersonal conflicts at work as a predictor of subsequent self-reported health outcomes: results from the GEE analysis

\begin{tabular}{|c|c|c|c|c|c|}
\hline & T0 & T3 & $\begin{array}{l}\text { Poor general } \\
\text { health } \\
\text { OR }^{\mathrm{a}}[95 \% \mathrm{Cl}]\end{array}$ & $\begin{array}{l}\text { Need for } \\
\text { recovery } \\
\text { OR }{ }^{a}[95 \% \mathrm{Cl}]\end{array}$ & $\begin{array}{l}\text { Prolonged } \\
\text { fatigue } \\
\mathrm{OR}^{\mathrm{a}}[95 \% \mathrm{Cl}]\end{array}$ \\
\hline \multicolumn{6}{|l|}{ Co-worker conflict } \\
\hline Group 1 & No & No & $1.00(\mathrm{ref})$ & 1.00 (ref) & 1.00 (ref) \\
\hline Group 2 & Yes & No & $1.28[0.94-1.75]$ & $1.90[1.26-2.85]$ & $1.23[0.88-1.74]$ \\
\hline Group 3 & No & Yes & $1.51[1.06-2.14]$ & $1.28[0.68-2.41]$ & $1.44[1.01-2.06]$ \\
\hline Group 4 & Yes & Yes & $1.82[1.21-2.75]$ & $1.86[1.00-3.46]$ & $1.49[0.93-2.40]$ \\
\hline \multicolumn{6}{|l|}{ Supervisor conflict } \\
\hline Group 1 & No & No & 1.00 (ref) & 1.00 (ref) & 1.00 (ref) \\
\hline Group 2 & Yes & No & $1.33[0.99-1.79]$ & $1.22[0.77-1.94]$ & $1.09[0.78-1.52]$ \\
\hline Group 3 & No & Yes & $1.33[1.00-1.77]$ & $1.81[1.16-2.82]$ & $1.64[1.22-2.22$ \\
\hline Group 4 & Yes & Yes & $1.20[0.81-1.77]$ & $2.46[1.31-4.65]$ & $1.53[1.03-2.27$ \\
\hline
\end{tabular}

a corrected for age (continuous), education, living situation, the presence of a long-term illness, psychological job demands, decision latitude, social support from co-workers (when examining effects of co-worker conflict) or social support from supervisors (when examining supervisor conflict), coping behavior, and baseline health outcome

Table 4 Interpersonal conflicts at work as a predictor of subsequent occupational mobility: results from the GEE analysis

\begin{tabular}{rllll}
\hline & & & $\begin{array}{l}\text { External mobility } \\
\text { OR }^{\mathrm{a}}[95 \% \mathrm{Cl}]\end{array}$ & $\begin{array}{l}\text { Internal mobility } \\
\text { OR }^{\mathrm{a}}[95 \% \mathrm{Cl}]\end{array}$ \\
\hline Co-worker conflict & & & & \\
Group 1 & No & No & $1.00(\mathrm{ref})$ & $1.00(\mathrm{ref})$ \\
Group 2 & Yes & No & $2.51[1.36-4.64]$ & $1.38[0.92-2.07]$ \\
Group 3 & No & Yes & $2.35[1.19-4.61]$ & $1.43[0.96-2.15]$ \\
Group 4 & Yes & Yes & $2.54[1.21-5.33]$ & $1.27[0.78-2.05]$ \\
\hline Supervisor conflict & & & & \\
Group 1 & No & No & $1.00($ ref $)$ & $1.00($ ref) \\
Group 2 & Yes & No & $1.48[0.69-3.19]$ & $0.86[0.56-1.34]$ \\
Group 3 & No & Yes & $3.65[2.12-6.28]$ & $1.76[1.23-2.52]$ \\
Group 4 & Yes & Yes & $3.07[1.44-6.55]$ & $1.59[1.03-2.45]$ \\
\hline
\end{tabular}

a corrected for age (continuous), education, living situation, the presence of a long-term illiness, psychological job demands, decision latitude, social support from co-workers (when examining effects of co-worker conflict) and supervisors (when examining supervisor conflict), and coping behavior 
Interpersonal conflicts as predictor of health and occupational mobility

\section{Discussion}

This prospective study showed that interpersonal conflicts at work are highly prevalent and it provided evidence for a statistically significant longitudinal relationship between the onset of interpersonal conflicts at work within one year of follow-up and the incidence of self-reported health outcomes and occupational mobility in the following year. In this study, a longitudinal design was used with relatively short time intervals between exposure and outcome. Moreover, the onset of an interpersonal conflict with either coworkers or supervisors was measured before the onset of a health problem or before changing jobs or job function, while correcting for demographic factors, the presence of a long-term illness, other workplace stressors and coping. Moreover, when examining the impact of conflicts at work on the onset of health problems, we also corrected for baseline health to rule out a possible reversed effect of health status on the onset of a conflict.

\section{Effects on self-reported health outcomes}

Both co-worker and supervisor conflict resulted in considerable effects on self-reported health. Results were, however, slightly different depending on the outcome studied. A possible explanation is that different time-dependent relationships existed between these conflicts and the different outcomes. However, the appropriate time that is needed for either a co-worker or a supervisor conflict to affect the different outcomes was not examined in this study. Not surprisingly, the results of this study showed that, in general, health effects were stronger when conflicts were reported both at baseline (TO) and at one-year follow-up (T3). It must, however, be noticed that these effects might still be a serious underestimation of the actual impact of conflicts at work. An indication for this reasoning is observed in table 2 showing high associations between conflicts and health outcomes at one-year follow-up (T3). However, to be able to disentangle the causal relationship, in the longitudinal analyses, the cases of the respective outcomes were excluded at one-year follow-up, and even then rather large effects were found. Furthermore, the prevalence of occupational mobility at one-year follow-up (T3) was rather low. This might indicate that the effect of conflicts on self-reported health occurs rather quickly, while it takes longer to actually decide to or be forced to change employers or job function, possibly because the latter was perceived as a more radical change.

In most cases, a settled conflict seems to have a small, though not significant residual effect on health. It must, however, be mentioned that the results for group 2 need to be interpreted with caution, because even when a conflict was no longer reported at T3, employees experiencing health complaints at T3 were still excluded from the analyses. 
One might question whether this situation still represents an actually probable situation. For group 2, it might have been more realistic not to separate the change in exposure from a change in the outcome over time, but rather to simultaneously examine whether health improves when the conflict disappears.

\section{Effects on occupational mobility}

Both co-worker and supervisor conflict resulted in considerable effects in terms of occupational mobility in the longitudinal analyses. The results showed that employees experiencing a conflict were more likely to change employers (external mobility) than to change job function (internal mobility). Especially when they experienced a conflict with the supervisor, the odds of changing employers were rather high. It seems that people try to avoid interaction with others involved in the conflict by changing employers and not by changing job function as the latter might still imply regular contact with others involved in the conflict.

\section{Strength of the effects}

Some methodological features of this study might have had an impact on the strength of the effects found. First, it must be noticed that we are not certain about whether or not we used the appropriate time frame to measure conflicts in this study. Despite frequent sampling in the Maastricht cohort study, interpersonal conflicts were only measured in the questionnaires that were sent out annually. This enabled us to study the onset of a conflict between baseline and one-year follow-up. However, this time interval does not enable us to identify the exact onset and duration of the conflict. It is possible that the conflict that was reported at one-year follow-up was already the second or the third conflict. The strength of the effects found in this study might have been influenced depending on when the conflict started, whether or not it recurred, and how long it lasted. For future research it might be interesting to use shorter time intervals to measure the onset of interpersonal conflicts at work. Second, in this study, the influence of possible confounding factors was examined. Among others, we controlled for social support in this study. Previous studies have indicated that conflicts and support are not the same constructs and may occur independently from one another ${ }^{42,43}$. It is possible that only one supportive person in the work environment is enough to help alleviate the otherwise harmful effects of interpersonal conflicts ${ }^{44}$. The results of this study show that the effects of interpersonal conflicts on self-reported health outcomes and occupational mobility remain significant over and above the potentially protective effect of social support. However, we are aware of the fact that controlling for social support might have lead to overcorrection. Far less research has been conducted on the interrelationship between co-worker and supervisor conflict. In an additional analysis (specific data not shown), we examined the impact of a mutual correction for the other conflict. These analyses 
showed that the odds ratios somewhat reduced in size but, in general, results remained the same. It should, however, be noted that this correction reduced the power of our analyses. For future research, it may be interesting to examine in more detail the interrelations between co-worker and supervisor conflict, and the way in which they might reinforce each other. Finally, we also examined whether correcting for other possible confounding factors, such as job tenure, shift work and the type of job (e.g. job sector or trade), influenced the strength of the relationship between interpersonal conflicts and the outcomes studied, but as none of these factors did, they were left out of the analyses. The characteristics of the job might have already been refiected in the work characteristics such as job demands and decision latitude, which the analyses had already been adjusted for. Despite the fact that a broad range of possible confounders was considered in this study, the possible existence of unidentified confounding factors cannot be ruled out.

\section{Limitations}

The following issues should also be kept in mind when interpreting the results. First, the results of this study apply to men only. It is possible that results for women are different. For example, it is possible that women are more emotionally responsive to interpersonal conflicts than men ${ }^{21}$, which might result in more serious effects on mental health among women. More research is needed to examine the effects of interpersonal conflicts at work for women. Second, negative affectivity was not included as a confounder in this study. The possible influence of negative affectivity was reduced in the prospective analyses in this study because intra-individual changes in both conflicts and in outcomes were studied ${ }^{45}$. Third, baseline prevalence data may be somewhat biased because of the initial response rate of $45 \%$. Fourth, both co-worker and supervisor conflict were measured with one item asking employees whether they had conflicts with their coworkers or supervisor. Especially when the construct being measured is multidimensional, single item measures might raise concern with respect to the validity of the study. A previous study ${ }^{46}$, however, obtained very high correlations between individuals' global assessments of interpersonal conflicts and a multidimensional measure of interpersonal conflicts based on assessments of disagreement, interference, and negative emotion, the three key dimensions of conflicts according to Barki and Hartwick ${ }^{47}$. Although our study did not provide an in-depth look at the underpinnings of the construct of interpersonal conflicts, and future research might benefit from using a multi-item scale for measuring interpersonal conflicts at work, we do think that our overall assessment of interpersonal conflicts is useful and valuable. In fact, our measures did not only show the expected effects in a large study population, but they also differentiated between co-worker and supervisor conflict, which was an important shortcoming of previous studies. Finally, results might be influenced by the chosen cutoff points in the dichotomization of the health variables. The dichotomies for prolonged 
fatigue and self-reported health used in this study have, however, previously shown to be reliable measures of health 31,34 . To date, there are no existing cut-off points for classifying employees with a marked need for recovery that would put them at risk for future health problems. In our study the upper tertile was used to define employees with a considerable need for recovery from work, the so-called need-for-recovery cases. So far, this appeared to be a good method since the distribution of need for recovery in the cohort covered the whole range of the scale and showed no cut-off points or peculiarities.

\section{Strengths}

Although the limitations of this study need to be taken into account when interpreting the results, the strengths of this study should be mentioned as well. This large prospective study examines the effects of both co-worker and supervisor conflict on different outcomes, while separating a change in exposure (the onset of a conflict) from a change in the outcome (onset of self-reported health problems and occupational mobility) over time using relatively short time intervals, and taking into account several confounding factors. Therefore, we conclude that the results of this study indicate a possible causal relationship between interpersonal conflicts at work and self-reported health and occupational mobility. Given the considerable impact of interpersonal conflicts at work on the individual worker and on the organization, and the fact that interpersonal conflicts at work are highly prevalent, these findings underline the need for interventions aimed at preventing the occurrence of interpersonal conflicts at work, or at least reducing the harmful effects on both the employee and the organization.

\section{REFERENCES}

1. Appelberg $\mathrm{K}$, Romanov $\mathrm{K}$, Heikkilä $\mathrm{K}$, Honkasalo ML, Koskenvuo M. Interpersonal conflict as a predictor of work disability: a follow-up study of 15,348 Finnish employees. J Psychosom Res. 1996;40(2):157-67.

2. Spector PE, Jex SM. Development of four self-report measures of job stressors and strain: Interpersonal Conflict at Work Scale, Organizational Constraints Scale, Quantitative Workload Inventory, and Physical Symptoms Inventory. J Occup Health Psychol. 1998;3(4):356-67.

3. Narayanan L, Menon S, Spector P. A cross-cultural comparison of job stressors and reactions among employees hoiding comparable jobs in five countries. Int $J$ Stress Manage. 1999;6(3):197-212.

4. Keenan A, Newton TJ. Stressful events, stressors, and psychological strains in young professional engineers. J Occup Behav. 1985;6:151-6.

5. Fortunato $\mathrm{VJ}$, Harsh J. Stress and sleep quality: The moderating role of negative affectivity. Pers Indiv Differ. 2006;41(5):825-36. 
Interpersonal conflicts as predictor of health and occupational mobility

6. Nakata A, Haratani $T$, Takahashi $M$, Kawakami $N$, Arito $H$, Kobayashi $F$, et al. Job stress, social support, and prevalence of insomnia in a population of Japanese daytime workers. SoC Sci Med. 2004;59(8):1719-30.

7. Appelberg $\mathrm{K}$, Romanov $\mathrm{K}$, Honkasalo ML, Koskenvuo M. The use of tranquilizers, hypnotics and analgesics among 18,592 Finnish adults - Associations with recent interpersonal conflicts at work or with a spouse. $J$ Clin Epidemiol. 1993;46(11):1315-22.

8. Romanov K, Appelberg K, Honkasalo ML, Koskenvuo M. Recent interpersonal conflict at work and psychiatric morbidity: A prospective study of 15,530 employees aged 24-64. J Psychosom Res. 1996;40(2):169-76.

9. Fujiwara K, Tsukishima E, Tsutsumi A, Kawakami N, Kishi R. Interpersonal conflict, social support, and burnout among home care workers in Japan. J Occup Health. 2003;45(5):31320.

10. Harvey $S$, Blouin $C$, Stout D. Proactive personality as a moderator of outcomes for young workers experiencing conflict at work. Pers Indiv Differ. 2006;40(5):1063-74.

11. Spector PE, Dwyer DJ, Jex SM. Relation of job stressors to affective, health, and performance outcomes - a comparison of multiple data sources. I Appl Psychol. 1988;73(1):11-9.

12. Hagerty BM, Williams RA. The effects of sense of belonging, social support, conflict, and Ioneliness on depression. Nurs Res. 1999;48(4):215-9.

13. Frone MR. Interpersonal conflict at work and psychological outcomes: testing a model among young workers. J Occup Health Psychol. 2000;5(2):246-55.

14. Cooper $\mathrm{CL}$, Marshall J. Occupational sources of stress: a review of the literature relating coronary heart disease and mental ill health. J Occup Organ Psychol. 1976;49:11-28.

15. Jehn KA. A multimethod examination of the benefits and detriments of intragroup conflict. Adm Sci Q. 1995;40(2):256-82.

16. Bültmann U, Kant I, Van den Brandt PA, KasI SV. Psychosocial work characteristics as risk factors for the onset of fatigue and psychological distress: Prospective results from the Maastricht Cohort Study. Psychol Med. 2002;32(2):333-45.

17. Rothman KJ, Greenland S. Causation and causal inference in epidemiology. Am J Public Health. 2005;95 Suppl 1:S144-50.

18. Bruk-Lee V, Spector PE. The social stressors-counterproductive work behaviors link: Are conflicts with supervisors and coworkers the same? J Occup Health Psychol. 2006;11(2):14556.

19. Frese $M$, Zapf $D$. Methodological issues in the study of work stress: Objective vs subjective measurement of work stress and the question of longitudinal studies. In: Cooper CL, Payne $\mathrm{R}$, editors. Causes, Coping and Consequences of Stress at Work. Chichester, UK: Wiley; 1988. p. 375-411.

20. Rugulies $R$, Bültmann $U$, Aust $B$, Burr $H$. Psychosocial work environment and incidence of severe depressive symptoms: prospective findings from a 5-year follow-up of the Danish work environment cohort study. Am J Epidemiol. 2006;163(10):877-87.

21. Schuster $T L$, Kessier RC, Aseltine RH. Supportive interactions, negative interactions, and depressed mood. Am J Community Psychol. 1990;18(3):423-38.

22. Kant 1, Bültmann U, Schroer KAP, Beurskens AJHM, Van Amelsvoort LGPM, Swaen GMH. An epidemiological approach to study fatigue in the working population: the Maastricht Cohort Study. Occup Environ Med. 2003;60 Suppl 1:i32-9. 
23. Bültmann U, Kant I, KasI SV, Beurskens AJ, van den Brandt PA. Fatigue and psychological distress in the working population: psychometrics, prevalence, and correlates. J Psychosom Res. 2002;52(6):445-52.

24. Jansen NWH, van Amelsvoort LGPM, Kristensen TS, van den Brandt PA, Kant I. Work schedules and fatigue: a prospective cohort study. Occup Environ Med. 2003;60 Suppl 1:i4753.

25. Kant I, Beurskens AJ, Schroër C, Nijhuis F, van Schayck CP. De Maastrichtse Cohort Studie naar langdurige psychische vermoeidheid in de arbeidssituatie [The Maastricht Cohort Study of prolonged fatigue at work]. Tijdschr Bedr-Verzek Geneeskd (TBV). 2000;8:226-32.

26. Van Veldhoven $M$, Meijman TF. Het meten van psychosociale arbeidsbelasting met een vragenlijst: de vragenlijst beleving en beoordeling van de arbeid (VBBA) [The measurement of psychosocial job demands with a questionnaire (VBBA)]. Amsterdam, NL: Netherlands Institute for the Working Environment NIA-TNO; 1994.

27. Aaronson NK, Muller M, Cohen PD, Essink-Bot ML, Fekkes $M$, Sanderman $R$, et al. Translation, validation, and norming of the Dutch language version of the SF-36 Health Survey in community and chronic disease populations. J Clin Epidemiol. 1998;51(11):105568.

28. Ala-Mursula L, Vahtera J, Kivimäki M, Kevin MV, Pentti J. Employee control over working times: associations with subjective health and sickness absences. $J$ Epidemiol Community Health. 2002;56(4):272-8.

29. Chandola T, Bartley M, Wiggins $R$, Schofield $P$. Social inequalities in health by individual and household measures of social position in a cohort of healthy people. J Epidemiol Community Health. 2003;57(1):56-62.

30. Dalstra JA, Kunst AE, Geurts JJ, Frenken FJ, Mackenbach JP. Trends in socioeconomic health inequalities in the Netherlands, 1981-1999. J Epidemiol Community Health. 2002;56(12):927-34.

31. Manor O, Matthews S, Power C. Dichotomous or categorical response? Analysing self-rated health and lifetime social class. Int J Epidemiol. 2000;29(1):149-57.

32. Van Veldhoven $M$, Broersen $S$. Measurement quality and validity of the "need for recovery scale". Occup Environ Med. 2003;60 Suppl 1:i3-9.

33. de Croon EM, Sluiter JK, Frings-Dresen MH. Psychometric properties of the Need for Recovery after work scale: test-retest reliability and sensitivity to detect change. Occup Environ Med. 2006;63(3):202-6.

34. Bültmann U, de Vries M, Beurskens AJ, Bleijenberg G, Vercoulen JH, Kant I. Measurement of prolonged fatigue in the working population: determination of a cutoff point for the checklist individual strength. J Occup Health Psychol. 2000;5(4):411-6.

35. Vercoulen JH, Swanink CM, Fennis JF, Galama JM, van der Meer JW, Bleijenberg G. Dimensional assessment of chronic fatigue syndrome. J Psychosom Res. 1994;38(5):383-92.

36. Karasek R, Brisson C, Kawakami N, Houtman I, Bongers P, Amick B. The Job Content Questionnaire (JCQ): an instrument for internationally comparative assessments of psychosocial job characteristics. J Occup Health Psychol. 1998;3(4):322-55.

37. Karasek RA. The Job Content Questionnaire and User's Guide (version 1.1). Los Angeles, CA: Department of Industrial and Systems Engineering, University of Southern California; 1985. 
38. Schreurs PJG, van de Willige G, Brosschot JF, Graus GMH. De Utrechtse Coping Lijst: UCL. Omgaan met problemen en gebeurtenissen [The Utrecht Coping List. Coping with problems and events]. Lisse: Swets Test Publishers; 1993.

39. SAS Institute Inc. SAS OnlineDoc® 9.1.2. Cary, NC: Sas Institue Inc.; 2004.

40. SPSS. SPSS Base 13.0. Chicago, III: SPSS Inc.; 2005.

41. StataCorp. Stata Statistical Software: Release 9.2. College Station, TX (USA): StataCorp LP; 2006.

42. De Raeve L, Jansen NWH, Van den Brandt $P$, Vasse R, Kant I. Risk factors for interpersonal conflicts at work: Results from a prospective cohort study. Submitted. 2007.

43. Finch JF, Okun MA, Pool GJ, RuehIman LS. A comparison of the influence of conflictual and supportive social interactions on psychological distress. J Pers. 1999;67(4):581-621.

44. Bowling NA, Beehr TA. Workplace harassment from the victim's perspective: A theoretical model and meta-analysis. J App/ Psychol. 2006;91(5):998-1012.

45. Spector $P E$, Zapf $D$, Chen $P Y$, Frese $M$. Why negative affectivity should not be controlled in job stress research: don't throw out the baby with the bath water. J Organ Behav. 2000;21(1):79-95.

46. Barki $\mathrm{H}$, Hartwick J. Interpersonal conflict and its management in information system development. MIS Q. 2001;25(2):195-228.

47. Barki $\mathrm{H}$, Hartwick J. Conceptualizing the construct of interpersonal conflict. Int $\mathrm{J}$ Confl Manage. 2004;15(3):216-44. 


\section{6}

\section{Changes in mental health as a predictor of changes in working time arrangements and occupational mobility: Results from a prospective cohort study}

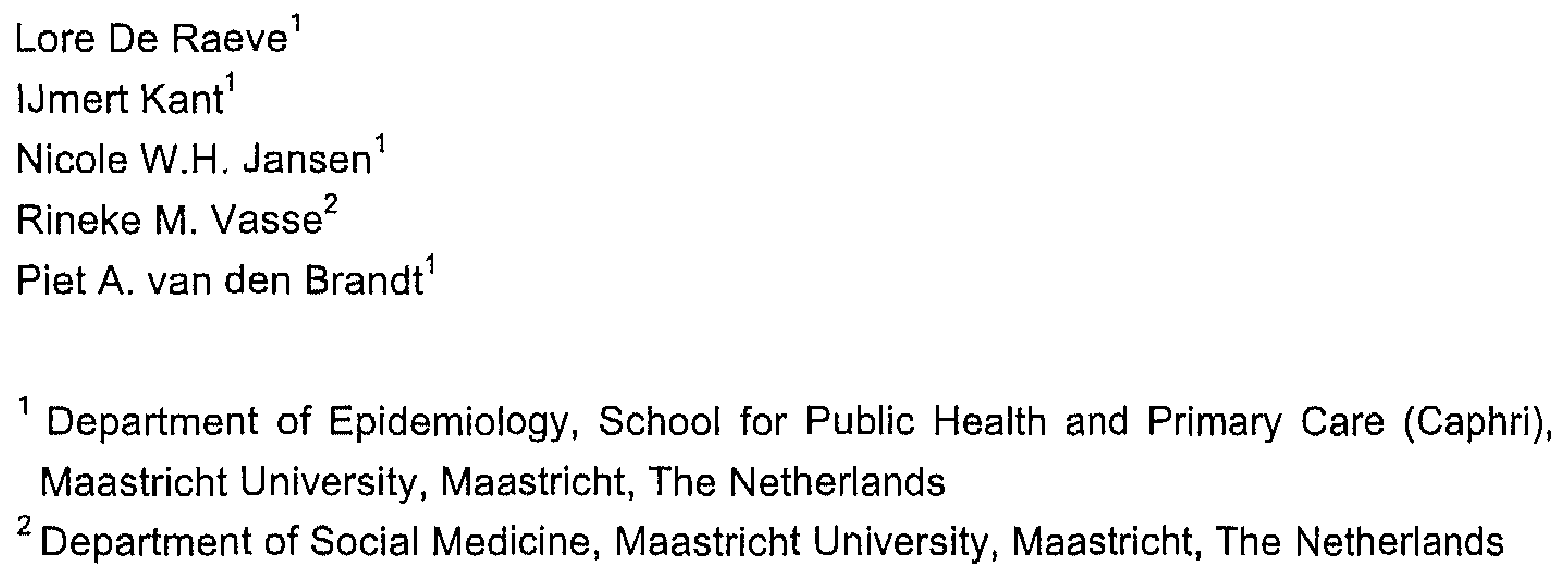




\section{ABSTRACT}

Objectives: The aim of this prospective study was to gain insight into a possible causal relationship between mental health and characteristics of the work situation.

Methods: Using longitudinal data from the Maastricht Cohort Study, this study examines whether deterioration in mental health (prolonged fatigue, need for recovery, and psychological distress) results in a subsequent change in working time arrangements (assessed by means of logistic regression analysis) or occupational mobility (assessed by means of Cox regression analysis).

Results: Compared to employees not experiencing a deterioration in mental health, employees who became a prolonged fatigue case were more likely to reduce their working hours (OR $2.49 ; 95 \% \mathrm{Cl} 1.42-4.35$ ) and leave a shift work job (OR $3.44 ; 95 \% \mathrm{Cl}$ 1.42-8.38). Employees who became a need for recovery case were more likely to reduce their working hours (OR $2.83 ; 95 \% \mathrm{Cl} 1.53-5.26$ ) or change jobs within the company (RR $1.31 ; 95 \% \mathrm{Cl} 1.07-1.61)$. Employees who became a psychological distress case were more likely to change jobs within the company (RR 1.38; $95 \% \mathrm{Cl} 1.16-1.65$ ) or to change jobs from one employer to another (RR $1.45 ; 95 \% \mathrm{Cl} 1.03-2.03$ ).

Conclusions: The results of this study provide evidence for a possible causal relationship between deterioration in mental health and subsequent change in working time arrangements or occupational mobility. These results suggest that workers adapt to the onset of a mental health problem by reducing their working hours, by leaving a shift work job, by changing jobs within the company, or by changing jobs from one employer to another. 


\section{INTRODUCTION}

Mental health problems are a major problem in the working population and are a leading cause of sickness absence and work disability. Several characteristics of the work situation, such as working time arrangements ${ }^{1-3}$, psychosocial work characteristics ${ }^{4-6}$, interpersonal conflicts at work ${ }^{7,8}$, and job mobility ${ }^{9}$, have previously been associated with mental health. The majority of studies examining the relationship between characteristics of the work situation and mental health is based on a cross-sectional design. Consequently, no causal conclusions can be drawn. Existing longitudinal research within the field of occupational health tried to provide evidence for a causal relationship between characteristics of the work situation and mental health, thereby mainly focusing on the so-called normal causal relationship, i.e., how do characteristics of the work situation affect mental health over time ${ }^{1,10}$ ? The reversed relationship, i.e., how does mental health influence the work situation, has hardly been examined so far ${ }^{11}$. ${ }^{12}$. Insight into this relationship may, however, provide valuable information for preventive strategies in the workplace as well as for human resource policies.

The onset of poor mental health may have different effects on employment decisions and turnover of workers. After a health problem emerges, employees may leave the labor force through, for example, unemployment, early retirement, or work disability. However, they may also remain in the labor force and find ways to change the work situation itself in an attempt to adapt to their changed health status. Existing research has mainly focused on individuals leaving the labor force because of ill health ${ }^{13-15}$. Far less research has been conducted on changes in the work situation itself as a result of deteriorated health. Employees may, for example, reduce the amount of working hours or change jobs or employers. A study of Van Amelsvoort et al. ${ }^{16}$ found that poor mental health was associated with an increased risk of leaving a shift work job. A previous study of Swaen et al. ${ }^{9}$, on the contrary, found no significant differences in baseline mental health between employees who did and those who did not change jobs from one employer to another in a one-year follow-up period.

To be able to examine the impact of mental health on characteristics of the work situation, a large sample of employees is needed in which both characteristics of the work situation and mental health are measured repeatedly over time. Moreover, a prerequisite for examining causality is that the change in exposure is measured before the actual change in the outcome ${ }^{17}$. Consequently, a change in mental health needs to be measured before the change in the work situation. Furthermore, it needs to be taken into account that effects may be different depending on both the mental health measures and the characteristics of the work situation studied. Therefore, different measures of both work characteristics and mental health were considered in this study. Mental health 
was assessed using measures of prolonged fatigue, need for recovery, and psychological distress. For example, it might be that people suffering from psychological distress are more likely to adjust their work situation than when they suffer from an elevated need for recovery. Moreover, different outcomes were studied that might react differently in the course of time, i.e., working time arrangements (working hours and work schedule) and occupational mobility (changing jobs and changing employers). For example, when trying to adapt to their deteriorated health, people may weigh up several options against each other. They might then tend to change their working time arrangements rather quickly in response to a deterioration in mental health, whereas it might take longer to actually decide to change jobs because of a change in mental health, possibly because the latter is a more radical change. Therefore, when studying the effects of changes in mental health on changes in the work situation, one also has to consider the time lag that is needed to detect the effects. When chosen time lags are too small, the effect may not have occurred yet. Long time lags on the other hand run the risk of resulting in an underestimation of the actual effect, because it is possible that initial effects have already taken place in an earlier stage and only residual effects are measured. Finally, the net effect of a change in health can only be determined by controlling for possible confounding factors that have shown to be associated with both exposure and outcome, such as demographics and other work characteristics.

Taking into account the above methodological and conceptual considerations, the aim of this prospective study was to gain insight into a possible causal relationship between mental health on the one hand and working time arrangements and occupational mobility on the other. Therefore, this study examines whether deterioration in mental health (prolonged fatigue, need for recovery, and psychological distress) between baseline and one-year follow-up subsequently results in a reduction of working hours per week, a change in work schedule from shift work to day work, a change in job function within the company, or a job change from one employer to another after the first year of follow-up, while controlling for potential confounding factors.

\section{METHODS}

\section{Design}

This study is based on data from the Maastricht Cohort Study, a prospective study on fatigue at work ${ }^{18}$, in which employees from 45 different companies (both blue-collar and white-collar jobs) were followed by means of self-administered questionnaires, which they received at four-month intervals. Once a year, in May, employees received an extensive questionnaire with items on work and non-work-related factors, demographics, and health factors. Twice a year (in September and in January), employees received a 
short questionnaire, capturing mainly outcome measures. In May 1998, the baseline questionnaire was sent out to 26,978 employees. Altogether, 12,161 employees completed and returned the baseline questionnaire (response rate of $45 \%$ ). Twenty-one questionnaires were excluded from analysis because of technical reasons. The baseline (TO) cohort thus consisted of 12,140 people. Details on non-response, the procedure, and sectors and trades represented in the Maastricht Cohort Study have been reported elsewhere ${ }^{18-21}$. Employees who had completed the baseline questionnaire and at least one of the following two short questionnaires ( $\mathrm{T} 1$ and/or $\mathrm{T} 2$ ) received the one-year follow-up questionnaire (T3) in May 1999 (response rate $79.5 \%, n=9655$ ). The employees who returned the questionnaire at $\mathrm{T} 3$ and at least one of the consecutive short questionnaires (T4 and T5) also received the extensive questionnaire (T6) in May 2000 (response rate $66.5 \%, n=8070$ ). Employees returning the T6 questionnaire also received the short questionnaire $T 7$ in September (response rate $63.1 \%, n=7662$ ) and the final T8 questionnaire in January 2001 (response rate $61.6 \%, n=7482$ ).

Changes in mental health were assessed between baseline (TO) and one-year follow-up (T3). In order to adapt to a deterioration in mental health, employees might change their working time arrangements. In this study, we particularly looked at changes in working hours and work schedule, which were assessed between one-year follow-up (T3) and two-year follow-up (T6). Employees might also change jobs in order to adapt to a deterioration in mental health. As it might take a longer period of time to actually decide to change jobs because of ill health, the occurrence of occupational mobility was assessed between one-year follow-up (T3) and the measurement at two years and eight months of follow-up (T8).

\section{Study population}

The study population used in this study was determined as follows. Because we wanted to examine the effect of deterioration in mental health between baseline and one-year follow-up, employees for whom at least baseline and one-year follow-up data were available $(n=9655)$ were considered for this study. Moreover, employees with multiple jobs at T0, T3, or T6 $(n=600)$ were excluded, because information about the content and the characteristics of the other job was lacking. Pregnant women at T0, T3, and T6 $(n=215)$ were also excluded from the analyses as they might change their work situation because of pregnancy-related health problems. Finally, for every mental health measure separately, cases at baseline were excluded and only non-cases were included. Consequently, three study populations, who were not mutually exclusive, were considered for this study, consisting of 6827 employees for the analyses with respect to the effect of prolonged fatigue, 5897 for need for recovery, and 6828 for psychological distress. Baseline characteristics of these study populations are presented in Table 1. 


\section{Measures}

Deterioration in mental health

Deterioration in mental health was defined as a change from non-caseness at To to caseness at T3 on three mental health measures: need for recovery, prolonged fatigue, and psychological distress. The need for recovery from work was assessed using an 11item scale from the Dutch Questionnaire on the Experience and Evaluation of Work [Dutch abbreviation, VBBA] ${ }^{22-24}$. The items represent short-term effects of a day of work. The total score ranged from 0 to 100 (Cronbach's alpha .78). In line with Broersen et al. ${ }^{25}$ a cut-off point of 6 on the 11-item scale was used for case classification. This cut-off point corresponds with a score of 54 on the total need for recovery scale, which also corresponds with a cut-off point based on the upper tertile of the need for recovery scale in the Maastricht Cohort Study. Prolonged fatigue was measured with the 20-item selfreported Checklist Individual Strength (CIS), which has been described extensively elsewhere ${ }^{26,27}$. A composite CIS-total score, ranging from 20 to 140 (Cronbach's alpha .93), was constructed by adding the item scores. A cut-off point of CIS total $>76$ was used for case classification. This cut-off point was established in a separate pilot study by means of defined samples with differences in fatigue levels ${ }^{26}$. Persons scoring $>76$ on the CIS-total were designated as probable cases of prolonged fatigue. Psychological distress was measured using the 12-item version of the General Health Questionnaire $(\mathrm{GHQ})^{28,29}$. Employees scoring four or more on the $12 \mathrm{GHQ}$ - items were considered to be probable cases of psychological distress ${ }^{30}$.

Changes in working time arrangements

A change in working hours was defined as a change from $\geq 36$ hours per week at $T 3$ to $<36$ hours per week at T6. A change in work schedule was defined as a change from shift work at T3 to day work at T6. In this study, day work captured normal working hours between 7 am and $7 \mathrm{pm}$. Shift work was defined as three-shift, four-shift, five-shift or irregular shift work, all including frequent night work.

Occupational mobility

Occupational mobility was divided into internal mobility and external mobility. Internal mobility was defined as a job change within the company and was assessed every four months with one item asking employees whether they changed their job function in the past four months (no/yes). External mobility was defined as a change in jobs from one employer to another and was assessed every four months with one item asking employees whether they changed employers in the past four months (no/yes).

\section{Confounding factors}

Information on gender, age (continuous), and educational level was obtained through self-report in the baseline questionnaire. Educational level was measured according to 
the highest level of education the person completed and was recoded in three categories: low (primary and lower vocational school), medium (lower secondary school, intermediate vocational school, and secondary school), and high (higher vocational school and university). Because psychosocial work characteristics may both be associated with a change in mental health between TO and T3, and may also cause employees to change their working time arrangements or to change jobs, we controlled for psychological job demands, decision latitude, and co-worker and supervisor social support at T3. These psychosocial work characteristics were measured with a Dutch version of the Job Content Questionnaire ${ }^{31,32}$. Psychological job demands were assessed by the sum of five items (Cronbach's alpha .69). Decision latitude (Cronbach's alpha 0.81 ) was measured by the sum of the following two subscales: skill discretion and decision authority. Response options on the two scales varied from strongly agree to strongly disagree on a four-point scale. Social support was assessed by the following two scales, each consisting of four items: supervisor support (Cronbach's alpha 0.85) and co-worker support (Cronbach's alpha 0.75).

\section{Statistical analysis}

The effects of deteriorated health on changes in working time arrangements were assessed by means of logistic regression analyses. The effects on occupational mobility were assessed by means of Cox regression analyses.

Logistic regression analyses

When examining the effect of deterioration in mental health between T0 and T3 on reduction of working hours from $\geq 36$ hours per week at $T 3$ to $<36$ hours per week at T6, only employees working $\geq 36$ hours at $\mathrm{T} 3$ were included in the analyses. When examining the effect of deterioration in mental health between TO and T3 on a change from shift work at T3 to day work at T6, only employees doing shift work at T3 were included in the analyses. Logistic regression analyses were conducted and odds ratios (OR) and $95 \%$ confidence intervals $(95 \% \mathrm{Cls})$ were calculated. In all the analyses, the reference group consisted of employees not being a case of the mental health measure at both TO and T3. In the analyses, we controlled for age, gender, and education at baseline, and for psychological job demands, decision latitude, and co-worker and supervisor social support at T3. The analyses were additionally corrected for baseline working hours and baseline work schedule respectively to account for any previous changes in working hours or work schedule. When studying the effect on working hours, we additionally controlled for work schedule at $T 3$ and $T 6$, to rule out the possibility that a change in working hours was actually merely the result of a change in work schedule. 
Cox regression analyses

When examining the effect of deterioration in mental health between T0 and T3 on internal mobility (a change in job function within the company) between T3 and T8, all employees reporting internal mobility between TO and T3 were excluded from the analyses. When examining the effect on external mobility (changing jobs from one employer to another) between $\mathrm{T} 3$ and $\mathrm{T} 8$, all employees reporting external mobility between TO and T3 were excluded from the analyses. Multivariate survival analyses using Cox regression were performed, in which we modeled the time to first job change at $T 4, T 5, T 6, T 7$, or T8. In all the analyses, the reference group consisted of employees not being a case of the mental health measure at both TO and T3. Relative risks (RRs) and $95 \% \mathrm{Cls}$ were calculated for both internal and external mobility, adjusted for age, gender, education, psychological job demands, decision latitude, and co-worker and supervisor support. All analyses were performed using the SPSS 13.0 statistical packages ${ }^{33}$.

\section{RESULTS}

\section{Frequency of changes in mental health}

Because cases of the respective mental health outcomes at baseline were excluded, three study populations were considered for this study, consisting of 6827 employees for prolonged fatigue, 5897 for need for recovery, and 6828 for psychological distress. Within these three groups, there were $807(12 \%)$ incident cases of prolonged fatigue, $774(14 \%)$ incident cases of need for recovery, and $961(14.2 \%)$ incident cases of psychological distress after one year of follow-up (T3).

\section{Effects of deterioration in mental health on changes in working time arrangements}

Table 2 shows that, after correction for possible confounders, becoming a fatigue case significantly predicted a reduction of working hours per week from $\geq 36$ to $<36$ hours per week (OR 2.49; $95 \% \mathrm{Cl} 1.42-4.35$ ). Moreover, becoming a need for recovery case also predicted a reduction of working hours to $<36$ hours per week (OR $2.83 ; 95 \% \mathrm{Cl} 1.53$ $5.26)$. Becoming a psychological distress case was not significantly associated with a reduction of working hours. 
Changes in mental health predict changes in work situation

Table 1 Baseline characteristics of the study populations for prolonged fatigue, need for recovery, and psychological distress and frequency of changes in mental health between $\mathrm{T} 0$ and $\mathrm{T} 3$

\begin{tabular}{|c|c|c|c|}
\hline & $\begin{array}{l}\text { Prolonged } \\
\text { fatigue } \\
\text { no case To }\end{array}$ & $\begin{array}{l}\text { Need for } \\
\text { recovery } \\
\text { no case To }\end{array}$ & $\begin{array}{l}\text { Psychological } \\
\text { distress } \\
\text { no case To }\end{array}$ \\
\hline \multicolumn{4}{|l|}{ Baseline (TO) characteristics } \\
\hline Total, $n$ & 6827 & 5897 & 6828 \\
\hline Male, $n(\%)$ & $5128(75.1)$ & $4352(73.8)$ & $5198(76.1)$ \\
\hline Age, mean (SD) & $41.58(8.70)$ & $41.59(8.72)$ & $41.72(8.70)$ \\
\hline \multicolumn{4}{|l|}{ Education, $n(\%)$} \\
\hline Low & $1219(18.4)$ & $1059(18.5)$ & $1246(18.7)$ \\
\hline Medium & $3020(45.5)$ & $2651(46.2)$ & $3008(45.3)$ \\
\hline High & $2399(36.1)$ & $2022(35.3)$ & $2398(36.0)$ \\
\hline \multicolumn{4}{|c|}{ Frequency of changes in mental health between $T 0$ and $T 3, n(\%)$} \\
\hline Incident cases of prolonged fatigue at $\mathrm{T3}$ & $807(12.0)$ & & \\
\hline Incident cases of need for recovery at T3 & & $774(14.0)$ & \\
\hline Incident cases of psychological distress at T3 & & & $961(14.2)$ \\
\hline
\end{tabular}

Table 2 Effect of deterioration in mental health between T0 and T3 on change in working hours between $\mathrm{T} 3$ and $\mathrm{T} 6$

\begin{tabular}{|c|c|c|c|c|c|}
\hline \multirow[b]{2}{*}{ Deterioration in health } & \multicolumn{5}{|c|}{ Change in working hours from $\geq 36 \mathrm{hrs} / \mathrm{wk}$ at $\mathrm{T} 3$ to $<36 \mathrm{hrs} / \mathrm{wk}$ at $\mathrm{T} 6$} \\
\hline & $\mathrm{n}$ & $\mathrm{OR}^{\mathrm{a}}[95 \% \mathrm{Cl}]$ & $\mathrm{OR}^{\mathrm{b}}[95 \% \mathrm{Cl}]$ & $\mathrm{ORc}[95 \% \mathrm{Cl}]$ & $\mathrm{ORd}[95 \% \mathrm{Cl}]$ \\
\hline \multicolumn{6}{|l|}{ Prolonged fatigue } \\
\hline TO: no case; T3: no caset & 104 & 1.00 (ref) & 1.00 (ref) & 1.00 (ref) & 1.00 (ref) \\
\hline TO: no case; T3: case & 25 & $2.47[1.51-4.06]$ & 2.28 [1.38-3.77] & $2.34[1.39-3.93]$ & $2.49[1.42-4.35]$ \\
\hline \multicolumn{6}{|l|}{ Need for recovery } \\
\hline TO: no case; T3: no case ${ }^{\dagger}$ & 75 & 1.00 (ref) & 1.00 (ref) & 1.00 (ref) & 1.00 (ref) \\
\hline T0: no case; T3: case & 28 & $2.12[1.26-3.56]$ & $2.19[1.29-3.69]$ & $2.55[1.46-4.46]$ & $2,83[1,53-5,26]$ \\
\hline \multicolumn{6}{|l|}{ Psychological distress } \\
\hline TO: no case; T3: no case ${ }^{\dagger}$ & 109 & 1.00 (ref) & 1.00 (ref) & 1.00 (ref) & 1.00 (ref) \\
\hline TO: no case; T3: case & 23 & $1.36[0.80-2.31]$ & $1.30[0.76-2.22]$ & $1.25[0.72-2.18]$ & $1.32[0.74-2.39]$ \\
\hline
\end{tabular}

${ }^{a}$ unadjusted $^{b}$ adjusted for gender, age, and education; ${ }^{c}$ additionally adjusted for psychological job demands, decision latitude, co-worker and supervisor social support T3; ${ }^{\mathrm{d}}$ additionally adjusted for work schedule (day work vs. shift work) T3 and T6, and working hours T0

${ }^{\dagger}$ Reference group

Table 3 shows that a change in work schedule from shift work to day work was significantly predicted by increased levels of fatigue, even after correction for gender, age, education, psychosocial work characteristics, and work schedule at TO (OR 3.44; $95 \% \mathrm{Cl} 1.42-8.38$ ). Becoming a need for recovery or a psychological distress case was also associated with higher odds of changing from shift work to day work, but these results were not significant. 
Table 3 Effect of deterioration in mental health between TO and T3 on change in work schedule between $\mathrm{T} 3$ and $\mathrm{T} 6$

\begin{tabular}{|c|c|c|c|c|c|}
\hline \multirow[b]{2}{*}{ Deterioration in health } & \multicolumn{5}{|c|}{ Change in work schedule from shift work at $\mathrm{T} 3$ to day work at $\mathrm{T} 6$} \\
\hline & $n$ & $\mathrm{ORa}[95 \% \mathrm{Cl}]$ & $\mathrm{ORv}[95 \% \mathrm{Cl}]$ & $\mathrm{ORc}[95 \% \mathrm{Cl}]$ & $\mathrm{ORd}[95 \% \mathrm{Cl}]$ \\
\hline \multicolumn{6}{|l|}{ Prolonged fatigue } \\
\hline TO: no case; T3: no case ${ }^{\dagger}$ & 85 & 1.00 (ref) & 1.00 (ref) & 1.00 (ref) & 1.00 (ref) \\
\hline T0: no case; T3: case & 18 & $3.56[1.61-7.90]$ & $4.18[1.82-9.64]$ & $3.35[1.38-8.12]$ & 3.44 [1.42-8.38] \\
\hline \multicolumn{6}{|l|}{ Need for recovery } \\
\hline T0: no case; T3: no case ${ }^{\dagger}$ & 65 & 1.00 (ref) & 1.00 (ref) & 1.00 (ref) & 1.00 (ref) \\
\hline T0: no case; T3: case & 14 & $1.35[0.38-4.80]$ & $1.61[0.44-5.93]$ & $1.51[0.39-5.86]$ & $1.36[0.34-5.45]$ \\
\hline \multicolumn{6}{|l|}{ Psychological distress } \\
\hline T0: no case; T3: no caset & 85 & 1.00 (ref) & 1.00 (ref) & 1.00 (ref) & 1.00 (ref) \\
\hline TO: no case; T3: case & 15 & $1.88[0.75-4.72]$ & $2.52[0.97-6.53]$ & $2.22[0.83-5.93]$ & $2.26[0.84-6.04]$ \\
\hline
\end{tabular}

"unadjusted ${ }^{b}$ adjusted for gender, age, and education; ${ }^{\circ}$ additionally adjusted for psychological job demands, decision latitude, and co-worker and supervisor social support $\mathrm{T} 3{ }^{\circ}{ }^{\mathrm{d}}$ additionally adjusted for work schedule TO

${ }^{\dagger}$ Reference group

\section{Effects of deterioration in mental health on occupational mobility}

Table 4 shows that internal job mobility was significantly predicted by increased levels of need for recovery (RR 1.31; $95 \% \mathrm{Cl} 1.07-1.61$ ) and psychological distress (RR 1.38; $95 \% \mathrm{Cl} 1.16-1.65$ ). Table 5 shows that external job mobility was significantly predicted by increased levels of psychological distress (RR 1.45; 95\% Cl 1.03-2.03).

Table 4 Effect of deterioration in mental health between TO and T3 on internal occupational mobility between $\mathrm{T} 3$ and $\mathrm{T} 8$

\begin{tabular}{|c|c|c|c|c|}
\hline \multirow[b]{2}{*}{ Deterioration in health ${ }^{\dagger}$} & \multicolumn{4}{|c|}{ Internal occupational mobility } \\
\hline & $\mathrm{n}$ & $\mathrm{RR}^{\mathrm{a}}[95 \% \mathrm{Cl}]$ & $\mathrm{RR}^{\mathrm{b}}[95 \% \mathrm{Cl}]$ & $\operatorname{RR}^{c}[95 \% \mathrm{Cl}]$ \\
\hline \multicolumn{5}{|l|}{ Prolonged fatigue } \\
\hline TO: no case; T3: no case ${ }^{\dagger}$ & 916 & 1.00 (ref) & 1.00 (ref) & 1.00 (ref) \\
\hline T0: no case; T3: case & 134 & $1.15[0.95-1.40]$ & $1.25[1.02-1.51]$ & $1.18[0.96-1.44]$ \\
\hline \multicolumn{5}{|l|}{ Need for recovery } \\
\hline TO: no case; T3: no case ${ }^{\dagger}$ & 697 & 1.00 (ref) & 1.00 (ref) & 1.00 (ref) \\
\hline T0: no case; T3: case & 139 & $1.37[1.12-1.66]$ & $1.44[1.19-1.76]$ & $1.31[1.07-1.61]$ \\
\hline \multicolumn{5}{|l|}{ Psychological distress } \\
\hline T0: no case; T3: no caset & 849 & 1.00 (геf) & 1.00 (ref) & 1.00 (ref) \\
\hline TO: no case; T3: case & 188 & $1.43[1.20-1.70]$ & $1.46[1.23-1.74]$ & $1.38[1.16-1.65]$ \\
\hline
\end{tabular}

${ }^{a}$ unadjusted; ${ }^{b}$ adjusted for gender, age, and education; ${ }^{c}$ additionally adjusted for psychological job demands, decision latitude, co-worker and supervisor social support T3

${ }^{\dagger}$ Reference group 
Table 5 Effect of deterionation in mental peath between TO and T3 on external oncupatonal mobohty between 13 and 18

\begin{tabular}{|c|c|c|c|c|}
\hline \multirow[b]{2}{*}{ Debroraton m heath } & \multicolumn{4}{|c|}{ 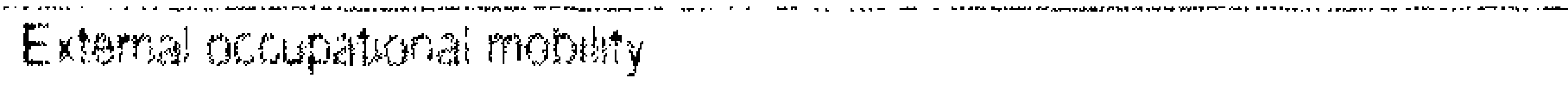 } \\
\hline & $n$ & 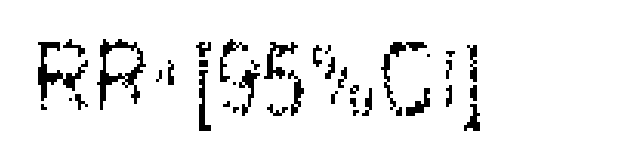 & $P R \cdot 195: 24$ & 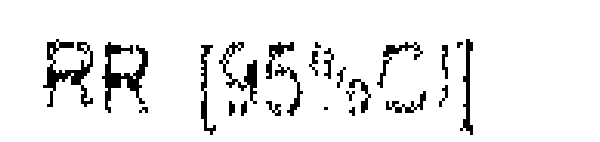 \\
\hline \multicolumn{5}{|l|}{ Proworyed ratguas } \\
\hline T0 no case. T3 no casser & 299 & $100 \log )$ & 100 (reft) & 100 (ref) \\
\hline To no case 13 caser & 42 & $136(0.94+97)$ & $152[105221]$ & $131[089+91]$ \\
\hline \multicolumn{5}{|l|}{ Need for reconery } \\
\hline To no cate T3 no base' & 192 & $100($ ref $)$ & $100(r 01)$ & $1.00 i r e f$ \\
\hline To no case To casse & 38 & $12110.82 \times 781$ & $131[089.92]$ & $1.18[079+16]$ \\
\hline \multicolumn{5}{|l|}{ Psychologione distress } \\
\hline To. no case. T3 no casse' & 226 & $1.00(\mathrm{ref})$ & $100(104)$ & $100(r e f)$ \\
\hline To no case T3 case & 52 & $1.52\lfloor 1092.11 !$ & $1.54[1.11 .215]$ & $1.45[1.03203]$ \\
\hline
\end{tabular}

\section{DISCUSSION}

The results of this study provide evidence for a longitudinal relationship between deterioration in mental health and subsequent change in working time arrangements or occupational mobility. The results of this study suggest that workers try to adapt to the onset of a mental health problem by reducing their working hours, by leaving a shift work job, by changing jobs within the company, or by changing jobs from one employer to another. As expected, different effects were found depending on the mental health concepts studied. Compared to employees not experiencing a deterioration in mental health, employees who became a need for recovery case were more likely to reduce their working hours or change jobs within the company. Employees who became a fatigue case were more likely to reduce their working hours and leave a shift work job. And employees who became a psychological distress case were more likely to change jobs within the company as well as to change jobs from one employer to another. This might have something to do with the nature of the concept and the seriousness of the complaints involved. With respect to need for recovery and prolonged fatigue, it seems that more short-term solutions are being sought, whereas more permanent, structural solutions are being sought with respect to psychological distress. For further research and prevention, the effects of a wide range of health measures may be studied as different health concepts may have different effects. 


\section{Time lag}

In this study, we examined the effects of deterioration in mental health between baseline and one-year follow-up on change in working time arrangements between one- and twoyear follow-up. It is, however, possible that this time period does not exactly match the time needed for a change in health to establish the strongest effect ${ }^{34}$. It is possible that employees have to be ill for several months before they decide to change their work situation. Employees becoming a case rather quickly after baseline and still being a case at one-year follow-up may then decide to reduce their working hours. It is also possible that, for employees whose health was already deteriorating rather quickly after baseline, changes in the work situation may have already set in before our one-year follow-up measurement (T3). Because we wanted to unravel the relationship in time, we excluded employees who, for example, already worked $<36$ hours per week at T3. Although these people may have already changed their work because of ill health, they were excluded from the analyses to enable us to actually separate a change in exposure from a change in the outcome over time. Consequently, the results of this study may be an underestimation of the actual effects of mental health on work.

\section{Specific subgroups and confounders}

When considering the effects of changes in health status, one might wonder whether the effects are different for certain subgroups, such as chronically ill patients. In preliminary analyses, we examined interaction effects with gender, the presence of a long-term illness, and sickness absence, but as none of these interactions was significant, the analyses in this study were not stratified for any of these factors. We then considered these factors as possible confounders. We examined whether correcting for the presence or the onset of a long-term illness caused a relevant $(>10 \%)$ change in the regression coefficients, but as they did not, the correction for long-term illness was left out of the analyses. The correction for gender was retained. Additionally, we did not correct for sickness absence in this study as this might eliminate the difference between people with deteriorated health who did and those who did not report sick from work.

In this study, we examined the effects of becoming ill (i.e., becoming a case of a particular mental health measure), irrespective of the cause of this illness. Therefore, we did not correct for changes in psychosocial work characteristics between T0 and T3, such as a change in psychological job demands. Suppose increasing job demands between TO and T3 increase a person's level of fatigue. Correcting for this change in demands would mean a correction for the cause of becoming ill, thereby reducing part of the effect of deteriorated health on the work situation. Continuing on this, we would have to correct not only for psychological job demands, but also for interpersonal conflicts, work-family conflicts, life events, etc. The question then remains "on the basis of which 
factors are employees allowed to get ill?" We did. however, control for the T3 value of the psychosocial work characteristics because the level of for example, job demands may both be associated with a change in mental health between To and $\mathrm{T} 3$. and may also cause an employee to change the work stuation. We are, however, aware of the fact that even controling for the T3 value is a rather rigid correction which might result in an underestimation of the actual effect of changes in mental health on changes in characteristics of the work situation. Despite the fact that a broad range of possible confounders was carefully considered in this study, the possible existence of unidentfied confounding factors cannot be completely ruled out.

\section{Cut-off points}

Previously established cut-off points for the mental health measures were used in this study 25263 . To ensure that the results were not driven by the chotce of the cut-off points for defining cases of the respective mental health measures, sensitivity analyses using adjacent cut-off points were performed. In general, sensitivity analyses showed that the strength of the effects found in this study was not substantially altered by the choice of the cut-off point. Only when a cut-off point of 7 out of 11 items on the need for recovery was used, the effects on changes in work schedule substantially changed. In that case, becoming a need for recovery case significantly predicted a change from shift work to day work (OR $3.26: 95 \% \mathrm{Cl} 1.31-8.08$ ).

\section{Non-response and selective loss to follow-up}

Although reasonable for survey in a working population ${ }^{35}$, the baseline response of $45 \%$ might raise the question of selective participation which may have threatened the external validity of this study. Non-response analyses at baseline yielded no significant differences between respondents and non-respondents regarding demographic characteristics. Non-respondents were somewhat less likely to report fatigue complaints at baseline ${ }^{18}$. A selective participation of employees could thus not be totally ruled out and one should be careful with generalizing the results of this study to other populations. Additionally, the loss to follow-up over time might raise the question of selective dropout, which may have threatened the internal validity of our results. We examined whether employees whose health deteriorated between baseline (TO) and one-year follow-up (T3) were less likely to respond to the two-year follow-up questionnaire (T6). No significant differences existed between respondents and non-respondents at T6 with respect to becoming a case on the need for recovery or the psychological distress scale between TO and T3. Employees becoming a prolonged fatigue case between TO and T3 were. however, somewhat less likely to respond to the questionnaire at T6. As employees becoming fatigued between TO and T3 have a higher probability of changing their work 
situation. the results might be an underestmation of the actual effect of increasing levels of fatigue on changes in working time arrangements and occupational mobilty.

\section{Strengths}

Although the above considerations need to be taken into account when interpreting the results, the strengths of the study should be mentioned as well. This study was based on longitudinal data from a large sample of employees, with repeated measurements on work conditions and mental health. Looking at reversed causality, this study turns over the usual sequence investigated in previous studies. It examines whether mental health influences characteristics of the work stuation by separating change in exposure (deteroration in mental health) from change in the outcome (changes in the work situationj over time using relatively short time intervals, and taking into account several possible confounding factors. As this study found relatively large and statistically significant effects of changes in mental health on changes in working time arrangements and occupational mobility over time, we conclude that the results of this study indicate a possible causal relationship between mental health and characteristics of the work. situation

\section{Policy implications}

The results of this study may provide important insights for prevention strategies in the workplace as well as for human resource specialists. So far, transitions in the work situation have been related to characteristics of the job itself, such as salary, learning opportunities, job demands, or work-family conflict. This study shows that mental health also seems to be an important predictor of changes in the work situation. This finding is important for primary prevention strategies, aimed at preventing people from becoming ill, as this may reduce the likelihood of job transitions and job turnover. For occupational health professionals, it is important to regularly assess the mental health of employees in order to be able to detect changes in mental health, as they may be an important predictor of future changes in working time arrangements or may be an antecedent of future occupational mobility. For human resource specialists, it might be interesting to provide employees with the opportunity to change their work situation, to give them information on the possibilities to change, or to provide skills for workers to facilitate a successful change. Providing opportunities to change jobs or change working time arrangements might enable employees to remain in the labor force in stead of leaving it because of deteriorated health. This may become increasingly important for the near future, as with the ageing of the workforce more health problems will probably arise in the working population. For future research, it might be interesting to examine the effects of deteriorated health on the work situation in a sample of older workers. It might also be interesting to examine whether these adaptations to ill health in terms of changing 
working time arrangements or occupational mobility prevent employees from leaving the labor force in the long run.

\section{REFERENCES}

1. De Raeve L, Jansen NWH, Kant 1. Health effects of transitions in work schedule, workhours and overtime in a prospective cohort study. Scand J Work Environ Health. 2007;33(2):10513.

2. Harrington JM. Shift work and health--a critical review of the literature on working hours. Ann Acad Med Singapore. 1994;23(5):699-705.

3. Sparks $K$, Cooper $C$, Fried $Y$, Shirom A. The effects of hours of work on health: A metaanalytic review. J Occup Organ Psych. 1997;70:391-408.

4. Van der Doef M, Maes S. The Job Demand-Control(-Support) model and psychological wellbeing: a review of 20 years of empirical research. Work Stress. 1999;13(2):87-114.

5. de Lange AH, Taris TW, Kompier MA, Houtman IL, Bongers PM. "The very best of the millennium": longitudinal research and the demand-control-(support) model. $J$ Occup Health Psychol. 2003;8(4):282-305.

6. Stansfeld S, Candy B. Psychosocial work environment and mental health - a meta-analytic review. Scand J Work Environ Health. 2006;32(6):443-62.

7. Hagerty BM, Williams RA. The effects of sense of belonging, social support, conflict, and loneliness on depression. Nurs Res. 1999;48(4):215-9.

8. Romanov K, Appelberg K, Honkasalo ML, Koskenvuo M. Recent interpersonal conflict at work and psychiatric morbidity: A prospective study of 15,530 employees aged 24-64. J Psychosom Res. 1996;40(2):169-76.

9. Swaen GM, Kant IJ, van Amelsvoort LG, Beurskens AJ. Job mobility, its determinants, and its effects: longitudinal data from the Maastricht Cohort Study. J Occup Health Psychol. 2002;7(2):121-9.

10. De Raeve $L$, Vasse RM, Jansen NWH, van den Brandt $P$, Kant I. Mental health effects of changes in psychosocial work characteristics: a prospective cohort study. $J$ Occup Environ Med. 2007;49:890-9.

11. Kalimo R. Reversed causality--a need to revisit systems modeling of work-stress-health relationships. Scand J Work Environ Health. 2005;31(1):1-2.

12. Zapf $D$, Dormann $C$, Frese $M$. Longitudinal studies in organizational stress research: a review of the literature with reference to methodological issues. $J$ Occup Health Psychol. 1996;1(2):145-69.

13. Bound JM, Schoenbaum M, Steinbrickner TR, Waidmann $T$. The dynamic effects of health on the labor force transitions of older workers. Labour Economics. 1999;6(2):179-202.

14. Mutchler JE, Burr JA, Massagli MP, Pienta A. Work transitions and health in later life. $J$ Gerontol B Psychol Sci Soc Sci. 1999;54(5):S252-61.

15. Riphahn RT. Income and employment effects of health shocks - A test case for the German welfare state. J Popul Econ. 1999;12(3):363-89.

16. van Amelsvoort LG, Jansen NW, Swaen GM, van den Brandt PA, Kant 1. Direction of shift rotation among three-shift workers in relation to psychological health and work-family conflict. Scand J Work Environ Health. 2004;30(2):149-56. 
17. Rothman KJ, Greenland S. Causation and causal inference in epidemiology. Am J Public Health. 2005;95 Suppl 1:S144-50.

18. Kant 1, Bültmann U, Schroer KAP, Beurskens AJHM, Van Amelsvoort LGPM, Swaen GMH. An epidemiological approach to study fatigue in the working population: the Maastricht Cohort Study. Occup Environ Med. 2003;60 Suppl 1:332-9.

19. Bültmann U, Kant I, KasI SV, Beurskens AJ, van den Brandt PA. Fatigue and psychological distress in the working population: psychometrics, prevalence, and correlates. J Psychosom Res. 2002;52(6):445-52.

20. Jansen NWH, van Amelsvoort LGPM, Kristensen TS, van den Brandt PA, Kant I. Work schedules and fatigue: a prospective cohort study. Occup Environ Med. 2003;60 Suppl 1:i4753.

21. Kant I, Beurskens AJ, Schroër C, Nijhuis F, van Schayck CP. De Maastrichtse Cohort Studie naar langdurige psychische vermoeidheid in de arbeidssituatie [The Maastricht Cohort Study of prolonged fatigue at work]. Tijdschr Bedr-Verzek Geneeskd (TBV). 2000;8:226-32.

22. de Croon EM, Sluiter JK, Frings-Dresen MH. Psychometric properties of the Need for Recovery after work scale: test-retest reliability and sensitivity to detect change. Occup Environ Med. 2006;63(3):202-6.

23. Van Veldhoven $M$, Broersen $S$. Measurement quality and validity of the "need for recovery scale". Occup Environ Med. 2003;60 Suppl 1:i3-9.

24. Van Veldhoven M, Meijman TF. Het meten van psychosociale arbeidsbelasting met een vragenlijst: de vragenlijst beleving en beoordeling van de arbeid (VBBA) [The measurement of psychosocial job demands with a questionnaire (VBBA)]. Amsterdam, NL: Netherlands Institute for the Working Environment NIA-TNO; 1994.

25. Broersen JPJ, Fortuin RJ, Dijkstra L, van Veldhoven M, Prins J. Monitor Arboconvenanten: kengetallen en grenswaarden. Tijdschr Bedr-Verzek Geneeskd (TBV). 2004;12(4):100-4.

26. Bültmann U, de Vries M, Beurskens AJ, Bleijenberg G, Vercoulen JH, Kant I. Measurement of prolonged fatigue in the working population: determination of a cutoff point for the checklist individual strength. J Occup Health Psychol. 2000;5(4):411-6.

27. Vercoulen JH, Swanink CM, Fennis JF, Galama JM, van der Meer JW, Bleijenberg $G$ Dimensional assessment of chronic fatigue syndrome. J Psychosom Res. 1994;38(5):383-92.

28. Goldberg DP, Williams P. The user's guide to the General Health Questionnaire. Windsor, UK: NFER-Nelson; 1991.

29. Koeter MWJ, Ormel J. General Health Questionnaire, Handleiding Nederlandse bewerking [General Health Questionnaire, Manual Dutch version]. Lisse, NL: Swets \& Zeitlinger; 1991.

30. Hardy GE, Shapiro DA, Borrill CS. Fatigue in the workforce of National Health Service Trusts: levels of symptomatology and links with minor psychiatric disorder, demographic, occupational and work role factors. J Psychosom Res. 1997;43(1):83-92.

31. Karasek R, Brisson C, Kawakami N, Houtman I, Bongers P, Amick B. The Job Content Questionnaire (JCQ): an instrument for internationally comparative assessments of psychosocial job characteristics. J Occup Health Psychol. 1998;3(4):322-55.

32. Karasek RA. The Job Content Questionnaire and User's Guide (version 1.1). Los Angeles, CA: Department of Industrial and Systems Engineering, University of Southern California; 1985.

33. SPSS. SPSS Base 13.0. Chicago, III: SPSS Inc.; 2005. 
34. Frese $M$, Zapf $D$. Methodological issues in the study of work stress: Objective vs subjective measurement of work stress and the question of longitudinal studies. In: Cooper $C L$, Payne R, editors. Causes, Coping and Consequences of Stress at Work. Chichester, UK: Wiley; 1988. p. 375-411.

35. Mohren D, Jansen NW, Van Amelsvoort LG, Kant I. An Epidemiological Approach of Fatigue and Work. Experiences from the Maastricht Cohort Study. Maastricht, NL: Programma Epidemiologie van Arbeid en Gezondheid; 2007. 


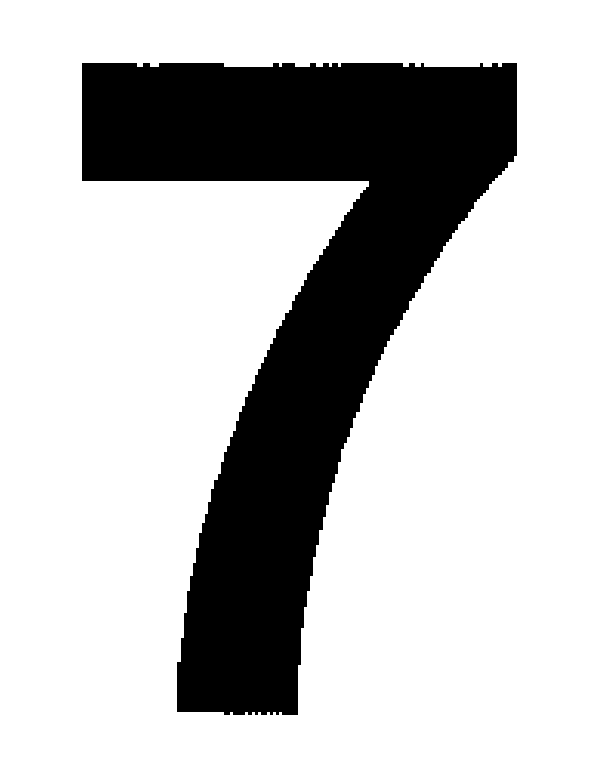

General discussion 


\section{MAIN FINDINGS}

This thesis concerns the relationship between the psychosocial work environment and health and well-being. Although several studies have previously examined this relationship, there is still a lack of clarity concerning their causal relationship 1,2 . However, insight into this causal relationship is indispensable for designing and implementing prevention and intervention strategies in the workplace. The general aim of this thesis was to gain more insight into a possible causal relationship between the psychosocial work environment and mental health and well-being by studying changes in psychosocial work characteristics and changes in mental health and well-being over time.

This thesis shows that changes in the psychosocial work environment are highly prevalent and have a considerable impact on health and well-being of employees. Results show that changes in working time arrangements are associated with changes in self-reported health outcomes. For example, a change from day work to shift work is associated with increased levels of prolonged fatigue and an increase in working hours is associated with an increase in need for recovery in men. Furthermore, changes in psychological job demands and decision latitude are associated with subsequent changes in need for recovery and prolonged fatigue. For example, an increase in psychological job demands is associated with a subsequent increase in the need for recovery, while an increase in decision latitude is associated with a subsequent decrease in the need for recovery. Additionally, several factors in the work environment, such as work content, working conditions, work relations, and the terms of employment are related to the onset of interpersonal conflicts with co-workers or supervisors. In turn, interpersonal conflicts at work are significant risk factors for the subsequent onset of mental health problems and occupational mobility. Apart from the fact that changes in the psychosocial work environment have a considerable impact on employee health and well-being, reversed relationships are found as well. Changes in mental health also affect subsequent changes in working time arrangements and occupational mobility. Compared to employees not experiencing a deterioration in mental health, employees with deteriorated health are more likely to reduce their working hours, leave a shift work job, or change jobs.

To our knowledge, the approach used in this thesis is quite innovative and unique, and has not been used previously with respect to the psychosocial work environment and mental health and well-being. Consequently, a direct comparison of the results of this thesis with results from previous studies on this subject is hardly possible. Our approach does, however, emphasize the use of a sound methodology in the studies presented in this thesis. Therefore, this chapter starts with an extensive discussion of the 
methodological issues before going into detail as regards the implications for future research and practice.

\section{MetHODOLOGICAL CONSIDERATIONS}

\section{Study population and measurement}

In the introduction chapter of this thesis, it was postulated that, to be able to examine the relationship between changes in the psychosocial work environment and changes in mental health, a large study population was needed with sufficient repeated measurements on both psychosocial work characteristics and mental health and a considerable amount of dynamics in exposure over time.

\section{Sample size}

The Maastricht Cohort Study appeared to be an adequate sample frame as it contained information on the psychosocial work environment and on mental health and well-being of a large group of employees over time. Moreover, the Maastricht Cohort Study contained enough respondents to define sub-samples of the study population in which a particular research question could be optimally studied. For example, when studying the effect of changes in working hours, only employees involved in day work activities were selected. As such, changes in working hours could be studied independently of changes in work schedules. When the effects of changes in the work environment were expected to be different for different subgroups, such as men and women, or for different age groups, the number of respondents and the loss to follow-up over time sometimes did not allow us to stratify for these factors. For example, the effects of interpersonal conflicts at work could only be studied in men, as the number of women appeared to be too limited to conduct a longitudinal analysis.

Non-response and loss to follow-up over time

The baseline response rate of the Maastricht Cohort Study of $45 \%$ and the loss to followup over time might raise the question of selective participation and selective dropout during follow-up, which may threaten the validity of our results. With regard to selective participation, a non-response analysis at baseline revealed no statistically significant differences between respondents and non-respondents on socio-demographic characteristics and general self-reported health ${ }^{3,4}$. The majority perceived their general health as good or excellent. Respondents did, however, report somewhat more fatigue complaints, which might result in an overestimation of the prevalence of fatigue at baseline. The dropout rate at one-year follow-up was about $20.5 \%$ and an additional $13 \%$ dropped out after two year of follow-up. When dropout during follow-up is selective, 
it may threaten the validity of the study results. Selective loss to follow-up occurs when dropouts differ in a systematic way from the remaining participants on important study variables. Selective dropout during follow-up was examined by comparing respondents and non-respondents on their mental health status one year before dropout ${ }^{3,4}$. These analyses revealed that non-respondents at follow-up were somewhat more likely to report mental health complaints, which might result in an underestimation of the incidence of mental health complaints. Moreover, non-respondents during the first year of follow-up were younger and had a lower educational level than respondents. No significant difference was observed with respect to gender. Furthermore, we examined whether deteriorated health between baseline and one-year follow-up predicted dropout at two-year follow-up. Employees who experienced an increase in need for recovery or psychological distress between baseline and one-year follow-up were equally likely to respond to the two-year follow-up questionnaire than those not experiencing a deterioration in health. Employees who became a prolonged fatigue case were, however, somewhat less likely to respond to the two-year follow-up questionnaire. As employees becoming fatigued between T0 and T3 have a higher probability of changing their work situation, the effect of an increase in fatigue on changes in the work situation examined in this thesis, might be an underestimation of the actual effect

\section{Dynamics}

Within the Maastricht Cohort Study, changes in the psychosocial work environment were rather prevalent. Changes in psychological job demands, decision latitude, and interpersonal conflicts with co-workers and supervisors occurred relatively often. Changes in working time arrangements, especially work schedules, were somewhat less prevalent. Therefore, it was necessary to pool the data from two transition periods in order to maximize the number of changes in working time arrangements and hence power and statistical significance of the study. Even after pooling the data, health effects of changes in work schedules could still only be studied in male employees. Because of the limited number of women in shift work jobs in the Maastricht Cohort Study, it was not possible to study the effects of changes in work schedules among women. In addition, changes in mental health were quite prevalent. Depending on the mental health measure studied, 12 to $14 \%$ incident cases were observed. The high prevalence of changes in both the psychosocial work environment and in mental health enabled us to study the mutual relationship between these changes in order to gain more insight into a possible causal relationship between the psychosocial work environment and mental health.

It is important to note, however, that the frequency of change depends on the definition of change. With respect to changes in working time arrangements, changes in interpersonal conflicts, or changes in mental health, a more or less clear-cut definition of change was applied. For example, a change in work schedule was defined as a change between day work and shift work. A change in mental health was defined as a change 
from non-caseness to caseness on a mental health measure. With respect to changes in demands and decision latitude, different definitions of change could have been applied. In our study, a change in demands was defined as the difference between the continuous score at T3 and the continuous score at T0, both continuous scores having a range from 12 to 48 . Consequently, even a small change in demands was defined as a change, which resulted in a relatively large number of employees experiencing changes in demands. When using the continuous change score, the effects were rather small. Defining change as a decrease or increase of at least one standard deviation on the total scale or as a change from the lowest to the highest tertile of the scale resulted, in the Maastricht Cohort Study, in lower frequencies of changes with larger effects. When studying changes, the definition of change should be carefully considered, as it influences the strength of the effects found and the interpretation of the results.

\section{Measurement of the variables in this study}

All variables in this study were measured by means of questionnaire data. The findings could thus reflect common method variance, which might have led to an overestimation of the strength of the observed relationships in this study. However, by examining the relationship between intra-individual changes in work and health over time, the influence of common method variance could largely be ruled out. Another potential disadvantage of the use of questionnaire data is that self-reports may be influenced by personality traits ${ }^{5}$. For example, people scoring high on negative affectivity may perceive both their work and their health as more negative, thereby increasing the association between work characteristics and health. There has been vigorous debate concerning the role of negative affectivity in job stress research ${ }^{6}$. In this thesis, the potential influence of personality traits, like negative affectivity, was largely reduced in the prospective analyses when intra-individual changes in both exposure and outcome were studied, while correcting for baseline outcome ${ }^{7,8}$.

Furthermore, because we only used questionnaire data to examine the relationships in this thesis, the measures, which included both objective and subjective factors, are actually measured in a subjective way. According to Frese and Zapf ${ }^{9}$, the term subjective depends on whether or not cognitive and emotional processing is implicated, meaning that any kind of measure can be placed on the dimension 'low on cognitive and emotional processing' to 'high on cognitive and emotional processing'. In this thesis, we used exposure and outcome measures representing both ends of the continuum. For example, psychological job demands or decision latitude are subjective work-related factors, expressing the perceived demands or control at work. Working time arrangements on the other hand, such as weekly working hours or working in shifts may reflect a more objective part of the work environment in the sense that they are less dependent on an individual's cognitions and emotions ${ }^{9}$. Different operationalizations of mental health and occupational mobility were studied as outcome measures in this 
thesis. While mental represents a more subjectively experienced outcome, occupational mobility should be interpreted as a more objective outcome.

\section{Time frame}

\section{Changes in exposure and outcome}

In this thesis, changes in the psychosocial work environment were measured over a period of one year from baseline to one-year follow-up. In the Maastricht Cohort Study, items regarding the psychosocial work environment were only included in the questionnaires that were sent out annually. Therefore, changes in work environment could only be assessed with an interval of one year. Consequently, it was not possible to assess the exact time at which the work environment changed. For certain work characteristics, such as psychological job demands, there might have been a more gradual change over the one-year follow-up period. For other work characteristics, such as working time arrangements, the change probably occurred at a particular time during follow-up. Shorter time intervals for measuring the change in the work environment might have given more insight into the exact onset and duration of the changes. Depending on the outcome studied, effects may occur earlier or later in the course of time. Mental health outcomes and occupational mobility were assessed every four months during follow-up, which enabled us to look at changes in these outcome measures within a relatively short period of time. Effects on need for recovery seemed to occur more quickly than the effects on prolonged fatigue. Moreover, effects on mental health outcomes seemed to develop earlier than the effects on occupational mobility. This may be because the former is a perceived change, while the latter most probably represents an actual change which requires employees to pursue concrete action to change their work situation. This may be perceived as rather drastic or radical.

\section{Sequence of exposure and outcome}

A prerequisite for examining causality is that the change in exposure takes place before a change in the outcome ${ }^{10,11}$. Most studies presented in this thesis succeeded in separating the change in exposure from a change in the outcome over time by examining changes in exposure within one year of follow-up and changes in the outcome in the following year. In order to realize this, a rather conservative approach was used in this thesis. The effects of changes in the work environment between TO and T3 on subsequent changes in self-reported health outcomes (e.g. between T3 and T6) were studied while excluding prevalent cases of the outcome at T3 or while controlling for the T3 level of the outcome. So although there may have already been an effect on T3, this effect was controlled for. For example, although the onset of a conflict between TO and T3 was associated with more health problems at T3 compared to employees not reporting any conflict, all prevalent cases of the health outcomes were excluded at T3 and incident cases of the outcome were studied until T6. Although this approach is 
adequate for effectively separating a change in exposure from a change in the outcome over time, it is rather rigorous, which may have resulted in an underestimation of the relationship between changes in the psychosocial work environment and changes in health and well-being.

Time course of cause and effect

In the light of the temporal sequence of cause and effect, the time lag for measuring changes in exposure and changes in the outcomes needs to be considered. Different time lags were applied in the separate studies in this thesis depending on the exposures and outcomes in the separate studies. Overall, large effects were found. As such, it seems that the time lags applied in the separate studies in this thesis were quite adequate. However, this thesis was not able to provide information on the "exact" time frame that should be used in occupational health research. It is possible that the time lags used in this thesis are actually sub-optimal and that the effects found are still an underestimation of the actual effects.

The relationship between changes in working time arrangements and changes in selfreported health was studied within the same period of time, i.e., between baseline and one-year follow-up. As a result of the relatively low number of changes in working time arrangements, it was not possible to study the effect of a change in work schedule or working hours on subsequent changes in self-reported health outcomes. Therefore, they were studied within the same period of time, hence not allowing causal inference. Consequently, we could not disentangle whether it was the change in working time arrangements that induced the change in health or whether changed health resulted in a change in working time arrangements. For example, when studying the health effects of changes in working time arrangements, a change from shift work to day work was associated with increased levels of need for recovery and psychological distress. A possible explanation could be that employees became a need for recovery case or a psychological distress case and therefore changed their work schedule from shift work to day work in order to cope with their deteriorated health. When we studied the effects of deteriorated mental health on subsequent changes in working time arrangements, we found that an increase in need for recovery and psychological distress increased the odds of subsequently changing from shift work to day work, but these results were not statistically significant. We did, however, find a large and significant effect of an increase in prolonged fatigue on a subsequent change from shift work to day work. Taking into account the different time lags in these two studies, the results may suggest that a deterioration in mental health in terms of need for recovery and psychological distress has a rather direct effect on changes from shift work to day work as these are associated within the same period of time. Moreover, the finding that a change in prolonged fatigue has an effect on subsequent changes in work schedules may suggest that it takes somewhat longer for prolonged fatigue to result in a change in work schedule. 
When studying the effects of changes in psychological job demands and decision latitude, there appeared to be both a simultaneous effect as well as a lagged effect of increasing demands or decision latitude on mental health outcomes over a four-month period. Semmer et al. ${ }^{12}$ showed (mostly) synchronous effects of work characteristics on psychosomatic complaints, while De Lange et al. ${ }^{13,14}$ detected the strongest effects with a one-year time lag. Our study showed that changes in job demands or decision latitude between baseline and one-year follow-up were not only associated with increased levels of need for recovery and prolonged fatigue within the same period of time, but increased levels of need for recovery were still observed in a period of four months following a change in job demands or decision latitude.

When studying the effects of interpersonal conflicts at work, effects were found on both mental health and on occupational mobility one year following the onset of a conflict. The onset of a conflict between baseline and one-year follow-up was already associated with a relatively large number of mental health cases at one-year follow-up. However, after excluding these prevalent cases and separating a change in exposure (onset of conflict) from a change in outcome (onset of a mental health problem) over time, we could still observe an effect on mental health in a period of one year following the onset of a conflict. A similar pattern was observed between conflicts and occupational mobility. In contrast to prolonged fatigue, however, the association between the onset of a conflict and occupational mobility at one-year follow-up was not very high. However, the effect on occupational mobility in the one-year period following the onset of a conflict was very large, suggesting that it might take longer for an employee to decide or be forced to change jobs as a result of a conflict in the work situation.

\section{Selection effects}

When studying the relationship between the psychosocial work environment and mental health and well-being, selection effects are likely to be encountered. Despite our attempts to minimize selection bias in this thesis, it is rather unlikely that we were able to eliminate all selection effects in our studies. In this respect, it can be argued that the first measurement of the Maastricht Cohort Study is not a true baseline measurement. Employees were already in the middle of an ongoing process both with regard to characteristics of the work environment and with regard to health. Consequently, a selection bias may have already occurred before the baseline measurement of the Maastricht Cohort Study. For example, employees who experienced health problems in the past may have never entered the labor market or may have already adjusted their job to match with their personal health needs. Or it is possible that employees who experienced high job demands have already reduced their working hours in an attempt to reduce the demands of the job and the hazards this might bring to their health. It is thus possible that a job change, an adjustment of tasks, or a change in working time 
arrangements had already taken place in the past, which in turn may have already had an effect on employee health. A specific type of selection bias is the healthy worker effect. For example, it is possible that only employees able to withstand the effects that accompany overtime, start or remain working overtime, which may explain the observed protective effect of repeatedly working overtime on mental health outcomes.

In this thesis, we examined whether changes in mental health affected the perception of the psychosocial work environment. Results showed that changes in mental health subsequently resulted in changes in working time arrangements and occupational mobility. A deterioration in mental health subsequently resulted in a reduction of working hours, a change from shift work to day work, a job change within the company, or a job change from one employer to another. Moreover, previous studies ${ }^{14-16}$ provided evidence for a reversed causal relationship between mental health, and psychological job demands and decision latitude. Even though this relationship was not examined in this thesis, it is likely that changed health affects the subsequent experience of psychological job demands or decision latitude in this thesis as well. Moreover, health problems could also increase the probability of interpersonal conflicts at work Employees experiencing a health problem might become more quickly irritated with issues that arise in the workplace. On the other hand, colleagues may also get annoyed when they have to work harder to help a sick colleague. To our knowledge, the effect of mental health on interpersonal conflicts at work has not been examined so far.

Because of this reversed relationship between mental health and characteristics of the psychosocial work environment, it is important to take into account potential health selection effects when studying the relationship between changes in the psychosocial work environment and changes in mental health. Controlling for initial health could minimize possible selection effects. In most studies presented in this thesis, initial health was taken into account, either by looking at incident cases of a particular health outcome, or by controlling for the baseline value of the outcome. For example, when studying the effects of interpersonal conflicts on subsequent changes in mental health, we corrected for baseline health to rule out a possible reversed effect of health status on the onset of a conflict. The relationship between simultaneous changes in job demands and changes in mental health between TO and T3 was controlled for mental health at TO. The relationship between changes in demands (between TO and T3) and subsequent changes in mental health (between T3 and T4) was corrected for mental health at T3. In the latter analysis, it might have been useful to control for mental health at T0 as well, to rule out the possible reversed effect of mental health on the perception of job demands at TO. When examining the effect of changes in the work environment on subsequent changes in health in future research, baseline health must always be carefully considered as it may be associated with the perception of work characteristics and may be an important predictor of change in the work environment. 


\section{Confounding}

When studying the relationship between changes in the psychosocial work environment and changes in health, it is important to control for other factors that could disturb this relationship ${ }^{17}$, as they may impose a threat to the validity of the study results. Based on the definition of confounding, confounders are associated with the exposure variable, are a risk factor for the outcome and are not in the causal pathway between exposure and outcome ${ }^{18}$. This requires some kind of knowledge on the causal relationship between the variables under study ${ }^{19}$. In the present thesis, for every study separately, potentially relevant confounders were identified, based on the definition of confounding stated above as well as on previous literature. Moreover, we carefully considered other possible confounding factors not previously mentioned in the literature that might also disturb the relationship between the psychosocial work environment and mental health outcomes. The Maastricht Cohort Study contained information on a broad range of potential confounders. However, not all factors should just be controlled for, as this would largely reduce the power of the analyses. In this thesis, identified potential confounders were added as a covariate in the analyses. If, after adjustment for the potential confounder, the regression coefficient of the outcome in the analysis changed more than $10 \%$ relative to the unadjusted regression coefficient, then the variable was considered a relevant confounder and it was retained in the analysis.

When studying changes in the work environment, it is important to notice that several aspects of the work environment are often interrelated. For example, a change from day work to shift work may be accompanied with a change in working hours. Therefore, when studying, for example, the effect of deteriorated mental health on a subsequent reduction in working hours, we adjusted for work schedule to rule out the possibility that a change in working hours was actually merely the result of a change in work schedule. Furthermore, it is also rather likely that changes in the work environment go hand in hand with job changes ${ }^{20}$. Consequently, when examining the effects of changes in, for example, working time arrangements or changes in job demands, we controlled for occupational mobility that occurred in the same period of time in which the change in the work environment took place. As such, we were able to study the effects of changes in the psychosocial work environment independent of changes in job function. Thus, when examining the effects of changes in the psychosocial work environment, it is important to take into account other changes that might have taken place in the same period of time, because these changes are often interrelated. When, on the other hand, potential confounders are assumed to be stable, then studying individual changes in exposure in relation to individual changes in health over time cancels out the possibility that observed associations are due to confounding by these (possibly unobserved) stable characteristics ${ }^{7}$. For example, when studying the effects of changes in job demands and control on changes in mental health, the change scores were computed by subtracting 
two measurements of the same variable. As both measurements were equally affected by the stable variables, the relationship between intra-individual changes was not affected $^{8}$.

Although potential confounders in the relationship between the psychosocial work environment and health and well-being outcomes were carefully considered for each research question in this thesis, the possible existence of unidentified confounding factors can never be ruled out completely.

\section{IMPLICATIONS FOR FUTURE RESEARCH}

The current study has shed new light on the issue of causality in the relationship between the psychosocial work environment and health and well-being, by examining the relationship between changes in the psychosocial work environment and changes in health and well-being, while separating a change in exposure from a change in the outcome over time. To our knowledge, previous research using the same methodology as was used in this thesis is not available yet. We do, however, believe that this approach can be of considerable value for future research and practice. For example, it may be interesting to examine whether the relationships found in this thesis can be replicated in different samples. Moreover, this approach can be expanded using different measures or it can be examined in different subgroups. Moreover, a methodological refinement of this approach could also be interesting for future research.

\section{Different measures}

It would not only be valuable to use this approach with other potentially harmful exposures in the psychosocial work environment, such as perceived job insecurity or role ambiguity, but also with exposures that may have a positive effect on worker health. One might, for example, examine whether experienced changes in job variety or learning opportunities affect changes in health. If increased learning opportunities or an increase in job variety result in a subsequent amelioration in health, it could provide important insights for occupational health professionals and human resource specialists. Furthermore, this approach could also be used with more objective measures of the work environment, such as salary changes, job changes identified by the organization or workplace closures, or with different outcome measures, such as sickness absence or physician-diagnosed health complaints. Furthermore, although not examined in this thesis, it could be useful to examine to what extent changes on the job are imposed by employers rather than sought by employees, and to compare the effects of these voluntary or involuntary changes. Changes that were forced upon the employee are 
more likely to result in negative effects, while voluntary changes possibly lead to more positive effects ${ }^{21}$. For example, an obligation to reduce the weekly working hours because of company restructuring may be a source of psychological distress. On the other hand, choosing to reduce working hours to increase leisure time activities or to spend more time with the family may have positive effects. Future research might also focus on the effects of unplanned or mandatory overtime. Additionally, in this thesis, we examined the effects of deteriorated health on changes in the psychosocial work environment. Positive changes in health do, however, also seem to occur quite frequently and it might be interesting to look at the effects of improved health on perceived work characteristics as well. Moreover, for future research, it may be interesting to examine whether, for example, employees who experienced a deterioration in health and subsequently reduced their working hours also benefited from this reduction in terms of ameliorated health? Finally, in this thesis, we examined the effects of deteriorated health on changes in working time arrangements and occupational mobility. For future research, the effects of changed health on changes in other characteristics of the psychosocial work environment, such as job demands, job control, or interpersonal conflicts at work could be studied as well.

\section{Different subgroups}

Using the same approach, it might be interesting to study the research questions in this thesis for different subgroups of the working population, e.g. to study the effects of interpersonal conflicts among women as they may be more emotionally responsive to conflicts than men; or to study the effects of overtime among part-time workers, as overtime might have a different effect for part-time than for fulltime workers ${ }^{22}$. It could also be interesting to examine the relationship between changes in the work environment and changes in health for different age groups. Young people entering the labor market might be an interesting subgroup to study, because changes that take place in their work environment are not influenced by their previous labor market history. In older workers, changing the work environment because of ill health may become an important issue. However, it is not always evident for older workers to change jobs, e.g. because their skills are not transferable to new jobs, or because they might experience substantial earning losses ${ }^{23}$. Changing jobs can then again have a deteriorating effect on health. Moreover, changes in the work environment may have a different impact on the health of chronically ill patients. Therefore, examining the research questions in this thesis in a sub-sample of chronically ill patients could provide valuable information for prevention and intervention strategies directed at this subgroup. 


\section{Methodological refinement}

Previous research found that cumulative exposure to a highly demanding work environment had more profound effects on worker health than short-term exposure ${ }^{9,20,}$ ${ }^{24}$. In this thesis, we found that health effects were stronger when, for example, conflicts were reported at two occasions during follow-up. The analyses applied in this thesis may, however, not have been optimal to study the effect of cumulative exposure. The rather conservative way of analyzing the data may not have given an accurate insight into the effects of cumulative exposure. After all, even when the exposure had already been present for one year, we still controlled for the outcome at one-year follow-up. Although this was necessary to actually separate the change in exposure from a change in the outcome over time, it probably resulted in an underestimation of the effects. For future research, it might be interesting to examine whether an accumulation in e.g. job demands, measured over multiple waves, is associated with a more or less simultaneous increase in levels of e.g. fatigue over multiple waves.

Additionally, this thesis did not provide information on the exact time frame that needs to be used in occupational health research. For future research, it might be interesting to examine which time lag would be the most appropriate for examining the relationship between changes in work and changes in health. The preferable length of the time lag will depend on the type of outcome being measured, the amount of exposure to the stressor of interest, and whether or not changes in work characteristics or job changes have taken place ${ }^{13}$. A way to provide information on the time lag that is needed to adequately examine the relationship between changes in the work environment and health-related outcomes, is to examine this relationship at each of many follow-up measurements with short time intervals between the measurements. Both the work environment and health should be assessed at each measurement, as was done in the Maastricht Cohort Study. However, it should be noticed that a large number of follow-up measurements might seriously reduce the response among employees ${ }^{13}$.

Finally, we believe that studying the effect of changes in exposure on subsequent changes in the outcome within a prospective cohort study provides important evidence for a possible causal relationship between the psychosocial work environment and health and well-being. Although an experimental design would be necessary to provide firm evidence for the causal relationship, practical, methodological, and ethical issues may prevent researchers from studying the relationship between changes in the psychosocial work environment and changes in mental health using an experimental design. With respect to the practical feasibility, one might wonder how changes in the psychosocial work environment can be actively introduced. For example, provoking a conflict between the employer and the employee, abruptly introducing shift work schedules among day workers, or imposing involuntary changes in working hours all seems quite unnatural and 
unfeasible within an organization. It has also been argued previously that organizations cannot be readily changed or improved by attempts to systematically manipulate their individual parts, and thus conventional scientific approaches may not be faithful to the true dynamics of the organizational change process ${ }^{25}$. By using an experimental design, it might be feasible to examine, for example, the effects of changes in work schedule, when the researchers know a company that is planning to switch from day work to shift work. They might then determine the health of the employees before and after the change. However, in that case, the methodological feasibility comes into play. For example, blinding of the study population seems unlikely if one wants to study changes in working hours or work schedule. Furthermore, it seems even more difficult and ethically unacceptable to examine whether deteriorated health results in a reduction in working hours or occupational mobility, because one would have to include healthy people and influence their health negatively. The experimental design might be useful to examine whether employees with poor health who reduce their working hours also benefit from this reduction in terms of ameliorated health? Although this is a different research question than the ones that were studied in this thesis, it might be interesting for future research. Apart from an experimental study, an observational study using a case-control design would also impose some restrictions to the research questions in this thesis. In a case-control study, two groups are selected: one with a certain outcome and one without the outcome. Information on determinants of the outcome is obtained retrospectively. Despite the fact that several case-control studies would be necessary, one for each outcome, the presence of the outcome might also influence the assessment of past exposure, invalidating the study results. Taking into account the above considerations, we believe that observational research using a prospective cohort design was appropriate for examining the relationships studied in this thesis.

\section{Practical implications}

This thesis showed that changes in the psychosocial work environment were highly prevalent and had a considerable impact on the health and well-being of workers. Based on the results and the high methodological quality of the studies presented in this thesis, we believe we have come one step closer in the causal chain linking the psychosocial work environment to health and well-being. Therefore, the results of this thesis may constitute an important starting point for prevention and intervention strategies in the workplace. 


\section{Assessment of changes}

According to the Working Conditions Act ${ }^{26}$, Dutch employers are obligated to conduct a Risk Inventory and Assessment (Dutch abbreviation, RI\&E), a written inventory and assessment of the health and safety risks to which employees are exposed as a result of their work. Moreover, employers are obliged to give employees the opportunity to consult an occupational health physician and to undergo Periodic Occupational Health Examinations (Dutch abbreviation, PAGO), which are examinations at regular time intervals aimed at preventing or limiting the risks work poses to their health.

When assessing occupational risk factors for employee health and well-being, considerable attention should be devoted to factors in the psychosocial work environment as they may impose a threat to employee health and well-being. Based on the results of this thesis, particular attention should be devoted to employees experiencing changes in these factors. Specific attention could, for example, be paid to employees requesting an adjustment in working time arrangements, such as a reduction in working hours, as this could indicate that they are anticipating or adapting to deteriorated health. Moreover, occupational health professionals should also devote more attention to employees experiencing changes in job demands or job control, regardless of whether or not they would be defined as a high risk group based on their absolute score on the psychological job demands or decision latitude scale. After all, this thesis showed that changes in demands or control had a considerable effect on changes in mental health, irrespective of whether or not this change in demands or control occurred below or beyond the cut-off point for classifying employees with high job demands or low job control. Employees experiencing changes in psychosocial work characteristics should therefore be considered a new target group for prevention and interventions in future occupational health practice.

Although occupational health examinations and consultations can be performed regularly, according to the Working Conditions Act, they are, however, often uncommon ${ }^{27}$. If these health examinations do take place, they might benefit from paying particular attention to changes in the psychosocial work environment and changes in health. For instance, it is important to identify workers experiencing changes in mental health, as these changes may be an important predictor of future changes in working time arrangements or may be an antecedent of future occupational mobility. As deteriorated mental health may have far-reaching effects on work characteristics and on the organization as a whole, monitoring changes in mental health may provide important insights for human resource specialists. 
To be able to detect changes in the psychosocial work environment and in mental health, a regular assessment (e.g. once a year) of both the psychosocial work environment and of mental health is needed. Moreover, it is important to monitor individual changes in work and health as, most probably, the average work score nor the average health score of a large group of employees will change a lot over a particular time ${ }^{28}$. Monitoring these individual changes may be most convenient within the context of Periodical Health Examinations in stead of in the context of a more general inventory of work-related health risks.

\section{Prevention and intervention}

Intervention strategies in the workplace could be targeted at the organization, focusing on changing the psychosocial work environment, or targeted at the individual, thereby focusing on how individuals cope with that work environment. Organizational interventions are preferable as preventative measures because they address the source of the problem ${ }^{29-31}$. Moreover, previous research showed that prevention, targeted at the organization of work, has more and longer lasting effects than individual approaches ${ }^{32}$ 34. Additionally, organizational level interventions are more ethically fair, because employees should not be required to adapt to unnecessary or excessive changes in, e.g., job demands or working hours. However, when looking at changes, it must be noted that these changes are often individually determined. Therefore, an individual approach might be required to handle the specific issues of an employee. Although it is not the aim of this thesis to provide a thorough overview of possible prevention and intervention strategies, we could provide some starting points for prevention and intervention based on the results of this thesis.

This thesis showed that changes in the psychosocial work environment seem to have both a simultaneous as well as a lagged effect on the health of workers. Therefore, preventing negative changes in the psychosocial work environment may prevent negative changes in mental health from occurring. For example, in sectors that regularly experience peaks in workload, such as tourism, catering, or sales, employers may prevent these increases in workload by hiring extra personnel during busy periods. Sometimes, however, changes in the work environment cannot readily be prevented. For example, in the future, organizations may be increasingly compelled to introduce shift work into their company in order to compete against others in our 24-hour society. However, employers or organizations should carefully consider the potentially negative effects of changing from a day work schedule to a shift work schedule, as some employees may not be able to cope with shift work. 
Once people's health deteriorated, it might be useful to provide them with the opportunity to change their work situation, to give them information on the possibilities to change or to provide skills for workers to facilitate a successful change. Providing opportunities to change jobs or change working time arrangements might enable employees to remain in the labor force in stead of leaving it because of deteriorated health. This may become increasingly important for the near future, as with the ageing of the workforce more health problems will probably arise in the working population.

In general, preventive efforts have the largest effect when they address highly prevalent risk factors with a large impact. This study showed that changes in working time arrangements, job demands, job control, and interpersonal conflicts are rather prevalent and have a considerable impact on mental health and occupational mobility. Although there may be more factors contributing to health and well-being, prevention strategies may concentrate on one of these factors, or on a combination of factors. As factors in the psychosocial work environment are often highly correlated, intervening on a particular factor may also influence other characteristics of the work environment. A challenge for the future may be to identify the most important component cause for public health intervention.

This thesis showed that changes in the psychosocial work environment were highly prevalent and had a considerable impact on health and well-being of employees. Moreover, changes in mental health also affected subsequent changes in working time arrangements and occupational mobility. Studying the relationship between changes in the psychosocial work environment and changes in health, while separating a change in exposure from a change in the outcome over time, appeared to be a promising strategy to gain insight into the mutual relationship between the psychosocial work environment and health and well-being. Therefore, we believe that, with this thesis, we have considerably contributed to future health and well-being of the working population.

\section{REFERENCES}

1. Van der Doef M, Maes S. The Job Demand-Control(-Support) model and psychological wellbeing: a review of 20 years of empirical research. Work Stress. 1999;13(2):87-114.

2. Zapf $D$, Dormann $C$, Frese $M$. Longitudinal studies in organizational stress research: a review of the literature with reference to methodological issues. J Occup Health Psychol. 1996;1(2):145-69.

3. Kant I, Bültmann U, Schroer KAP, Beurskens AJHM, Van Amelsvoort LGPM, Swaen GMH. An epidemiological approach to study fatigue in the working population: the Maastricht Cohort Study. Occup Environ Med. 2003;60 Suppl 1:i32-9. 
4. Mohren D, Jansen NW, Van Amelsvoort LG, Kant I. An Epidemiological Approach of Fatigue and Work. Experiences from the Maastricht Cohort Study. Maastricht, NL: Programma Epidemiologie van Arbeid en Gezondheid; 2007.

5. Amick B, Kasl S. Work Stress. In: MCDonald C, editor. Epidemiology of work-related diseases, London: BMJ Publishing Group; 2000. p. 283-308.

6. Spector PE, Zapf $D$, Chen PY, Frese M. Why negative affectivity should not be controlled in job stress research: don't throw out the baby with the bath water. J Organ Behav. 2000;21(1):79-95.

7. Head J, Kivimaki M, Martikainen P, Vahtera J, Ferrie JE, Marmot MG. Influence of change in psychosocial work characteristics on sickness absence: The Whitehall II Study. J Epidemiol Community Health. 2006;60(1):55-61.

8. Rodgers WL. Comparison of alternative approaches to the simple causal models from panel data. In: Kasprzyk D, Duncan G, Kalton G, Singh MP, editors. Panel Surveys. New York: Wiley; 1989. p. 432-56.

9. Frese $M$, Zapf $D$. Methodological issues in the study of work stress: Objective vs subjective measurement of work stress and the question of longitudinal studies. In: Cooper CL, Payne R, editors. Causes, Coping and Consequences of Stress at Work. Chichester, UK: Wiley; 1988. p. 375-411.

10. Gordis L. From association to causation: deriving inferences from epidemiologic studies. In: Gordis L, editor. Epidemiology. Philadelphia, PA: W.B. Saunders Company; 1996.

11. Rothman KJ, Greenland S. Causation and causal inference in epidemiology. Am J Public Health. 2005;95 Suppl 1:S144-50.

12. Semmer NK, Grebner S, Elfering A. Beyond self-report: Using observational, physiological, and situation-based measures in research on occupational stress. In: Perrewé PL, Ganster $D C$, editors. Research in occupational stress and well-being. New York: Elsevier; 2004.

13. de Lange AH, Taris TW, Kompier MA, Houtman IL, Bongers PM. "The very best of the millennium": longitudinal research and the demand-control-(support) model. $J$ Occup Health Psychol. 2003;8(4):282-305.

14. de Lange AH, Taris TW, Kompier MAJ, Houtman ILD, Bongers PM. The relationships between work characteristics and mental health: Examining normal, reversed and reciprocal relationships in a 4-wave study. Work Stress. 2004;18(2):149-66.

15. de Jonge J, Dormann C, Janssen PPM, Dollard MF, Landeweerd JA, Nijhuis FJN. Testing reciprocal relationships between job characteristics and psychological well-being: A crosslagged structural equation model. J Occup Organ Psych. 2001;74:29-46.

16. de Lange AH, Taris TW, Kompier MA, Houtman IL, Bongers PM. Different mechanisms to explain the reversed effects of mental health on work characteristics. Scand $J$ Work Environ Health. 2005;31(1):3-14.

17. McNamee R. Confounding and confounders. Occup Environ Med. 2003;60(3):227-34; quiz $164,234$.

18. Weinberg CR. Toward a clearer definition of confounding. Am J Epidemiol. 1993;137(1):1-8.

19. Hernan MA, Hernandez-Diaz S, Werler MM, Mitchell AA. Causal knowledge as a prerequisite for confounding evaluation: an application to birth defects epidemiology. Am J Epidemiol. 2002;155(2):176-84.

20. de Lange AH, Taris TW, Kompier MA, Houtman IL, Bongers PM. Effects of stable and changing demand-control histories on worker health. Scand $J$ Work Environ Health. 2002;28(2):94-108. 
21. Barton J, Smith L, Totterdell P, Spelten E, Folkard S. Does Individual Choice Determine Shift System Acceptability. Ergonomics. 1993;36(1-3):93-9.

22. Beckers DG, van der Linden D, Smulders PG, Kompier MA, Taris TW, Van Yperen NW. Distinguishing between overtime work and long workhours among full-time and part-time workers. Scand J Work Environ Health. 2007;33(1):37-44.

23. Gallo WT, Bradley EH, Siegel M, KasI SV. Health effects of involuntary job loss among older workers: findings from the health and retirement survey. J Gerontol B Psychol Sci Soc Sci. 2000;55(3):S131-40.

24. Godin I, Kittel F, Coppieters $Y$, Siegrist J. A prospective study of cumulative job stress in relation to mental health. BMC Public Health. 2005;5(1):67.

25. Colarelli SM. Psychological interventions in organizations - An evolutionary perspective. Am Psych. 1998;53(9):1044-56.

26. Arbeidsomstandighedenwet 1998 [Working Conditions Act 1998]. Staatsblad. 1999;184.

27. Bos C, Engelen M. De Werkgeversmonitor arbeidsomstandigheden. Leiden: Research voor beleid; 2005.

28. Taris TW, Kompier M. Challenges in longitudinal designs in occupational health psychology. Scand J Work Environ Health. 2003;29(1):1-4.

29. Burke RJ. Organizational-level interventions to reduce occupational stressors. Work Stress. 1993;7(1):77-87.

30. Parkes KR, Sparkes TJ. Organizational interventions to reduce work stress: Are they effective? A review of the literature. Oxford (UK): University of Oxford, Health and Safety Executive, Contract Research Report No. 193/1998; 1998.

31. Karasek R. Stress prevention through work reorganisation: a summary of 19 case studies. Conditions of Work Digest 1992;11:23-42.

32. Bourbonnais R, Brisson C, Vinet A, Vezina $M$, Abdous B, Gaudet $M$. Effectiveness of a participative intervention on psychosocial work factors to prevent mental health problems in a hospital setting. Occup Environ Med. 2006;63(5):335-42.

33. Reynolds S. Psychological well-being at work: Is prevention better than cure? J Psychosom Res. 1997;43(1):93-102.

34. Kompier MA, Kristensen TS. Organizational work stress interventions in a theoretical, methodological and practical context. . In: Dunham J, editor. Stress in the workplace: past, present and future. London: Whurr Publishers; 2001. p. 164-90. 


\section{SUMMARY}

The psychosocial work environment refers to the content of work, the psychological demands of work, the organization of work, and the social relations at the workplace, and has previously been associated with mental health and well-being of workers. There is, however, still a lack of clarity concerning the causal relationship between the psychosocial work environment and mental health and well-being. However, insight into this causal relationship is indispensable for designing and implementing effective prevention and intervention strategies in the workplace. The majority of studies examining the relationship between the psychosocial work environment and mental health is based on a cross-sectional design, thereby making causal inference impossible. Even longitudinal studies often fail to provide insight into a cause and effect relationship between the psychosocial work environment and mental health and well-being. Several methodological shortcomings, such as small study populations, the inability to control for the initial value of the outcome variable, or the inability to measure exposure before outcome, often prevent researchers from providing evidence for a causal relationship between characteristics of the work situation and mental health. Moreover, previous research has often examined the influence of work characteristics measured at baseline on the occurrence of a health outcome during a specified period of follow-up, thereby assuming a stable work environment. It seems, however, that a rather extensive part of the working population experiences changes in the work environment. The changes that take place in the work environment may invalidate baseline data as a predictor of future health. Therefore, when examining a possible causal relationship between the psychosocial work environment and mental health, the dynamic nature of the work environment should be taken into account, as this may provide a more accurate view of the work environment. Moreover, from a methodological point of view, the dynamics in the work environment can be used as a means of gaining insight into a possible causal relationship between characteristics of the work environment and mental health. The general aim of this thesis was to gain more insight into a possible causal relationship between the psychosocial work environment and mental health and well-being by studying changes in psychosocial work characteristics and changes in mental health and well-being over time. This thesis focused on the effects of changes in working time arrangements, job demands, job control, and interpersonal conflicts at work on changes in self-reported (mental) health and occupational mobility. Furthermore, this thesis also examined the reverse relationship, i.e., the relationship between changes in mental health and subsequent changes in working time arrangements and occupational mobility. Longitudinal data from the Maastricht Cohort Study, a prospective cohort study on 'fatigue at work' were used to examine these relationships. 
In chapter 2, the longitudinal relationship between transitions in working time arrangements (work schedules, working hours and overtime) and changes in selfreported health outcomes was studied. Gender stratified logistic regression analyses using generalized estimating equations were conducted for each of the dichotomized health outcomes: self-reported general health, need for recovery, prolonged fatigue, and psychological distress. The study showed that transitions in working time arrangements were prospectively related to changes in several self-reported heaith outcomes. Substantial and significant associations were found for transitions in work schedule and the incidence of prolonged fatigue and need for recovery among men. Transitions in working hours and overtime were studied among day workers. Changes in working hours affected the need for recovery among men, while they influenced general health and psychological distress among women. Transitions in overtime were significantly associated with the incidence of need for recovery in both men and women. Although this study used a longitudinal design, it was not possible to draw conclusions about causality as the change in exposure was measured during the same time period as a change in the outcomes.

In chapter 3, a possible causal relationship between psychosocial work characteristics and mental health was examined by studying the effects of changes in psychological job demands and decision latitude on subsequent changes in need for recovery and prolonged fatigue. Results from the linear regression analyses showed a significant longitudinal relationship between changes in psychological job demands and decision latitude within one year of follow-up and changes in need for recovery and prolonged fatigue within the same period of time. Moreover, changes in mental health also occurred in a period of four months following a change in job demands or decision latitude. Increasing job demands were a significant predictor of a subsequent increase in need for recovery and prolonged fatigue. An increase in decision latitude predicted a subsequent decrease in need for recovery and prolonged fatigue. After adjusting for changes in other work characteristics, the effects on changes in prolonged fatigue were no longer significant, while the effects on the need for recovery remained significant. In this study, the dynamic nature of the work characteristics was thoroughly taken into account, the influence of possible confounding factors was minimized, and changes in exposure were measured before changes in mental health outcomes. Therefore, we believe that these findings support a possible causal relationship between psychological job demands and decision latitude on the one hand and mental health on the other.

Before examining the effects of interpersonal conflicts with co-workers and supervisors on health and occupational mobility, first, a study was conducted on the etiology of these conflicts. The objectives of this study, which is described in chapter 4 of this thesis, were to gain insight into the prevalence and incidence of interpersonal conflicts with coworkers and supervisors, to describe the overlap between interpersonal conflicts with 
and social support from co-workers and supervisors, and to examine the role of several work-related risk factors at baseline in the onset of a conflict with co-workers or supervisors after one year of follow-up. Results showed that the baseline prevalence of an interpersonal conflict was $7.1 \%$ for co-worker conflict and $9.7 \%$ for supervisor conflict. The incidence of a conflict after one year of follow-up was $3.9 \%$ for co-worker conflict and $5.3 \%$ for supervisor conflict. Moreover, this study showed that employees were able to experience both interpersonal conflicts and high social support simultaneously. However, low social support from and interpersonal conflicts with co-workers were only modestly related in this study, while the overlap between low social support from and conflict with the supervisor was somewhat larger. Additionally, the results from the logistic regression analyses showed that several factors in the work environment were related to the onset of interpersonal conflicts at work. Higher psychological job demands, higher levels of role ambiguity, physical demands at work, higher musculoskeletal demands, a poorer physical working environment, working in shifts, working overtime, and higher levels of job insecurity significantly predicted the onset of both a co-worker conflict and a supervisor conflict. Higher levels of co-worker and supervisor social support, more autonomy concerning the terms of employment, a good overall job satisfaction, monetary gratification, and esteem reward significantly protected against the onset of both a co-worker conflict and a supervisor conflict. Higher levels of decision latitude and more career opportunities also significantly protected against the onset of a supervisor conflict.

In chapter 5, the effects of interpersonal conflicts with co-workers or supervisors on subsequent self-reported health outcomes and occupational mobility were examined. Interpersonal conflicts were assessed between baseline and one-year follow-up. Outcomes were studied every four months between one-year and two-year follow-up. Logistic regression analyses using generalized estimating equations were conducted for each of the dichotomous outcomes: self-reported general health, need for recovery, prolonged fatigue, internal mobility (i.e., changing job function within the company), and external mobility (i.e., changing jobs from one employer to another). Due to statistical power considerations, the analyses were conducted for men only. In general, this study showed that co-worker conflict was a statistically significant risk factor for the subsequent onset of an elevated need for recovery, prolonged fatigue, poor general health and external occupational mobility. Supervisor conflict was a significant risk factor for the subsequent onset of an elevated need for recovery, prolonged fatigue, internal and external occupational mobility. In this large, prospective study a change in exposure (the onset of a conflict) was separated from a change in the outcome (onset of self-reported health problems and occupational mobility) over time using relatively short time intervals. Moreover, baseline health was controlled for, and several other confounding factors were taken into account. Therefore, the results of this study indicate a possible causal 
relationship between interpersonal conflicts at work and self-reported health and occupational mobility.

Chapters 2 to 5 focused on the impact of the psychosocial work environment on employee health and well-being. In chapter 6 of this thesis, a possible reversed causal relationship between mental health and characteristics of the work situation was examined by studying the relationship between changes in mental health (need for recovery, prolonged fatigue, and psychological distress) and subsequent changes in working time arrangements and occupational mobility. This study examined whether a deterioration in mental health between baseline and one-year follow-up resulted in a subsequent change in working time arrangements between one-year and two-year follow-up, or in occupational mobility between one-year and two years and eight months of follow-up. Results showed that, compared to employees not experiencing deterioration in mental health, employees who became a need for recovery case were more likely to reduce their working hours or to change jobs within the company. Employees who became a prolonged fatigue case were more likely to reduce their working hours or leave a shift work job. Employees who became a psychological distress case were more likely to change their job function within the company or to change jobs from one employer to another. In this study, a change in exposure was separated from a change in the outcome over time, while using relatively short time intervals, controlling for the initial level of the outcome, and taking into account several possible confounding factors. Therefore, the results of this study indicate a possible causal relationship between mental health on the one hand and working time arrangements or occupational mobility on the other.

In chapter 7, the general discussion, the overall results of this thesis were described and discussed in terms of methodological quality, and implications with respect to future research, prevention and interventions. This thesis shows that changes in the psychosocial work environment are highly prevalent and have a considerable impact on mental health and well-being of employees. Moreover, changes in mental health also affect subsequent changes in working time arrangements and occupational mobility. Studying the relationship between changes in the psychosocial work environment and changes in health, while separating a change in exposure from a change in the outcome over time, appears to be a promising strategy to gain insight into the mutual relationship between the psychosocial work environment and health and well-being. This quite unique approach can be of considerable value for future research examining potential causal relationships between work characteristics and health. Based on the results and the high methodological quality of the studies presented in this thesis, we believe we have come one step closer in the causal chain linking the psychosocial work environment to mental health and well-being. Therefore, the results of this thesis may 
constitute an important starting point for designing and implementing effective prevention and intervention strategies in the workplace. 


\section{SAMENVATTING}

De psychosociale werkomgeving verwijst naar de arbeidsinhoud, de psychologische eisen van het werk, de organisatie van het werk en de sociale relaties op de werkvloer en werd in het verleden reeds geassocieerd met mentale gezondheid en welzijn van werknemers. Er bestaat echter nog heel wat onduidelijkheid over de causale relatie tussen de psychosociale werkomgeving en mentale gezondheid en welzijn. Inzicht in deze causale relatie is nochtans essentieel voor de ontwikkeling en implementatie van effectieve preventie- en interventiestrategieën op de werkvloer. De meeste studies die de relatie tussen de psychosociale werkomgeving en mentale gezondheid bestuderen, zijn gebaseerd op een cross-sectioneel design, wat causale gevolgtrekkingen onmogelijk maakt. Zelfs longitudinale studies slagen er vaak niet in om inzicht te verschaffen in de oorzaak-gevolg relatie tussen de psychosociale werkomgeving en mentale gezondheid en welzijn. Verscheidene methodologische beperkingen, zoals kleine studiepopulaties, het niet kunnen controleren voor de uitgangswaarde van de uitkomstmaat, of het onvermogen om de expositie voor het effect te meten, weerhouden onderzoekers ervan om de causale relatie tussen kenmerken van de werksituatie en mentale gezondheid aan te tonen. Daarnaast heeft vroeger onderzoek zich vaak toegelegd op de invloed van werkkenmerken, die gemeten werden op baseline, op het ontstaan van een gezondheidsuitkomst na een bepaalde follow-up periode. Daarbij werd een stabiele werkomgeving verondersteld. Het blijkt echter dat een aanzienlijk deel van de werkende populatie veranderingen ervaart in de werkomgeving. Die veranderingen maken baseline gegevens ongeschikt als een voorspeller van toekomstige gezondheid. Wanneer een mogelijk causale relatie tussen de psychosociale werkomgeving en mentale gezondheid onderzocht wordt, is het van belang dat het dynamische karakter van de werkomgeving in acht genomen wordt omdat dit een meer accuraat beeld verschaft van de werkomgeving. Vanuit methodologisch oogpunt kan deze dynamiek in de werkomgeving bovendien gebruikt worden als een manier om inzicht te krijgen in een mogelijke causale relatie tussen kenmerken van de werkomgeving en mentale gezondheid. Het algemene doel van deze thesis was om meer inzicht te verkrijgen in een mogelijke causale relatie tussen de psychosociale werkomgeving en mentale gezondheid en welzijn door het bestuderen van veranderingen in psychosociale werkkenmerken en veranderingen in mentale gezondheid en welzijn over de tijd. In deze thesis werd voornamelijk aandacht besteed aan de effecten van veranderingen in werktijdregelingen, werkdruk, controle over het werk en interpersoonlijke conflicten, op veranderingen in zelfgerapporteerde (mentale) gezondheid en arbeidsmobiliteit. Daarnaast werd in deze thesis ook de omgekeerde relatie bestudeerd, i.e., de relatie tussen veranderingen in mentale gezondheid en de daaropvolgende veranderingen in werktijdregelingen en arbeidsmobiliteit. Om deze relaties te onderzoeken werd gebruikt gemaakt van 
longitudinale data van de Maastrichtse Cohort Studie, een prospectieve cohort studie naar vermoeidheid in de arbeidssituatie.

In hoofdstuk 2 werd de longitudinale relatie tussen transities in werktijdregelingen (arbeidsduur, arbeidspatroon en overwerk) en veranderingen in zelfgerapporteerde gezondheidsuitkomsten bestudeerd. Logistische regressieanalyses voor longitudinale data (generalized estimating equations) werden uitgevoerd voor elke gedichotomiseerde gezondheidsuitkomst: zelfgerapporteerde algemene gezondheid, herstelbehoefte, langdurige vermoeidheid en psychologisch welziin. De analyses werden gestratificeerd naar geslacht. Deze studie toonde een prospectieve relatie aan tussen transities in werktijdregelingen en veranderingen in zelfgerapporteerde gezondheidsuitkomsten. Veranderingen in arbeidspatroon waren sterk en significant geassocieerd met de incidentie van langdurige vermoeidheid bij mannen. Veranderingen in arbeidsduur en overwerk werden bestudeerd in een groep dagdienstmedewerkers. Transities in arbeidsduur hadden een invloed op de herstelbehoefte van mannen, terwijl bij vrouwen de algemene gezondheid en het psychologisch welzijn beïnvloed werden. Verandering in overwerk was significant geassocieerd met veranderingen in herstelbehoefte bij mannen en vrouwen. Ondanks het feit dat er in deze studie gebruik gemaakt werd van een longitudinaal design, was het niet mogelijk om conclusies te trekken met betrekking tot causaliteit omdat de verandering in blootstelling en de verandering in uitkomsten in dezelfde tijdsperiode gemeten waren.

In hoofdstuk 3 werd een mogelijke causale relatie onderzocht tussen psychosociale werkkenmerken en mentale gezondheid door de effecten van veranderingen in werkdruk en regelmogelijkheden op daaropvolgende veranderingen in herstelbehoefte en langdurige vermoeidheid te bestuderen. De resultaten van lineaire regressieanalyses toonden aan dat er een significant longitudinaal verband bestaat tussen veranderingen in werkdruk en regelmogelijkheden binnen één jaar follow-up en veranderingen in herstelbehoefte en langdurige vermoeidheid in dezelfde tijdsperiode. Daarnaast traden veranderingen in mentale gezondheid ook op in een periode van vier maanden na de verandering in werkdruk of regelmogelijkheden. Toenemende werkdruk bleek een significante voorspeller van een daaropvolgende toename in herstelbehoefte en langdurige vermoeidheid. Een toename in regelmogelijkheden voorspelde een daaropvolgende afname in herstelbehoefte en langdurige vermoeidheid. $\mathrm{Na}$ controle voor veranderingen in andere werkkenmerken waren de effecten voor langdurige vermoeidheid niet meer significant terwijl de effecten op herstelbehoefte wel overeind bleven. In deze studie werd het dynamische karakter van de werkkenmerken nauwgezet in acht genomen, werd de invloed van mogelijke confounders geminimaliseerd, en werden veranderingen in blootstelling gemeten vóór de veranderingen in mentale gezondheidsuitkomsten. Daarom zijn we van mening dat deze bevindingen het bestaan 
van een mogelijke causale relatie tussen werkdruk en regelmogelijkheden enerzijds en mentale gezondheid anderzijds ondersteunen.

Alvorens de effecten van conflicten met collega's en leidinggevenden op gezondheid en arbeidsmobiliteit te bestuderen, werd een studie uitgevoerd naar de etiologie van deze conflicten. Het doel van deze studie, die beschreven werd in hoofdstuk 4 van deze thesis, was om inzicht te krijgen in de prevalentie en incidentie van conflicten met collega's en leidinggevenden, om de overlap tussen conflicten met en sociale steun van collega's en leidinggevenden te beschrijven, en om de rol van verscheidene werkgerelateerde risicofactoren op baseline in het ontstaan van conflicten na één jaar follow-up te onderzoeken. De baseline prevalentie van conflicten in deze studie was $7.1 \%$ voor conflicten met collega's en $9.7 \%$ voor conflicten met de leiding. De incidentie van een conflict na één jaar follow-up was $3.9 \%$ voor conflicten met collega's en $5.3 \%$ voor conflicten met de leiding. Daarnaast toonde deze studie aan dat werknemers tegelijkertijd zowel conflicten als sociale steun kunnen ervaren. Lage sociale steun van en conflicten met collega's waren echter slechts matig gerelateerd in deze studie, terwij de overlap tussen lage sociale steun van en conflicten met de leiding iets hoger was. Vervolgens toonden de resultaten van de logistische regressie aan dat verschillende factoren in de werkomgeving gerelateerd waren aan het ontstaan van interpersoonlijke conflicten op het werk. Een hogere werkdruk, meer rolonduidelijkheid, fysiek inspannend werk, een hogere belasting aan het bewegingsapparaat, een slechtere fysieke werkomgeving, ploegendienst, overwerk en meer toekomstonzekerheid bleken significante voorspellers van conflicten met zowel collega's als met de leiding. Meer sociale steun van collega's en leidinggevenden, meer autonomie ten aanzien van de arbeidsvoorwaarden, een goede algemene arbeidssatisfactie, en van mening zijn dat de inkomsten en de waardering die men krijgt voor het werk in overeenstemming zijn met de geleverde inspanningen en prestaties, bleken de werknemer significant te beschermen tegen het ontstaan van conflicten met collega's en leidinggevenden. Meer regelmogelijkheden en meer leer- en loopbaanmogelijkheden bleken daarenboven significante beschermende factoren te zijn tegen het ontstaan van een conflict met de leidinggevende.

In hoofdstuk 5 werden de effecten van conflicten met collega's en leidinggevenden op zelfgerapporteerde gezondheidsuitkomsten en arbeidsmobiliteit onderzocht. Conflicten werden gemeten tussen baseline en één jaar follow-up. De uitkomsten werden, tussen één jaar en twee jaar follow-up, om de vier maanden geregistreerd. Logistische regressieanalyses voor longitudinale data (generalized estimating equations) werden uitgevoerd voor elke dichotome uitkomst: zelfgerapporteerde algemene gezondheid, herstelbehoefte, langdurige vermoeidheid, interne mobiliteit (functieverandering binnen het bedrijf) en externe mobiliteit (verandering van werkgever). Met het oog op de power van de studie, werden de analyses enkel voor mannen uitgevoerd. Deze studie toonde 
aan dat een conflict met collega's een statistisch significante risicofactor was voor het daaropvolgend ontstaan van een hogere herstelbehoefte, langdurige vermoeidheid, een slechte algemene gezondheid en externe mobiliteit. Een conflict met de leidinggevende was een significante risicofactor voor het daaropvolgend ontstaan van een hogere herstelbehoefte, langdurige vermoeidheid, interne en externe mobiliteit. In deze grote, prospectieve cohort studie werden de verandering in blootstelling (het ontstaan van een conflict) en de verandering in de uitkomst (ontstaan van zelfgerapporteerde gezondheidsproblemen en arbeidsmobiliteit) in de tijd uit elkaar getrokken, waarbij gebruik gemaakt werd van korte tijdsintervallen. Bovendien werd gecontroleerd voor gezondheid op baseline en werd rekening gehouden met verschillende andere confounders. Daarom wijzen de resultaten van deze studie op een mogelijke causale relatie tussen interpersoonlijke conflicten op het werk en zelfgerapporteerde gezondheid en arbeidsmobiliteit.

In hoofdstukken 2 tot en met 5 stond de invloed van de psychosociale werkomgeving op gezondheid en welzijn van de werknemers centraal. In hoofdstuk 6 van deze thesis werd een mogelijke omgekeerde causale relatie tussen mentale gezondheid en kenmerken van de werksituatie onderzocht door te kijken naar de relatie tussen veranderingen in mentale gezondheid (herstelbehoefte, langdurige vermoeidheid en psychologisch welzijn) en daaropvolgende veranderingen in werktijdregelingen en arbeidsmobiliteit. Deze studie onderzocht of een verslechtering in mentale gezondheid tussen baseline en één jaar follow-up resulteerde in een daaropvolgende verandering in werktijdregelingen tussen één jaar en twee jaar follow-up, of in arbeidsmobiliteit tussen één jaar en twee jaar en 8 maanden follow-up. De resultaten van deze studie toonden aan dat, in vergelijking met werknemers die geen verslechtering in mentale gezondheid ervoeren, werknemers die een herstelbehoefte case werden meer geneigd waren om hun werkuren te reduceren of om van functie te veranderen binnen het bedrij. Werknemers die een vermoeidheidscase werden, waren meer geneigd om hun werkuren te reduceren of te stoppen met ploegendienst. Werknemers waarbij psychologisch onwelbevinden ontstond, waren meer geneigd om van functie te veranderen binnen het bedrij, of om van werkgever te veranderen. In deze studie werden de verandering in blootstelling en de verandering in de uitkomst in de tijd van elkaar gescheiden, waarbij gebruik gemaakt werd van relatief korte tijdsintervallen. Bovendien werd gecontroleerd voor de uitgangswaarde van de uitkomst, en werden verschillende mogelijke confounders in acht genomen. Daarom wijzen de resultaten van deze studie op een mogelijke causale relatie tussen mentale gezondheid enerzijds en werktijdregelingen of arbeidsmobiliteit anderzijds.

In hoofdstuk 7, de algemene discussie, werden de resultaten van deze thesis beschreven en bediscussieerd in termen van methodologische kwaliteit en implicaties met betrekking tot toekomstig onderzoek, preventie en interventies. Deze thesis toont 
aan dat veranderingen in de psychosociale werkomgeving vaak voorkomen en een aanzienlijk effect hebben op de mentale gezondheid en het welzijn van werknemers. Daarnaast beïnvloeden veranderingen in mentale gezondheid ook daaropvolgende veranderingen in werktijdregelingen en arbeidsmobiliteit. Het bestuderen van de relatie tussen veranderingen in de psychosociale werkomgeving en veranderingen in gezondheid, waarbij veranderingen in blootstelling en veranderingen in de uitkomst over de tijd van elkaar gescheiden worden, blijkt een veelbelovende strategie te zijn om inzicht te verkrijgen in de wederzijdse relatie tussen de psychosociale werkomgeving en gezondheid en welzijn. Deze nogal unieke benadering kan bijzonder waardevol zijn voor toekomstig onderzoek dat mogelijke causale relaties tussen werkkenmerken en gezondheid bestudeert. Op basis van de resultaten en de hoge methodologische kwaliteit van de studies in deze thesis, zijn we van mening dat we een stap verder gekomen zijn in het ontrafelen van de causale relatie tussen de psychosociale werkomgeving en mentale gezondheid en welzijn. Daarom kunnen de resultaten van deze thesis een belangrijk aanknopingspunt bieden voor het ontwikkelen en implementeren van effectieve preventie- en interventiestrategieën op de werkvloer. 


\section{DANKWOORD}

Zonder twijfel is het dankwoord het meest gelezen stukje tekst in een proefschrift! En met reden... het is het enige stukje tekst dat zeker iedereen begrijpt. Met dit proefschrift is dat niet anders. Mij rest nu nog de dankbare taak om een dankwoord uit te spreken voor alle mensen die bijgedragen hebben aan de totstandkoming van dit proefschrift.

Eerst laat ik het klaroengeschal luiden voor de leden van de projectgroep. In de eerste plaats IJmert Kant, mijn co-promotor en dagelijkse begeleider. IJmert, bedankt voor je stimulerende begeleiding en je enthousiasme. Bedankt om me de ruimte te geven om me te ontwikkelen. Bedankt voor de leuke discussies op het werk en de gezellige babbels na het werk. Fijn dat ik altijd en voor alles bij je terecht kon en nog steeds kan! Mijn speciale dank gaat ook uit naar Nicole Jansen voor de dagelijkse begeleiding. Nicole, bedankt voor je positivisme en de gedrevenheid die je steeds weer weet over te brengen. Bedankt dat je deur altijd voor me open stond en dat je altijd de tijd nam om me met raad en daad bij te staan. Je hebt een erg belangrijke bijdrage geleverd aan dit proefschrift! Ik wil ook Rineke Vasse, mijn tweede co-promotor, bedanken. Rineke, na het overlijden van Peter Jansen ben je toegetreden tot de projectgroep. Hartelijk dank voor het meedenken, voor je aanvullingen op de artikelen en voor de waardevolle inbreng vanuit de BEOZ/Social Medicine- hoek. Ook mijn promotor, Piet van den Brandt, wil ik van harte bedanken. Beste Piet, ik heb je snelle, concrete en kritische reactie op de toegezonden stukken erg gewaardeerd!

Verder wil ik al mijn collega's en ex-collega's bij de capaciteitsgroep epidemiologie bedanken. Ik denk met plezier terug aan de lunchwandelingen, de gezellige pauzes en koffiebreaks en de leuke capgroepuitjes. Boukje van Dijk, mijn eerste kamergenootje, bedankt dat je mij tijdens de eerste maanden van mijn AIO-tijd wegwijs gemaakt hebt in het wel en wee van de afdeling. Mijn collega's van arbeidsepi: Ludovic van Amelsvoort, Petra Brouns, Carin de Brouwer, Renée Gruisen, Nathalie Janssen, Danielle Mohren en Jos Slangen. Bedankt voor de constructieve samenwerking, de gezellige verjaardagslunches bij Thembi en de nooit te overtroeven arbeidsepi-etentjes. Ook bedankt aan de (ex-)promovendi van arbeidsepi: Karolien Driesen, Saskia Duijts, Stephanie Leone en Monique Lexis. Ik denk met plezier terug aan onze mensa-meetings, onze gezamenlijke congressen, de soms ingewikkelde discussies over 'de dingen des levens' en de steeds weer plezierige pré-vakantie, pré-Kerst of pré-congres etentjes. Elke gelegenheid was reden genoeg om het gezellig te maken! Een bijzonder woord van dank gaat uit naar mijn kamergenootje Stephanie Leone. Lieve Steph, bedankt voor je betrokkenheid, je luisterend oor en je relativeringsvermogen. Bedankt dat ik je altijd mocht overvallen met werk- en niet-werkgerelateerde kwesties. Fijn dat we samen onze 'Everest' konden beklimmen! Ik wil ook graag Karolien Driesen speciaal bedanken. Lieve Karolien, fijn dat 
je me in de laatste maanden van dit proefschrift bent komen vergezellen op deze fascinerende reis. Met plezier denk ik terug aan onze kotbelevenissen, aan de onmenselijk vroege busreizen naar Maastricht en aan onze supergezellige momenten samen. Ik hoef maar te bellen en je raam gaat open! Samen in Diepenbeek beginnen te studeren... het doet me deugd om het samen in Maastricht met je af te maken! Bedankt dat je naast me wilt staan op deze bijzondere dag! Aan alle collega's van het SMILEteam, bedankt voor de prettige samenwerking tijdens de eerste jaren van mijn promotietraject. Mijn nieuwe collega's van KLAV wil ik bedanken voor hun steun en interesse in de laatste maanden voor de promotie.

Ook bedankt aan 'ons klasje', het kliekje Belgen dat besloot om vanuit Diepenbeek de sprong over de Maas te wagen om gezondheidswetenschappen te gaan studeren in Maastricht. Bedankt Jelle Braeken, Sigrid Cox, Sara De Clerck, Bram Moors en Ellen Wijnen. Ook al zijn we ieder een andere weg opgewandeld, ik ben blij dat we elkaar nog niet uit het oog verloren zijn! Optie B houdt stand!

Mijn lieve vriendinnen uit Zonhoven: Greet, Jolijn, Katrien en Kirstin. Ik kan me al haast niet meer herinneren wanneer we vriendinnen geworden zijn, maar ik ben blij dat we het na al die jaren nog altijd zo goed met elkaar kunnen vinden. Kirstin, fijn dat je al 15 jaar mijn beste vriendin bent en dat je ook tijdens de verdediging naast me zal staan! lk draag jou en Wim een heel warm hart toe! Wim, heel hartelijk bedankt om de mooie cover te ontwerpen voor dit proefschrift.

Ik wil mijn familie, schoonfamilie en vrienden bedanken voor hun belangstelling, hun onvoorwaardelijke steun en het vertrouwen dat ze de laatste jaren in mij gehad hebben. Hoewel het niet altijd even duidelijk was wat ik juist deed, ben ik er zeker van dat jullie met evenveel enthousiasme naar dit moment hebben toegeleefd. Een simpele vermelding in dit proefschrift kan nooit recht doen aan het aandeel dat mijn ouders gehad hebben in het behalen van dit doctoraat. Moeke, papa, bedankt voor alle mogelijkheden die jullie mij geboden hebben. Bedankt voor jullie steun en interesse. Bedankt voor alles! Bram, dit is dus waar uw zuske zich de afgelopen 4,5 jaar mee heeft bezig gehouden. Toch schoon als het af is, hè! Save the best for last... Lieve Kevin, bedankt omdat je altijd voor me klaar staat. Dankjewel om wie je bent!

Aan de lezer die zich de moeite genomen heeft om tot deze laatste bladzijden door te bladeren... leest $u$ gerust het voorgaande ook eens. Misschien ontdekt $u$ wel het antwoord op de vraag: "Wat heeft ze daar nu die afgelopen 4,5 jaar zitten doen?". De regelmatige vraag "Ben je nu al klaar?" kan ik eindelijk volmondig met "ja!" beantwoorden.

Lore 


\section{ABOUT THE AUTHOR}

Lore De Raeve was born on May 11, 1981 in Genk (Belgium). After completing secondary school at the Vrije Middenschool and the Sint-Jan Berchmansinstituut in Zonhoven in 1999, she started studying Biomedical Sciences at the Limburgs Universitair Centrum (nowadays Hasselt University). She pursued her education at Maastricht University in 2001, which resulted in a Master's degree in Health Sciences in 2003, with specialization in Work and Health, and in Health Education and Health Promotion. Between November 2003 and May 2008 she worked as a PhD-student at the department of Epidemiology at Maastricht University, conducting research on the mutual relationship between changes in psychosocial work characteristics and changes in health and well-being. Since June 2008, Lore De Raeve works as an expert in pharmaceutical care, health policy, and care for the elderly at the Koninklijk Limburgs Apothekers Verbond (KLAV) in Hasselt, Belgium. 


\section{LIST OF PUBLICATIONS}

1. De Raeve L, Jansen NWH, Kant I. Health effects of transitions in work schedule, workhours and overtime in a prospective cohort study. Scand J Work Environ Health. 2007;33(2):105-13.

2. De Raeve L, Vasse RM, Jansen NW, van den Brandt PA, Kant I. Mental health effects of changes in psychosocial work characteristics: a prospective cohort study. $J$ Occup Environ Med. 2007;49(8):890-9

3. van den Akker M, Spigt MG, De Raeve $L$, van Steenkiste B, Metsemakers JF, van Voorst EJ, et al. The SMILE study: A Study of Medical Information and Lifestyles in Eindhoven, the rationale and contents of a large prospective dynamic cohort study. BMC Public Health. 2008;8(1):19.

4. De Raeve L, Jansen NW, Van den Brandt P, Vasse R, Kant I. Risk factors for interpersonal conflicts at work. Scand J Work Environ Health. 2008;34(2):96-106.

5. De Raeve L, Kant I, Jansen NW, Vasse R, Van den Brandt $P$. Changes in mental health as a predictor of changes in working time arrangements and occupational mobility: results from a prospective cohort study. J Psychosom Res.; in press.

6. De Raeve $L$, Jansen NW, Van den Brandt P, Vasse R, Kant I. Interpersonal conflicts at work as a predictor of self-reported health outcomes and occupational mobility. Occup Environ Med.; in press. 